\title{
EFETTO dO BALANÇO de CÁtIONS E ÂNIONS dA PLANTA NA ACIDIFICAÇÃO DO SOLO POR FERTILIZANTES NITROGENADOS
}

\author{
JUAN CARLOS QUEVEDO CAMACHO \\ Engenheiro Agrônomo
}

Orientador: Prof. Dr. JORGE DE CASTRO KIEHL

Dissertação apresentada à Escola Superior de Agricultura "Luiz de Queiroz" da Universidade de São Paulo, para obtenção do título de Mestre em Agronomia. Área de Concentração: Solos e Nutrição de Plantas.

P I R A C I C A B A

Estado de São Paulo - Brasil

Março - 1995 
Ficha cataiografica predarada dela Secta de Livros da Divisáo de Eiblioteca e Documentacào - FClQ/USF

$\mathrm{OSE}$

Gueveda Eamacho. Juan Carios

Efeito do balanco de cations e anions da pianta na acidificaça do solo por fertilizantes nitrouenados. Firacicaba, 1995.

1065 .

Diss - Mestre\} - ESALG

Bibliografia.

3. Adubo nitrooenado 2. Cultura aoricola - Balañco eletrolitico 3. Latossoio roxo distrofico 4 . Solo - A

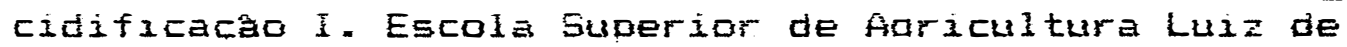
Gueiroz. Firacicaba

$\operatorname{CDO} 631.84$

631.42 


\section{EFEITO DO BALANÇO DE CÁTIONS E ÂNIONS DA PLANTA NA ACIDIFICAÇÃO DO SOLO POR FERTILIZANTES NITROGENADOS}

Aprovado em 17-04-1995

Comissão Julgadora:

Prof. Dr. Jorge de Castro Kiehl

Prof. Dr. Takashi Muraoka

Prof. Dr. Cyro Antonio Rosolem
ESALQ/USP

CENA/USP

FCA/UNESP

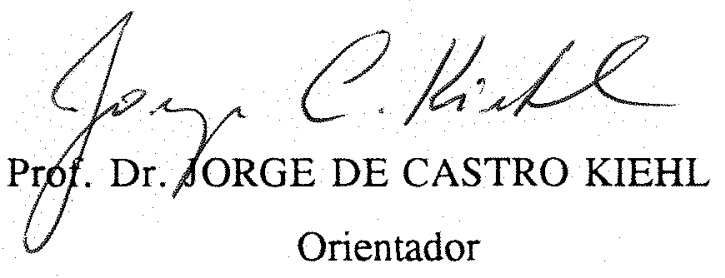


Aos meus pais,

Alberto e Lucia Fara, pelo

amor dedicado e exemplo

de trabalho e honestidade.

Aos meus irmãos,

Maria Cristina (in memorian)

e Francisco, com gratidão e

carinho,

DEDICO

À minha esposa,

Estefânia, pelo apoio e incentivo em todos os anos de convívio.

Aos meus filhos,

Ana Claudia e Rodrigo, pelo amor

e compreensão, indispensáveis na realização desta tarefa. 


\section{AGRADECIMENTOS}

A Deus, Luz constante no caminho, sempre nos governando na busca de algo mais.

Ao Prof. Dr. Jorge de Castro Kiehl, pela orientação e incentivo no decorrer do Curso de Pós-Graduação.

Ao Prof. Dr. Takashi Muraoka, do Centro de Energia Nuclear na Agricultura - CENA/USP e Prof. Dr. Cyro Antonio Rosolem, da Faculdade de Ciências Agronômicas - UNESP, pelas valiosas contribuições.

Ao Dr. Bernardo van Raij, do Instituto Agronômico de Campinas, pela amizade e sugestões de grande expressão para a realização deste trabalho.

À Fundação de Amparo à Pesquisa do Estado de São Paulo - FAPESP, pela concessão de bolsa de estudo.

À Associação Brasileira para Pesquisa da Potassa e do Fosfato (POTAFOS), em especial ao seu Diretor, Dr. Tsuioshi Yamada, pelo apoio constante e pelas lições de vida.

Ao Dr. Hélio do Prado, do Instituto Agronômico de Campinas, pela amizade e pelo idealismo transmitido em nossa convivência.

À Escola Superior de Agricultura "Luiz de Queiroz" - USP, pela oportunidade da realização deste curso.

Aos funcionários do Departamento de Ciência do Solo da ESALQ/USP, pela ajuda e cessão de uso de equipamentos.

Às bibliotecárias da ESALQ, em particular Kátia Maria de Andrade Ferraz e Eliana Maria Garcia Sabino, pela revisão das referências bibliográficas. À Clotilde Maria Batochio Cunha, pela digitação da dissertação e amizade.

A todas as pessoas que direta e indiretamente auxiliaram no desenvolvimento deste trabalho. 


\section{ÍNDICE}

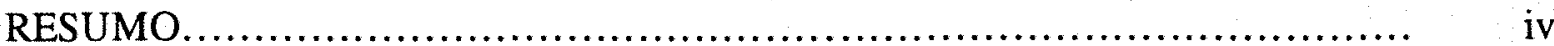

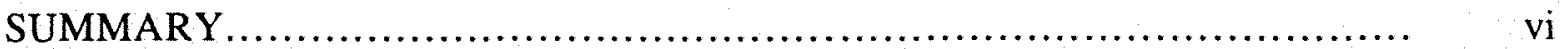

1. INTRODUÇÃO

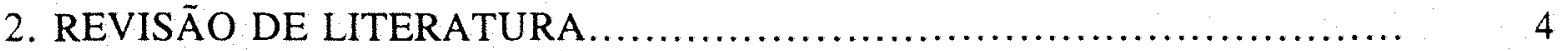

2.1. Acidificação do Solo pelos Fertilizantes Nitrogenados.................. 4

2.2. Efeito das Plantas no $\mathrm{pH}$ do Solo.............................. 12

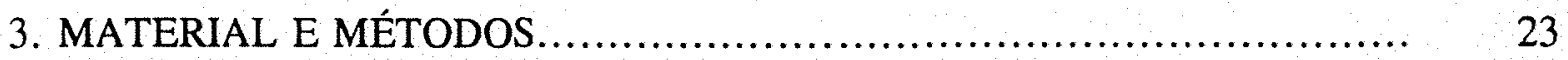

3.1. Solo Selecionado e Amostragem................................ 23

3.2. Delineamento Experimental................................... 25

3.3. Instalação e Condução do Experimento.............................. 25

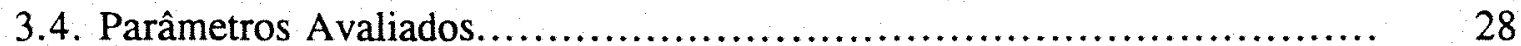

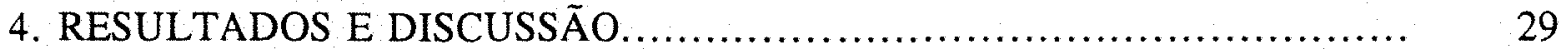

4.1. Influência dos Fertilizantes Nitrogenados e da Cultivação sobre as

Propriedades Químicas do Solo..................................... 29

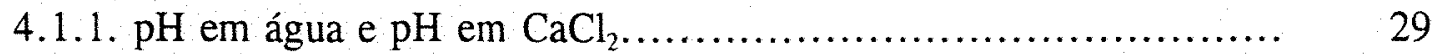

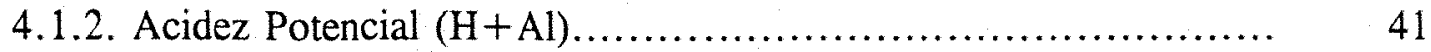




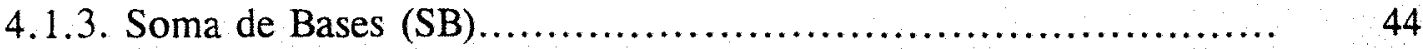

4.1.4. Nitrogênio Amoniacal........................................ 51

4.1.5. Nitrogênio Nítrico...................................... 55

4.2. Influência dos Fertilizantes Nitrogenados sobre os Parâmetros da Planta. $\quad 58$

4.2.1. Produção de Matéria Seca...................................... 58

4.2.2. Teor de Nitrogênio........................................ 67

4.2.3. Somatório de Cátions.......................................... 67

4.2.4. Somatório de Ânions............................................. 71

4.2.5. Excesso de Bases (EB) ................................... 76

4.2.6. Relação Excesso de Bases/Nitrogênio (EB/N).................. 83

4.3. Correlações entre o $\mathrm{pH}$ do Solo e os Parâmetros de Planta............... 86

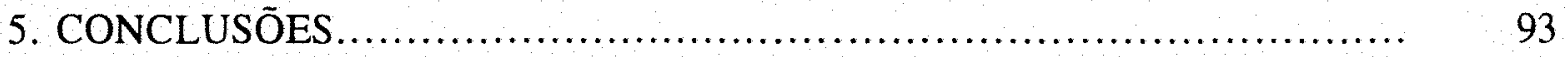

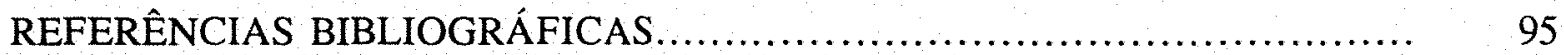




\title{
EFEITO DO BALANÇO DE CÁTIONS E ÂNIONS DA PLANTA NA ACIDIFICAÇÃO DO SOLO POR FERTILIZANTES NITROGENADOS
}

\author{
Autor: JUAN CARLOS QUEVEDO CAMACHO \\ Orientador: Prof. Dr. JORGE DE CASTRO KIEHL
}

\section{RESUMO}

Com o objetivo de determinar o balanço entre cátions e ânions de diferentes espécies vegetais adubadas com três fertilizantes nitrogenados e avaliar a influência desse balanço na reação do solo, um experimento em vasos foi conduzido em casa de vegetação com amostra do horizonte Ap de um Latossolo Roxo distrófico. O delineamento experimental, inteiramente casualizado, foi composto de 36 tratamentos em arranjo fatorial $4 \times 3 \times 3$ com três repetições. O fatorial foi constituído de quatro modos de cultivo (sem cultivo e cultivos com milho, arroz e trigo sarraceno), três fontes de nitrogênio (nitrato de cálcio, NC; nitrato de amônio, NA; e sulfato de amônio, $\mathrm{SA}$ ) e três doses de nitrogênio $\left(0,200\right.$ e $\left.400 \mathrm{mg} \cdot \mathrm{kg}^{-1} \mathrm{de} \mathrm{N}\right)$.

A amostra de solo foi previamente tratada com uma mistura de $\mathrm{CaCO}_{3}$ e $\mathrm{MgCO}_{3}$ na proporção de $4: 1$, homogeneizada, umedecida e incubada por 15 dias com a finalidade de elevar o $\mathrm{pH} \mathrm{em} \mathrm{CaCl}_{2}$ a 5,6. Todas as parcelas receberam adição dos nutrientes $\mathrm{P}, \mathrm{K}$, $\mathrm{Cu}, \mathrm{Fe}, \mathrm{Zn}, \mathrm{Mn}, \mathrm{Mo}$ e B. Seis plantas de trigo sarraceno (Fagopyrum esculentum Moench.), quatro plantas de milho híbrido (Zea mays L.), cv. ICI-8586 e oito de arroz (Oryza sativa L.), cv. IAC-165 foram cultivadas durante 24,32 e 40 dias, respectivamente, em vaso contendo $4 \mathrm{~kg}$ de terra. $\mathrm{O}$ material proveniente da parte aérea das plantas foi submetido às determinações de $\mathrm{N}, \mathrm{P}, \mathrm{K}, \mathrm{Ca}, \mathrm{Mg}, \mathrm{S}, \mathrm{Na}$ e $\mathrm{Cl}$. Amostras de terra dos vasos foram coletadas e submetidas às determinações de $\mathrm{pH}$ em água, $\mathrm{pH}$ em $\mathrm{CaCl}_{2}$ 0,01M, acidez potencial $(\mathrm{H}+\mathrm{Al}), \mathrm{Ca}, \mathrm{Mg}$ e $\mathrm{K}$ trocáveis e $\mathrm{N}$ mineral $\left(\mathrm{NH}_{4}{ }^{+}\right.$e $\left.\mathrm{NO}_{3}{ }^{-}\right)$. 
$\mathrm{Na}$ ausência de plantas, o efeito acidificante dos adubos sobre o solo foi maior para o SA do que para o NA, mostrando-se pequeno para NC. O NC, associado a plantas de milho e arroz, causou elevação do $\mathrm{pH}$, mas na presença do trigo sarraceno exerceu pouca influência na reação do solo; o NA e o SA mostraram-se sempre acidificantes.

As plantas tratadas com NC apresentaram maiores valores de excesso de bases (ou $\mathrm{EB}$, significa a soma dos cátions inorgânicos $\mathrm{Ca}^{2+}, \mathrm{Mg}^{2+}, \mathrm{K}^{+} \mathrm{e} \mathrm{Na} \mathrm{Na}^{+}$, menos os ânions inorgânicos $\mathrm{H}_{2} \mathrm{PO}_{4}^{-}, \mathrm{SO}_{4}^{2-}$ e $\mathrm{Cl}$, expressos em equivalentes) que as adubadas com $\mathrm{NA} \mathrm{e}$ $\mathrm{SA}$, sugerindo que o nitrato estimulou a absorção de cátions e reduziu a de ânions. Independentemente da fonte nitrogenada, o trigo sarraceno apresentou valores de EB maiores do que o milho e o arroz, indicando que a aquela dicotiledônea acumulou maior quantidade de cátions que as monocotiledôneas.

As plantas adubadas com o nitrogênio na forma de nitrato mostraram relações excesso de bases/nitrogênio ( $E B / N)$ maiores que as tratadas com a forma amoniacal. Os aumentos do teor de nitrogênio nas plantas, causados pelas aplicaçōes dos fertilizantes, não foram acompanhados de iguais aumentos no excesso de bases, resultando em diminuição da relação EB/N. Na ausência de nitrogênio aplicado, assim como na presença de NC, o trigo sarraceno mostrou relações $\mathrm{EB} / \mathrm{N}$ superiores às das gramíneas, mas quando a forma amoniacal foi aplicada, a relação no trigo sarraceno caiu ao nível das gramíneas.

$O$ nitrogênio na forma nítrica conferiu relações $E B / N$ menores que 1 nas plantas de milho e arroz, e efeito alcalinizante no solo; por outro lado, resultou relações maiores que um nas plantas de trigo sarraceno e efeito acidificante no solo. $O$ nitrogênio nas formas nítrica-amoniacal e amoniacal propiciou relaçōes $\mathrm{EB} / \mathrm{N}$ menores que um independentemente da espécie cultivada, e um efeito acidificante no solo. As observações de Pierre e colaboradores, de que plantas com relações $\mathrm{EB} / \mathrm{N}$ menores que um, apresentam efeito alcalinizante sobre o solo, enquanto as que possuem relações maiores que um, mostram efeito acidificante, foram válidas somente quando adubadas com o $\mathrm{N}$ na forma nítrica, não se verificando quando se empregaram as formas nítrica-amoniacal e amoniacal. 


\title{
EFFECT OF CATION-ANION BALANCE OF PLANTS ON SOIL
}

\section{ACIDIFICATION BY NITROGEN FERTILIZERS}

\author{
Author: JUAN CARLOS QUEVEDO CAMACHO \\ Adviser: Prof. Dr. JORGE DE CASTRO KIEHL
}

\section{SUMMARY}

A pot experiment was carried out in a greenhouse with soil samples collected from the surface horizon of a distrophic Red-Latosol (Typic Haplorthox) with the objective of determining the cation-anion balance of different plant species treated with three nitrogen fertilizers, and evaluating the influence of this balance on the soil reaction. A completely randomized design with three replications was utilized, comprising 36 treatments in a $4 \mathrm{x}$ $3 \times 3$ factorial arrangement. The treatments consisted of four cultivation methods (no cultivation and cultivation with maize, rice and buckwheat), three nitrogen fertilizers (calcium nitrate, $\mathrm{CN}$; ammonium nitrate, $\mathrm{AN}$; and ammonium sulphate, $\mathrm{AS}$ ) and three nitrogen rates $\left(0,200\right.$ e $400 \mathrm{mg} . \mathrm{kg}^{-1}$ of $\left.\mathrm{N}\right)$.

The soil sample was previously treated with a mixture of $\mathrm{CaCO}_{3}$ and $\mathrm{MgCO}_{3}$ in a ratio of $4: 1$, homogenized, moistened and incubated for a period of 15 days in order to raise the $\mathrm{pH}$ in $\mathrm{CaCl}_{2}$ to 5.6. All pots received the addition of the nutrients $\mathrm{P}, \mathrm{K}, \mathrm{Cu}, \mathrm{Fe}$, $\mathrm{Zn}, \mathrm{Mn}, \mathrm{Mo}$ and B. Six buckwheat (Fagopyrum esculentum Moench) plants; four hybrid maize (Zea mays L.) plants, cv. ICI-8586, with medium tolerance to soil acidity; and eight rice (Oryza sativa L.) plants, cv. IAC-165 were cultivated for 24,32 and 40 days, respectively, in pots with $4 \mathrm{~kg}$ of soil. Plant tops were collected and subjected to $\mathrm{N}, \mathrm{P}, \mathrm{K}$, $\mathrm{Ca}, \mathrm{Mg}, \mathrm{S}$, $\mathrm{Na}$ e $\mathrm{Cl}$ determinations. Soil samples were collected and analyzed for $\mathrm{pH}$ in water, $\mathrm{pH}$ in $1 \mathrm{M} \mathrm{CaCl}$, potential acidity $(\mathrm{H}+\mathrm{Al})$, exchangeable $\mathrm{Ca}, \mathrm{Mg}$ and $\mathrm{K}$, and mineral $\mathrm{N}\left(\mathrm{NH}_{4}^{+}\right.$e $\left.\mathrm{NO}_{3}^{-}\right)$. 
In absence of plants, soil acidification from AS was more expressive than from AN, whereas $\mathrm{CN}$ showed a low influence on the soil reaction. $\mathrm{CN}$ in combination with maize and rice plants increased soil $\mathrm{pH}$, but when associated to buckwheat the influence on the soil reaction was small. AN and AS always displayed an acidic effect.

Excess base (or EB, means the excess of inorganic cations $\mathrm{Ca}^{2+}, \mathrm{Mg}^{2+}, \mathrm{K}^{+}$and $\mathrm{Na}^{+}$over the inorganic anions $\mathrm{H}_{2} \mathrm{PO}_{4}{ }^{-}, \mathrm{SO}_{4}{ }^{2}$ and $\mathrm{Cl}$, expressed as equivalents) values were higher in plants treated with $\mathrm{CN}$ than in plants receiving $\mathrm{AN}$ and $\mathrm{AS}$, suggesting that nitrate stimulated the absorption of cations and reduced the absorption of anions. For any of the nitrogen sources, buckwheat plants showed higher EB values than maize and rice, indicating that the dicotyledon accumulated a higher amount of cations than the monocotyledons.

Excess base/nitrogen $(\mathrm{EB} / \mathrm{N})$ ratios of plants fertilized with nitrogen as nitrate were higher than those of plants treated with nitrogen as ammonium. The increases in the nitrogen content of plants due to the fertilizers applications were not followed by similar increases in the excess of bases; the result was a decrease in the EB/N ratio of the plant. When nitrogen was not applied, or when it was applied as $\mathrm{CN}$, buckwheat showed EB/N ratios higher than the grasses; however, when the ammonium form was added, the $\mathrm{EB} / \mathrm{N}$ ratio of buckwheat dropped to the level of those found in grasses.

Maize and rice plants fertilized with nitrogen as nitrate showed EB/N ratios lower than 1, whereas the soil $\mathrm{pH}$ increased; in the other hand, in the pots with buckwheat the plants displayed $\mathrm{EB} / \mathrm{N}$ values higher than 1 and the soil $\mathrm{pH}$ decreased. When nitrogen was applied in the nitric-ammonium and ammonium forms, the EB/N ratios of the plants were lower than 1 either in the grasses or buckwheat, and the soil $\mathrm{pH}$ also decreased. The observations of Pierre and co-workers, that plants having EB/N ratios less than one should decrease the acidity of nitrogen fertilizers, whereas those with a ratio greater than one should increase it, showed to be valid only when the plants were fertilized with nitric nitrogen; therefore, the observations were not confirmed when a nitric-ammoniacal or an ammoniacal source was applyed. 


\section{INTRODUÇÃO}

A exploração intensiva do solo por culturas de alta produtividade exige o emprego de quantidades elevadas de fertilizantes, dentre os quais os nitrogenados se destacam por serem portadores de um dos nutrientes mais exigidos pelos vegetais. Os fertilizantes nitrogenados, contudo, dependendo da sua composição química, podem deixar no solo um resíduo ácido, neutro ou alcalino. Dentre os acidificantes, a redução do pH é mais intensa para aqueles adubos que contém elevada proporção do elemento na forma amoniacal ou amídica, pois a oxidação do $\mathrm{NH}_{4}{ }^{+}$a $\mathrm{NO}_{3}$ é acompanhada da liberação de prótons $\mathrm{H}^{+}$; essa reação constitui o principal processo de acidificação do solo.

O sulfato de amônio tem-se mostrado o mais acidificante dos nitrogenados; 0 nitrato de amônio, por possuir apenas a metade do nitrogênio na forma amoniacal, é menos acidificante que o sulfato. Essa acidificação pode beneficiar uma pequena parcela das terras agrícolas compreendidas por solos calcários ou alcalinos, mas pode causar sérios problemas de excessiva acidez nas áreas restantes. $O$ nitrato de cálcio, ao contrário dos fertilizantes portadores de formas amoniacais e amídicas, apresenta um efeito alcalino, atenuando em parte o problema da acidificação dos solos.

A capacidade de acidificação ou alcalinização de um fertilizante nitrogenado, ao contrário do que os experimentos revelam, tem sido considerada uma constante, sendo muitas vezes denominada de "índice de acidez" ou "índice de alcalinidade". Muitos livrostexto e manuais sobre fertilizantes chegam a publicar tabelas relacionando as fontes de 
nitrogênio e seus respectivos índices. Contudo, estudos desenvolvidos por Jessen e por Engel e Kaufman, nos EUA, mostraram que os valores de $\mathrm{pH}$ de solos cultivados tratados com fertilizantes nitrogenados acidificantes foram maiores que os dos solos sem cultivo.

Embora o problema da acidificação do solo pelos fertilizantes nitrogenados seja reconhecido há muito tempo, ainda não se tem informaçōes precisas sobre o papel da planta como fator modificador desse processo. Isso se deve principalmente à complexa dinâmica do nitrogênio na natureza. Por ser a forma predominante no solo, o íon $\mathrm{NO}_{3}$ constitui a principal fonte de nitrogênio absorvida pelas plantas; porém, diversos trabalhos tem mostrado que certas dicotiledôneas, como o trigo sarraceno, mesmo quando adubadas com fertilizantes nítricos, tendem a acidificar o solo.

Trabalhos realizados posteriormente mostraram que plantas adubadas com a forma nítrica tendem a elevar o $\mathrm{pH}$ do solo devido à extrusão de ânions $\mathrm{OH}$ ou $\mathrm{HCO}_{3}{ }^{-}$ pelas raizes, enquanto as fertilizadas com a forma amoniacal tendem a diminuir o $\mathrm{pH}$ pela eliminação de íons $\mathrm{H}^{+}$; a extrusão de íons pelas raízes está relacionada à necessidade de a planta manter o balanço interno entre cátions e ânions. A dificuldade de se avaliar o efeito da cultivação na reação do solo aumenta quando se considera que o padrão de absorção de cátions e ânions entre plantas de diferentes espécies ou até da mesma espécie pode sofrer amplas variações.

O efeito das plantas sobre a acidificação refere-se somente à porção do nitrogênio aplicado que é efetivamente absorvida pelo vegetal e removida pela colheita; portanto, (a) o nitrogênio excedente pode exercer no solo todo o seu potencial de acidificação e (b) quanto maior a quantidade de nitrogênio excedente, menor a influência da cultura.

Devido à existência dos fatores anteriormente citados, torna-se difícil, senão impossível, prever em que grau se dará o baixamento do $\mathrm{pH}$ após o emprego de um fertilizante nitrogenado sob determinada condição de solo, clima e cultura. Por outro lado, o conhecimento dos mecanismos de acidificação reveste-se não somente de grande 
importância prática face ao consumo acentuadamente crescente de fertilizantes nitrogenados na agricultura, como também de considerável importância científica pelo fato de permitir melhor compreensão dos fenômenos envolvidos no processo de acidificação do solo por esses insumos.

O principal objetivo deste trabalho é determinar o balanço entre cátions e ânions de diferentes espécies vegetais adubadas com três fertilizantes nitrogenados e avaliar a influência desse balanço na acidificação de um Latossolo Roxo distrófico. 


\section{REVISÃO DE LITERATURA}

\subsection{Acidificação do Solo pelos Fertilizantes Nitrogenados}

O nitrogênio encontra-se no solo sob formas minerais e orgânicas, sendo estas últimas predominantes e não prontamente absorvidas pelas plantas. Com o processo de mineralização, formam-se inicialmente íons amônio. Tanto 0 amônio originado da mineralização da matéria orgânica quanto aquele proveniente da aplicação de fertilizantes amoniacais tende a ser nitrificado em solos arejados.

O processo da nitrificação consiste na oxidação biológica do amônio a nitrato, realizado em duas etapas. Na primeira, o amônio é oxidado a nitrito, conforme a reação:

$$
2 \mathrm{NH}_{4}^{+}+3 \mathrm{O}_{2}-2 \mathrm{NO}_{2}^{-}+2 \mathrm{H}_{2} \mathrm{O}+4 \mathrm{H}^{+}
$$

Após a formação do nitrito, numa segunda fase ocorre a oxidação deste a nitrato:

$$
2 \mathrm{NO}_{2}^{-}+\mathrm{O}_{2}->2 \mathrm{NO}_{3}^{-}
$$

Ambas as reaçōes são mediadas no solo pela atividade de dois grupos de bactérias autotróficas: a primeira reação é promovida pelas bactérias do gênero Nitrosomonas, e a segunda, pelas do gênero Nitrobacter.

Os nitrificadores autotróficos são estritamente aeróbios, e dependem da energia produzida na oxidação do amônio a nitrito a fỉm de efetuarem a redução do gás carbônico. Além disso, são altamente influenciados pelos fatores ambientais, tais como suprimento de 
amônio, pH, aeração, temperatura e umidade do solo (HAYNES, 1986a; MELLO, 1987). Dentre os fatores mais estudados está a acidez, possivelmente devido à importância desta característica para o crescimento das plantas.

Do ponto de vista agronômico, o processo da nitrificação assume grande relevância porque (a) $\circ \mathrm{NO}_{3}$ produzido é uma importante forma de absorção de nitrogênio pelas culturas, (b) $\circ \mathrm{NO}_{3}^{-}$é um ânion extremamente sujeito a perder-se do solo por lixiviação e, sob condições de baixa drenagem, por desnitrificação, (c) o $\mathrm{NO}_{3}$ pode acumular-se nas águas subterrâneas e causar problemas de saúde ao homem e animais, e d) a oxidação do amônio a nitrato resulta na liberação de íons $\mathrm{H}^{+}$que tendem a acidificar o solo.

Este último aspecto, o da acidificação do solo, há muito vem merecendo a atenção de numerosos pesquisadores (WHEELER, 1918; PIERRE, 1928a e 1928b) dada a sua elevada significância em sistemas de agricultura intensiva, nos quais altas doses de nitrogênio são empregadas anualmente. Stammer', citado por WALLACE (1994), considera que a acidificação do solo resultante do emprego de fertilizantes cornerciais é uma das principais causas da degradação dos solos.

\section{Capacidade de Acidificação dos Fertilizantes Nitrogenados}

A literatura estrangeira cita numerosos experimentos conduzidos com a finalidade de avaliar a influência dos fertilizantes nitrogenados na reação do solo. VOLK \& TIDMORE (1946), por exemplo, conduzindo experimentos de longo prazo em solos do Alabama (EUA), verificaram que as fontes amoniacais promoveram acidificação do solo tanto para a cultura do algodoeiro quanto para a do milho, enquanto a calciocianamida e o nitrato de sódio, este em menor grau, elevaram o pH.

\footnotetext{
1. STAMMER, L.B. Study finds serious harm in 108 of world's best soil. Los Angeles Times, January (quotations from World Resources Institute of U.N. Environmental program.), 1992 .
} 
WOLCOTT et al. (1965) compararam o efeito de diferentes adubos nitrogenados sobre o $\mathrm{pH}$ do solo na camada de $0-38 \mathrm{~cm}$ e verificaram que os fertilizantes se classificaram na seguinte ordem quanto à capacidade de acidificação: $\left(\mathrm{NH}_{4}\right) \mathrm{SO}_{4}>$ $\mathrm{NH}_{4} \mathrm{Cl}>\mathrm{NH}_{4} \mathrm{NO}_{3} \approx$ uréia. O $\mathrm{Ca}\left(\mathrm{NO}_{3}\right)_{2}$ e o $\mathrm{NaNO}_{3}$ mostraram efeito residual básico.

MAHLER et al. (1985) procuraram determinar as causas, a velocidade e a magnitude do declínio do $\mathrm{pH}$ de solos situados em duas regiões nos EUA, baseando-se em resultados coletados durante um período de 40 anos. Verificaram que a acidez do solo resultou do uso intensivo e a longo prazo de fertilizantes amoniacais, e que houve acidificação mais acentuada nos últimos 25 anos devido às elevadas doses de nitrogênio aplicadas.

OBI (1989), estudando o comportamento dos fertilizantes nitrogenados sulfato de amônio, uréia e nitrocálcio sobre o pH de um Ultisol tropical da Nigéria, depois de quinze anos de cultivação contínua, comprovaram que as três fontes nitrogenadas, além de reduzirem a porcentagem de matéria orgânica no solo, diminuiram a produção agrícola devido ao baixamento do $\mathrm{pH}$ e aumento do alumínio solúvel; o uso contínuo do sulfato de amônio acelerou o desenvolvimento da acidez trocável tanto em superfície como em subsuperfície.

RASMUSSEN \& ROHDE (1989), avaliando os resultados de um experimento conduzido durante 44 anos nos EUA, constataram que o uso contínuo de fertilizantes na forma amoniacal provocou uma redução no $\mathrm{pH}$ do solo, sendo que o grau e a profundidade de acidificação foram influenciados pela dose de $\mathrm{N}$, pela natureza do fertilizante nitrogenado e pelo sistema de manejo empregado.

STUMPE \& VLEK (1991) avaliaram, através de colunas de terra, o efeito do uso de fertilizanteś nitrogenados a longo prazo, sobre algumas características químicas dos solos Oxic Paleustalf, Typic Paleudult e Tropeptic Haplustox. O poder de acidificação das fontes nitrogenadas variou na seguinte ordem: sulfato de amônio $>$ uréia $>$ nitrocálcio. No Oxisol e Ultisol, além da diminuição do $\mathrm{pH}$ do solo, houve aumento do teor de $\mathrm{Al}$ e 
Mn trocáveis. No Alfisol a acidificação acarretou diminuição da CTC e aumento da predominância de $\mathrm{Al}$ e $\mathrm{Mn}$.

Pesquisas realizadas no Brasil também comprovam a influência das fontes nitrogenadas na mudança do $\mathrm{pH}$ do solo. NEVES et al. (1960), avaliando o efeito do salitre do Chile, da uréia e do sulfato de amônio sobre o pH de um solo da Estação Experimental de Campinas, constataram que o salitre do Chile contribuiu para atenuar a acidificação do solo e que o maior efeito acidificante foi apresentado pelo sulfato de amônio, que fez baixar o $\mathrm{pH}$ em aproximadamente 1,5 unidade.

MELLO \& ANDRADE (1973) resumiram os resultados obtidos por Chica \& Lotero $^{2}$ sobre os efeitos de adubações de pastagens com nitrato de sódio, sulfato de amônio e uréia. Os resultados mostraram que o nitrato de sódio elevou o $\mathrm{pH}$ do solo, a uréia baixou-o moderadamente e o sulfato de amônio o fez fortemente.

MORAES (1974), aplicando diferentes fontes nitrogenadas em cafeeiros cultivados em vasos contendo amostras de três solos do Estado de São Paulo, observou que, com exceção do salitre do Chile, os fertilizantes apresentaram acentuada ação acidificante sobre o solo, cuja intensidade obedeceu a seguinte ordem: sulfato de amônio $>$ nitrato de amônio $>$ uréia.

Após conclusão de experimento de longa duração sobre competição de fontes nitrogenadas em cafeeiro, MORAES et al. (1976) tomaram amostras de terra sob as copas das plantas e no meio das ruas e determinaram o pH e os teores de $\mathrm{Ca}^{2+}+\mathrm{Mg}^{2+}$ trocáveis. Observaram que o salitre do Chile elevou o $\mathrm{pH}$ do solo, enquanto o sulfato de amônio e a uréia mostraram acentuada acidificação; esta esteve correlacionada com forte redução dos teores de $\mathrm{Ca}^{2+}+\mathrm{Mg}^{2+}$ e elevação no teor de $\mathrm{Al}^{3+}$. A ação acidificante provocada pelo nitrocálcio foi menos pronunciada.

\footnotetext{
2 CHICA, J. \& LOTERO, J. Revista do Instituto Colombiano Agropecuário, $4(2): 31,1969$.
} 
HIROCE et al. (1977), estudando o efeito acidificante provocado no solo e em plantas de cafeeiro pelas aplicações de quatro fertilizantes nitrogenados, verificaram que o sulfato de amônio, a uréia e o nitrocálcio tiveram efeitos acidificantes no solo, na seguinte ordem: sulfato de amônio $>$ uréia $\approx$ nitrocálcio $>$ salitre do Chile. A acidificação causada pelos três primeiros adubos refletiu mais intensamente nas folhas através dos teores mais elevados de manganês.

KIEHL et al. (1981) avaliaram, em condições de laboratório, o efeito acidificante de três adubos nitrogenados em solos de diferentes texturas do município de Piracicaba (SP), constatando que o grau de acidificação não se correlacionou com a textura; porém, os solos com maiores valores de $\mathrm{pH}$ foram os que mais se acidificaram, sendo que o maior decréscimo observado foi de 0,7 unidade de $\mathrm{pH}$. O poder de acidificação dos adubos obedeceu a ordem $\left(\mathrm{NH}_{4}\right)_{2} \mathrm{SO}_{4}=\mathrm{NH}_{4} \mathrm{NO}_{3}>$ Uréia.

MELLO \& ARZOLLA (1983) verificaram que após a primeira colheita de milho, a uréia praticamente não acidificou o solo, o nitrato de amônio teve um efeito muito pequeno e o sulfato de amônio mais pronunciado. Após a segunda colheita, a uréia e o nitrato de amônio elevaram muito pouco a acidez potencial do solo, enquanto o sulfato de amônio elevou-a sensivelmente.

Incubando amostras de Latossolo Vermelho Escuro do município de Piracicaba, tratadas e não tratadas com $\mathrm{Ca}(\mathrm{OH})_{2}$, com a finalidade de verificar o efeito do sulfato de amônio e da uréia na acidificação, MELLO et al. (1986) concluíram que tanto a uréia quanto o sulfato de amônio tenderam a reduzir o pH do solo, sendo o efeito do segundo mais intenso.

A influência da adição de $150 \mathrm{mg} \cdot \mathrm{kg}^{-1}$ de $\mathrm{N}$, nas formas de uréia, sulfato de amônio e nitrato de amônio, sobre a acidificação do solo e o crescimento do feijoeiro em terras com diferentes teores de matéria orgânica e níveis de $\mathrm{pH}$, foi avaliada por SILVA (1994). Observou que as principais limitações à produção da cultura suprida predominantemente com o íon amônio estão relacionadas aos efeitos combinados da 
acidificação da rizosfera e do acúmulo de quantidades tóxicas de amônio nos tecidos das plantas; nos solos com maior poder tampão esse efeito foi amenizado, mesmo quando se aplicou sulfato de amônio. Os maiores níveis de nitrato produzidos foram observados nos solos com teores mais elevados de matéria orgânica. A uréia, seguida do nitrato de amônio, foi a fonte que propiciou as maiores produções de matéria seca devido ao suprimento mais balanceado de amônio e nitrato à planta.

\section{Acidez Imediata e Acidez Residual}

A influência dos adubos nitrogenados na acidez do solo, segundo DONALD et al. (1963), pode ser dividida em imediata, aquela que se verifica logo após a aplicação do adubo, e residual, aquela observada em prazos mais longos, decorrentes de reaçōes ou transformações do fertilizante no solo. É importante considerar que em cada caso os efeitos podem diferir amplamente em magnitude ou até mesmo ser opostos. A uréia, por exemplo, segundo ALEXANDER (1965), quando aplicada ao solo, sofre hidrólise numa reação mediada pela enzima urease, produzindo amônia. Esta, reage com íons $\mathrm{H}^{+}$do meio causando elevação do $\mathrm{pH}$ na região de aplicação a valores que podem atingir a faixa de 8,0 a 9,0; após algumas semanas, contudo, manifesta-se o efeito residual, que é o de baixar o $\mathrm{pH}$ devido à liberação de íons $\mathrm{H}^{+}$no processo de oxidação microbiana do nitrogênio amoniacal.

O sulfato e o nitrato de amônio, por sua vez, quando aplicados ao solo produzem diretamente íons amônio, sendo considerados fertilizantes fisiologicamente ácidos (MELLO, 1987). Segundo DONALD et al. (1963), apresentam um efeito inicial ácido, o qual tende a aumentar com o tempo devido à nitrificação do amônio que encerram.

\section{Acidez Teórica e Acidez Efetiva}

Estudos desenvolvidos por Pierre (PIERRE, 1928a e 1928b; PIERRE et al., 1970) permitiram a introdução do conceito da "acidez teórica" dos fertilizantes nitrogenados. Esses autores (PIERRE et al., 1971) constataram que os fertilizantes 
amoniacais tem a capacidade de produzir acidez equivalente a $3,5 \mathrm{~kg}$ de ácido sulfúrico por quilograma de $\mathrm{N}$ aplicado ao solo; isso significa que são necessários $3,57 \mathrm{~kg}$ de $\mathrm{CaCO}_{3}$ para neutralizar um quilograma de nitrogênio na forma amoniacal. Essa acidez desenvolvida no solo, denominada de acidez teórica por PIERRE et al. (1971), é definida como a quantidade máxima de acidez produzida pela completa nitrificaçāo do nitrogênio aplicado na forma amoniacal a um solo não cultivado. Esses mesmos autores observaram que a nitrificação e a subseqüente lixiviação do nitrato podem ser as maiores causas do decréscimo do $\mathrm{pH}$ e da percentagem de saturação por bases dos solos agrícolas.

Em outro trabalho, PIERRE et al. (1970) comentam que a acidificação proporcionada pelos adubos nitrogenados nem sempre corresponde à calculada devido à influência de diversos fatores, sendo difícil prever em que grau se dará o baixamento do $\mathrm{pH}$ após o emprego de um fertilizante nitrogenado em determinada condição de solo, clima e cultura. A dificuldade está em avaliar corretamente o grau de influência dos diferentes fatores que agem sobre os mecanismos de acidificação. Os mesmos autores acreditam que a espécie cultivada seja o mais importante de todos esses fatores.

TISDALE et al. (1985) relaciona os seguintes fatores: (1) emprego de fertilizantes comerciais, especialmente fontes amoniacais que produzem íons $\mathrm{H}^{+}$durante a nitrificação; (2) remoção de cátions básicos pela cultura; (3) lixiviação desses cátions, sendo substituídos no colóide por $\mathrm{H}^{+}$e posteriormente por $\mathrm{Al}^{3+}$ e (4) decomposição de resíduos orgânicos.

BOLAN et al. (1991) constataram que os principais processos de acidificação que ocorrem durante o ciclo do $\mathrm{N}$ no solo são: (1) desequilíbrio entre a absorção de cátions e ânions na rizosfera de plantas cuja principal fonte de nitrogênio é a fixação simbiótica ou o $\mathrm{NH}_{4}^{+}$do solo; (2) nitrificação do $\mathrm{NH}_{4}^{+}$proveniente de fertilizantes amoniacais e amídicos, e da fixação simbiótica, e (3) remoção pelas colheitas e perda de nitrato por lixiviação, seja ele proveniente do $\mathrm{NH}_{4}{ }^{+}$, do $\mathrm{R}-\mathrm{NH}_{2}$ ou da fixação do $\mathrm{N}_{2}$. 
Segundo os mesmos autores, a lixiviação induz uma acidificação "permanente" do solo somente quando a perda do nitrato libera um íon $\mathrm{H}^{+}$no meio, o que ocorre principalmente em duas situações:

a) Se os fertilizantes à base de $\mathrm{NH}_{4}{ }^{+}$e/ou $\mathrm{R}-\mathrm{NH}_{2}$ são adicionados ao solo $\mathrm{e}$ são subseqüentemente oxidados a nitrato, haverá formação de íons hidrogênio livres, sendo que dois $\mathrm{H}^{+}$são gerados pelo processo da nitrificação, no primeiro caso, e um $\mathrm{H}^{+}$pela combinação dos processos de amonificação e nitrificação, no segundo caso. Esses íons poderão ser neutralizados se os mesmos forem consumidos durante a redução do $\mathrm{NO}_{3}{ }^{-}$ e síntese do $\mathrm{R}-\mathrm{NH}_{2}$ dentro da planta. $\mathrm{O}$ processo de redução e assimilação do nitrato libera um íon $\mathrm{OH}^{-}$por mol de $\mathrm{NO}_{3}$ reduzido:

$$
\mathrm{NO}_{3}+8 \mathrm{H}^{+}+8 \mathrm{e}^{-}-\mathrm{NH}_{3}+2 \mathrm{H}_{2} \mathrm{O}+\mathrm{OH}^{-}
$$

Porém, se o nitrato é perdido por lixiviação do sistema, o excesso de íons hidrogênio livres ocasionará uma acidificação "permanente" do solo.

b) Quando a fixação do $\mathrm{N}_{2}$ atmosférico e conversão do $\mathrm{NH}_{3}$ em proteína dentro da planta libera íons $\mathrm{H}^{+}$na rizosfera, e a decomposição da proteína vegetal ou de seus derivados culmina com nitrificação, a menos que todo - $\mathrm{NO}_{3}$ seja reassimilado pelas plantas ou microrganismos, os íons $\mathrm{H}^{+}$ excedentes na rizosfera mais os íons $\mathrm{H}^{+}$provenientes da nitrificação do $\mathrm{R}$ $\mathrm{NH}_{2}$ permanecerão no solo.

Nas duas situações (a) e (b), o excedente de íons $\mathrm{H}^{+}$persistirá no solo quando o nitrato lixiviado for acompanhado por cátions básicos (JARVIS \& ROBSON, 1983a). Assim, em solos muito ácidos a lixiviação do nitrato provavelmente induza menor acumulação de $\mathrm{H}^{+}$do que em solos com elevados teores de cátions básicos trocáveis. Talvez a lixiviação do $\mathrm{H}^{+}$junto com o $\mathrm{NO}_{3}{ }^{-}$seja a causa da acidificação do subsolo e das águas subterrâneas. 
Para WALLACE (1994), a acidez que os fertilizantes nitrogenados causam efetivamente no solo pode ser modificada por diversos fatores, sendo o mais importante a absorção diferencial de cátions e ânions pela planta. Esse autor considera que para neutralizar a acidez de um quilograma de nitrogênio na forma amoniacal é necessário 1,8 $\mathrm{kg}$ de $\mathrm{CaCO}_{3}$, o que corresponde a $50 \%$ da acidez teórica encontrada por PIERRE et al. (1971); para esse raciocínio, Wallace considerou que metade do nitrogênio aplicado é absorvida pela planta e, portanto, nāo gera acidez. Contudo, o $\mathrm{N}$ aplicado em quantidade acima da exigida pela planta irá desenvolver seu poder total de acidificação ( $100 \%$ da acidez teórica), descontando-se as partes perdidas por lixiviação, volatilização e desnitrificação, bem como a porção incorporada à matéria orgânica do solo.

\subsection{Efeito das Plantas no $\mathrm{pH}$ do Solo}

Hartwell et $\mathrm{al}^{3}$., citados por PIERRE et al. (1970) realizaram experimentos de longa duração mostrando que a acidez do solo após a cultivação variava com a espécie, e relacionaram esse efeito à maior ou menor alcalinidade das cinzas vegetais. Posteriormente, estudando 0 efeito acidificante de vários fertilizantes nitrogenados, PIERRE (1928a) demonstrou que apenas cerca da metade da acidez teoricamente esperada foi desenvolvida no solo após quatro cultivos sucessivos em casa-de-vegetação. Sugeriu, para explicar o fenômeno, que aproximadamente metade do $\mathrm{N}$ absorvido pelas plantas tenha sido acompanhada da absorção de quantidade equivalente de íons $\mathrm{H}^{+}$, ou então, que as raizes tenham liberado para o solo íons bicarbonato $\left(\mathrm{HCO}_{3}\right)$ em quantidade equivalente a cerca da metade da quantidade de $\mathrm{N}$ nítrico absorvido. Valores de acidificação abaixo daqueles previstos teoricamente também têm sido encontrados em experimentos de longa duração (CROWTHER, 1925; HARTWELL \& DAMON, 1927 e VOLK \& TIDMORE, 1946).

3 HARTWELI, J.B.S. \& DAMON, S.C. The influence of crop plants on those which follow. III. R.I. Agri. Exp. sta. Bull. 210, 1927 . 
Segundo PIERRE (1928b), a conseqüência da influência das plantas na reação do solo é que o efeito acidificante dos fertilizantes amoniacais, na prática, é menor que o esperado a partir da reação de nitrificação. No caso de fertilizantes essencialmente nítricos, conforme apontam TISDALE et al. (1985), ocorre elevação do pH, já que há intensa absorção de nitrato e não há nitrificação. Pesquisas realizadas por Jessen ${ }^{4}$ e por Engel \& Kaufman ${ }^{5}$, citados por PIERRE et al. (1970), revelaram que o pH de solos adubados com nitrogênio e cultivados era maior do que o de solos adubados e não cultivados.

Dessas informaçōes deduz-se que o pH do solo na região de influência das raizes em determinada etapa do crescimento da cultura pode estar longe do ideal, muito embora o pH do solo como um todo apresente valores adequados. Essa consideração é de extrema importância para a planta porque o $\mathrm{pH}$ influi na disponibilidade de elementos essenciais, na solubilidade de elementos tóxicos, na atividade de organismos benéficos (fungos micorrízicos e bactérias fixadoras de nitrogênio, por exemplo) e na atividade de organismos patógenos.

Conforme se observa, o efeito das plantas no $\mathrm{pH}$ do solo está diretamente ligado à necessidade de manutenção de um equilíbrio entre cátions e ânions no interior do vegetal. Segundo HAYNES (1990), os principais mecanismos utilizados na manutenção desse equilíbrio são: (a) acumulação e degradação de ácidos orgânicos que ocorrem na planta, principalmente como ânions orgânicos, e sua transferência de um local para outro do vegetal e (b) extrusão de cátions $\mathrm{H}^{+}$ou de ânions $\mathrm{OH}^{-}$pelas raízes. Quando o desequilibrio entre cátions e ânions é pequeno, a planta recorre ao primeiro mecanismo, enquanto para diferenças maiores o segundo mecanismo é utilizado.

\footnotetext{
4 JESSEN, von $W$. Über die physiologische reaktion einiger stickstoff and kalidüngemittel. Zeit f. Pflanzenern., Düng. u. Bodenk. A22:307-322, 1931.

5 ENGEL, H. \& KAUFMAN, A. Transformation of ammonium nitrate and urea in soils. Zeit f. Pflanzenern., Düng. u. Bodenk. A29:16-24, 1933.
} 
Outra possibilidade de a planta compensar o desequilibrio entre cátions e ânions absorvidos é através da eliminação de ácidos orgânicos pelas raízes; PETERSEN \& BÖTTGER (1991), contudo, constataram que a contribuição desse mecanismo para a acidificação da rizosfera é de apenas 0,2 a $0,3 \%$, e que a redução no $\mathrm{pH}$ é predominantemente causada pela extrusão de prótons $\mathrm{H}^{+}$.

No caso deste segundo mecanismo, a extrusão de cátions ou de ânions é determinada pela diferença entre a quantidade de nutrientes ânions absorvidos $\mathrm{NO}_{3}+\mathrm{Cl}$ $\left.+\mathrm{SO}_{4}^{2-}+\mathrm{H}_{2} \mathrm{PO}_{4}\right)$ e a de nutrientes cátions ${ }^{6}$ absorvidos $\left(\mathrm{NH}_{4}^{+}+\mathrm{Ca}^{2+}+\mathrm{Mg}^{2+}+\mathrm{K}^{+}\right.$ $+\mathrm{Na}^{+}$, expressas em equivalentes, isso porque o excesso de ânions ou de cátions nutrientes absorvidos é compensado pela excreção na rizosfera, de uma quantidade estequiometricamente igual de ions $\mathrm{OH}^{-}$ou de íons $\mathrm{H}^{+}$, respectivamente; portanto, no primeiro caso haverá uma alcalinização do solo e, no segundo, uma acidificação.

Normalmente as plantas tendem a alcalinizar a rizosfera porque absorvem mais ânions nutrientes do que cátions nutrientes quando o íon nitrato é a principal forma de $\mathrm{N}$ disponível. A relação entre nutrientes catiônicos e aniônicos absorvidos normalmente varia entre 1:2 e 7:10 (NYE, 1981). O nitrato em geral constitui mais da metade do total de equivalentes de ânions absorvidos, mas esse ânion é rapidamente reduzido a compostos orgânicos na planta; portanto, embora geralmente a planta absorva mais ânions do que cátions, quase sempre acumula mais cátions livres do que ânions. Desde que o desequilibrio iônico não seja muito grande, a eletroneutralidade é mantida através da síntese de ânions orgânicos como malato e citrato (HAYNES \& GOH, 1978).

Quando a principal fonte de $\mathrm{N}$ é o $\mathrm{NH}_{4}{ }^{+}$, a quantidade de cátions absorvida pode superar a de ânions, resultando na acidificação do solo. Conforme destacam RAIJ \& DIEST (1979) e BEKELE et al. (1983), algumas plantas, como o trigo sarraceno

\footnotetext{
- As denominaçōes "nutrientes cătions" e "nutrientes ânions" foram aqui utilizadas para destacar que no cálculo do balanço iônico, ions que nāo são nutrientes não são considerados; contudo, por simplicidade, $e a$ exemplo do que se observa na literatura, nas páginas seguintes esses ions serão referidos somente por "cátions" e "ânions".
} 
(Fagopyrum esculentum Moench), por possuirem uma capacidade excepcional de utilizar o cálcio e o magnésio do solo, absorvem maiores quantidade de cátions do que de ânions mesmo quando o $\mathrm{NO}_{3}$ é a principal fonte de $\mathrm{N}$.

A absorção de maior quantidade de ânions do que de cátions pelas plantas foi chamada de "absorção acídica"7 por RAIJ \& DIEST (1979), enquanto o processo inverso foi denominado "absorção alcalina". BEKELE et al. (1983), similarmente empregaram os termos "acidic uptake pattern" e "alkaline uptake pattern" para distinguir as plantas que absorvem mais ânions do que cátions daquelas que retiram mais cátions do que ânions do solo, respectivamente. É preciso cuidado no emprego desses termos porque a conseqüência da "absorção acídica", ao contrário do que o nome poderia sugerir, é a elevação do $\mathrm{pH}$ do solo, enquanto a denominada "absorção alcalina" resulta em acidificação. Conforme será abordado adiante, esses termos referem-se a alterações na entrada e saída de íons $\mathrm{H}^{+} \mathrm{e} \mathrm{OH}^{-}$ da planta, e não do solo.

Por serem passiveis de interpretação equivocada, as expressōes "absorção acídica" e "absorção alcalina" devem ser evitadas quando se consideram seus efeitos sobre o solo. No trabalho de RAIJ et al. (1988), por exemplo, os autores mencionam equivocadamente que a absorção alcalina é acompanhada de elevação do $\mathrm{pH}$ da rizosfera, e a absorção "acídica", de acidificação do meio.

Na chamada absorção acídica, uma das maneiras de a planta compensar a retirada de maior quantidade de ânions (nitrato, principalmente) do solo é eliminar íons $\mathrm{OH}$ provenientes da hidrólise do ADP, que por sua vez é gerado a partir do ATP; esse mecanismo de absorção ativa, segundo OSMOLOVSKAYA \& IVANOVA (1990), é denominado uniporte. Outra possibilidade é a do íon $\mathrm{NO}_{3}$ ser absorvido juntamente com o $\mathrm{H}^{+}$através do transporte ativo denominado simporte.

\footnotetext{
7 A expressão "absorção acídica" foi traduzida inadequadamente do inglês "acidic uptake", pois a palavra "acídica" não consta da língua portuguesa; sugere-se a forma "absorção ácida", à semelhança de "absorção alcalina".
} 
RILEY \& BARBER (1969) comprovaram que raízes de plantas podem tanto aumentar como diminuir o pH do solo adjacente. $\mathrm{A}$ intensidade e o sentido da alteração dependeu da diferença entre as taxas de absorção de cátions e de ânions. Quando prevalecia a absorção de $\mathrm{NH}_{4}{ }^{+}$, a quantidade de cátions absorvida passava a ser maior que a de ânions, exigindo que íons $\mathrm{H}^{+}$fossem liberados pela raíz para equilibrar as cargas do sistema. Ao contrário, quando a absorção de $\mathrm{NO}_{3}$ era maior, havia liberação de íons $\mathrm{OH}^{-}$ ou $\mathrm{HCO}_{3}^{-}$para compensar o excesso de ânions absorvidos do solo. Este mesmo efeito é relatado por EPSTEIN (1975) para diferentes espécies vegetais.

Alterações no $\mathrm{pH}$ do solo nas proximidades do sistema radicular, influenciadas pela adição de nitrato e de amônio, têm sido observadas com freqüência (KIRKBY, 1968; RILEY \& BARBER, 1971; RÖMHELD, 1986; HÄUSSLING et al., 1985; GIJSMAN, 1990a). Conforme observaram RILEY \& BARBER (1971), a aplicação de fertilizante amoniacal em plantas de soja causou diminuição do $\mathrm{pH}$ do rizocilindro, enquanto a adição da forma nítrica aumentou o $\mathrm{pH}$. A diferença de $\mathrm{pH}$ no rizocilindro de plantas adubadas com $\mathrm{NH}_{4}^{+}$e de plantas adubadas com $\mathrm{NO}_{3}$ foi de 1,9 unidade quando o $\mathrm{pH}$ era 5,2 , e de 0,2 unidade quando era 7,8. Comparando o efeito de dois fertilizantes nitrogenados em um solo cujo pH original era 6,2, RÖMHELD (1986) encontrou diferenças superiores a três unidades entre o pH da rizosfera de plantas de trigo tratadas com nitrato de cálcio, cujo valor elevou-se para 7,5, e o de plantas tratadas com sulfato de amônio, cujo índice reduziu-se para menos de 4,5 .

O fenômeno de alteração do $\mathrm{pH}$ na rizosfera é grandemente influenciado pela espécie vegetal. Segundo BEKELE et al. (1983), em geral as gramíneas adubadas com nitrato absorvem com maior intensidade os ânions, principalmente nitrato, do que os cátions, como $\mathrm{Ca}^{2+}, \mathrm{Mg}^{2+} \mathrm{e} \mathrm{K}^{+}$; por outro lado, as dicotiledôneas, notadamente as leguminosas, atuam de modo inverso. Portanto, o pH da rizosfera tende a se elevar no caso das gramíneas e a diminuir no caso de leguminosas. 
O aumento da acidez do solo causado pelas plantas fixadoras de nitrogênio vem há muito sendo estudado, pois muitas leguminosas liberam íons $\mathrm{H}^{+}$para a rizosfera durante a atividade da fixação do $\mathrm{N}_{2}$ (NYATSANGA \& PIERRE, 1973; JARVIS \& ROBSON, 1983c; BOLAN et al., 1991). A quantidade de íons hidrogênio liberada durante a fixação depende principalmente da forma e da quantidade de aminoácidos e ácidos orgânicos sintetizados dentro da planta.

\section{Balanço de Cátions e Ânions e Acidificação do Solo}

Para quantificar a influência das plantas no processo de acidificação do solo pelos fertilizantes nitrogenados, diferentes procedimentos tem sido utilizados. CUNNINGHAM (1964a, 1964b e 1964c), KIRKBY (1968), RAIJ \& DIEST (1979) e HEDLEY et al. (1983), por exemplo, adotaram a relação C/A, ou seja, o quociente entre o somatório dos cátions $\left(\mathrm{Ca}^{2+}+\mathrm{Mg}^{2+}+\mathrm{K}^{+}+\mathrm{Na}^{+}\right)$e o somatório dos ânions $\left(\mathrm{H}_{2} \mathrm{PO}_{4}^{-}+\mathrm{SO}_{4}^{2-}\right.$ $+\mathrm{Cl}^{-}$) existentes na planta, expressos em equivalentes por unidade de massa de matéria seca. SCHJORRING (1986), por sua vez, utilizaram a diferença A-C, que é igual à quantidade de ânions $\left(\mathrm{NO}_{3}+\mathrm{H}_{2} \mathrm{PO}_{4}+\mathrm{SO}_{4}^{2-}\right)$ menos a de cátions $\left(\mathrm{Ca}^{2+}+\mathrm{Mg}^{2+}+\mathrm{K}^{+}\right)$, enquanto PIERRE et al. (1970, 1971), PIERRE \& BANWART (1973), AKTAS \& EGMOND (1979), BEKELE et al. (1983), TROELSTRA et al. (1985), CAMBRAIA et al. (1987), RAIJ et al. (1988), GIJSMAN (1990b) e WALLACE (1994) empregaram a diferença $C-A^{8}$, dada pela quantidade de cátions menos a de ânions; dentre estes, certas variações são encontradas, as quais envolvem a inclusão ou não de certos íons como $\mathrm{NO}_{3}$, $\mathrm{SiO}_{4}^{4}, \mathrm{Cl}, \mathrm{NH}_{4}^{+}$e $\mathrm{Na}^{+}$no somatório de anions e de cátions.

Como a alcalinidade das cinzas vegetais é influenciada pelas quantidades de cátions e ânions acumuladas na planta, esse parâmetro também tem sido utilizado na avaliação do efeito das plantas na reação do solo. JARVIS \& ROBSON (1983c)

\footnotetext{
8 Em seus trabalhos mais recentes, Pierre e colaboradores denominam essa diferença, de "excesso de bases" ou EB. Já ROBSON \& JARVIS (1983a) preferiram a expressão "excesso de cátions".
} 
determinaram a alcalinidade das cinzas tratando-as inicialmente com $\mathrm{HCl} 1 \mathrm{M}$ e titulando o ácido residual com solução de $\mathrm{NaOH} 0,25 \mathrm{M}$. Verificaram haver acentuada influência do balanço de cátions e ânions na acidez do solo, e que essa acidez aumenta com a alcalinidade das cinzas. A relação entre a alcalinidade das cinzas vegetais e a acidificação do solo também foi estudada por PIERRE \& BANWART (1973) e JARVIS \& ROBSON (1983b e 1983c).

JARVIS \& ROBSON (1983a) constataram que as mudanças de pH de amostras de solo sob condições de lixiviação, provenientes de áreas cultivadas e não cultivadas de duas regiōes do oeste da Austrália, tratadas com diferentes fontes de nitrogênio, estiveram fortemente relacionadas com o balanço de cátions e ânions de trevo subterrâneo. Houve diminuição do $\mathrm{pH}$ do solo quando o $\mathrm{N}$ foi aplicado na forma amoniacal, comprovando que a intensidade de absorção de cátions pela leguminosa foi maior que a de ânions.

Em outro experimento, JARVIS \& ROBSON (1983b) avaliaram o mesmo efeito para as culturas de trigo, azevém, trevo branco e trevo subterrâneo, em amostras do mesmo solo, porém, não submetido à lixiviação; verificaram que, para todas as leguminosas, a concentração total de ânions foi sempre menor em plantas adubadas com nitrato do que nas tratadas com amônio, resultando menor acidez do solo; no trigo, contudo, esse fato não foi constatado.

GIJSMAN (1990b, 1990c), investigando a influência do balanço iônico no pH da rizosfera de coníferas adubadas com diferentes doses de nitrogênio nas formas de $\mathrm{Ca}\left(\mathrm{NO}_{3}\right)_{2}, \mathrm{NH}_{4} \mathrm{NO}_{3}$ e $\left(\mathrm{NH}_{4}\right)_{2} \mathrm{SO}_{4}$, e cultivadas em solo com $\mathrm{pH}$ em água de 3,8 , verificou que a forma amoniacal baixou levemente o $\mathrm{pH}$ da rizosfera independentemente das doses de nitrogênio; as formas nítrica e nítrica-amoniacal tiveram comportamento similar nas doses menores, porém, houve elevada alcalinização da rizosfera com a dose mais alta. Com a aplicação de $\mathrm{N}$-amoniacal, o balanço cátions-ânions foi menor do que o observado com a adição da fonte nítrica, enquanto valores intermediários foram obtidos quando ambas as formas foram utilizadas. 
ARNOLD \& DIEST (1991), utilizando fontes contendo ${ }^{15} \mathrm{~N}$, mostraram que o $\mathrm{NH}_{4}{ }^{+}$é absorvido por Larix kaempferi Lamb. mais rapidamente que o $\mathrm{NO}_{3}^{-}$, e que a absorção total de cátions foi bem maior do que a de ânions. $O$ resultado foi um efeito acidificante no solo, sendo esse mecanismo considerado como uma das maiores causas da acidificação de solos de florestas na Holanda.

A absorção diferenciada de cátions e ânions pelas plantas contribui para aumentar a acidez do solo em proporções que podem variar apreciavelmente entre espécies e entre variedades de uma mesma espécie (WALLACE, 1994). A cultura pode acidificar o solo independentemente do fato de o nitrogênio fornecido à planta ser proveniente de fertilizantes minerais, da matéria orgânica do solo ou da fixação simbiótica, pois sabe-se que as leguminosas acidificam consideravelmente o solo.

Se a absorção de íons pelas plantas exerce um efeito mensurável no $\mathrm{pH}$ do solo como um todo, nas proximidades da raíz esse efeito deve ser ainda maior. De fato, diversos trabalhos têm mostrado que o pH do solo vizinho à raiz, ou seja, da região conhecida como rizosfera, pode diferir substancialmente do $\mathrm{pH}$ de regiōes mais distantes. Segundo RÖMHELD (1986), isso se deve aos seguintes fatores:

a) Liberação de $\mathrm{CO}_{2}$ produzido na respiração das raízes e dos organismos que habitam a rizosfera;

b) Liberação ativa de prótons durante o crescimento celular na extremidade da raíz;

c) Liberação ativa de prótons pela raíz, resultantes da absorção desequilibrada de cátions e ânions; $\mathrm{e}$

d) Liberação de ácidos orgânicos.

Para avaliar quantitativamente o efeito das plantas na acidificação do solo pelos fertilizantes nitrogenados, PIERRE et al. (1970) levaram em consideração a chamada 
"relação excesso de bases/nitrogênio", ou EB/N. Essa relação é obtida dividindo-se o excesso de bases (quantidade de cátions absorvidos, como $\mathrm{Ca}^{2+}, \mathrm{Mg}^{2+}, \mathrm{K}^{+}$e $\mathrm{Na}^{+}$, menos a quantidade de ânions absorvidos, como $\mathrm{H}_{2} \mathrm{PO}_{4}^{-}, \mathrm{SO}_{4}{ }^{2-} \mathrm{e} \mathrm{Cl}$ ) pelo teor de nitrogênio da planta, ambos os valores expressos em equivalentes.

De acordo com aqueles autores, a relação $\mathrm{EB} / \mathrm{N}$ deve permitir uma avaliação quantitativa mais adequada do efeito de uma cultura sobre a reação do solo, já que o excesso de cátions contribui para aumentar o efeito acidificante do adubo nitrogenado e a quantidade de $\mathrm{N}$ acumulada ajuda a diminuí-lo. Assim, plantas com relações $\mathrm{EB} / \mathrm{N}$ menores que uma unidade devem reduzir o efeito acidificante causado pela nitrificação do adubo nitrogenado, enquanto aquelas com relações maiores que uma unidade devem aumentá-lo. Embora a maioria das plantas apresente excessos de bases consideravelmente menores que as quantidades de $\mathrm{N}$, diversas culturas, como o trigo sarraceno, possuem relações $\mathrm{EB} / \mathrm{N}$ iguais ou maiores que um. Apesar de o trigo sarraceno apresentar a característica de absorver quantidades de cátions bem superiores às de ânions, poucos trabalhos têm sido realizados com essa cultura para avaliação do efeito acidificante da planta sobre o solo; alguns desses trabalhos são apresentados a seguir.

PIERRE \& BANWART (1973) determinaram as relaçōes EB/N de 27 espécies vegetais com a finalidade de verificar de que modo essa relação altera o efeito do fertilizante nitrogenado sobre a reação do solo. Houve variações acentuadas entre as espécies, com valores oscilando de 0,24 para o repolho até 1,09 para o trigo sarraceno. Isso significa que o nitrogênio removido pelo repolho reduziu para $24 \%$ a acidez produzida no solo pela nitrificação do fertilizante aplicado, enquanto a remoção da mesma quantidade de nitrogênio pelo trigo sarraceno aumentou levemente a acidez do fertilizante.

Os resultados da pesquisa de PIERRE et al. (1970) mostraram que a acidez causada pelo nitrato de amônio aplicado em amostras de solo na ausência de plantas foi quase igual à que teria sido teoricamente gerada pela nitrificação. Na presença de plantas de aveia, contudo, a acidificação foi $27 \%$ menor que a esperada, enquanto na presença do 
trigo sarraceno, foi $87 \%$ maior. As análises químicas das plantas mostraram que as amplas variações observadas no efeito acidificante do nitrato de amônio foram plenamente explicadas pela relação entre o excesso de bases absorvidas pela planta e o seu teor de $\mathrm{N}$ $(\mathrm{EB} / \mathrm{N})$.

Embora a importância da relação entre o balanço de cátions e ânions na planta e a acidificação do solo seja reconhecida no exterior, poucas informações existem no Brasil sobre o assunto. Elas são encontradas no trabalho de RAIJ \& DIEST (1979), porém, referem-se à acidificação do solo pela aplicação de diferentes fontes de fósforo. Os autores compararam a eficiencia relativa de diferentes fertilizantes fosfatados utilizando seis espécies de plantas. Para as três fontes que apresentaram os maiores índices de eficiência agronômica (superfosfato triplo, fosfato de alumínio calcinado e hiperfosfato), houve correlação negativa entre a acidez do solo e a quantidade de $\mathrm{P}$ absorvido pela planta, $\mathrm{e}$ correlação positiva entre o $\mathrm{P}$ absorvido e a relação entre o somatório de cations $\mathrm{e} O$ somatorio de anions, expressos em equivalentes; conseqüentemente, o pH do solo foi correlacionado negativamente com a citada relação.

CAMBRAIA et al. (1987), estudando a inter-relação entre o balanço iônico e a capacidade das plantas de sorgo, submetidas a níveis tóxicos de alumínio ( 0 e 5 ppm de alumínio na forma $\left.\mathrm{Al}_{2}\left(\mathrm{SO}_{4}\right)_{3}\right)$, para modificar o $\mathrm{pH}$ das soluçōes nutritivas, constataram que esse índice aumentou quando o nitrogênio foi fornecido exclusivamente na forma de $\mathrm{NO}_{3}$; contudo, quando havia também $\mathrm{NH}_{4}^{+}, \mathrm{o} \mathrm{pH}$ tendeu a decrescer. Na presença de alumínio, o $\mathrm{pH}$ foi sempre menor que na sua ausência, exceto quando a relação $\mathrm{NO}_{3} / \mathrm{NH}_{4}{ }^{+}$foi de 50/50; de um modo geral a concentração de ânions absorvidos pela planta sofreu uma redução mais forte que a de cátions, explicando o efeito manifestado pelas plantas de acidificar a solução nutritiva, principalmente na presença de alumínio; esse efeito também foi observado por KIRBY \& MENGEL (1967).

RAIJ et al. (1988) estudaram o efeito da absorçāo de nitrogênio pelo sorgo, na presença e na ausência de gesso, sobre a reação do solo e o balanço de cátions e ânions 
absorvidos pela planta, utilizando as seguintes fontes de nitrogênio: nitrato de cálcio, nitrato de magnésio, nitrato de amônio e sulfato de amônio; verificaram haver um efeito estequiométrico dos adubos nitrogenados na reação do subsolo, pelo qual os nitratos reduziram a acidez e os sais de amônio aumentaram-na; observaram também que a variação de acidez relacionou-se com a diferença entre os cátions $\left(\mathrm{Ca}^{2+}+\mathrm{Mg}^{2+}+\mathrm{K}^{+}+\mathrm{NH}_{4}^{+}\right)$ e os ânions $\left(\mathrm{H}_{2} \mathrm{PO}_{4}+\mathrm{SO}_{4}{ }^{2-}+\mathrm{NO}_{3}{ }^{-}\right)$absorvidos pelo sorgo.

SILVA (1994), avaliando o efeito da acidez do solo e da adição de fontes de nitrogênio sobre o crescimento inicial do feijoeiro em quatro solos com amplo espectro de capacidade tampão, constatou que a produção de matéria seca total do feijoeiro, de um modo geral, foi maior quando se aplicou uréia ou nitrato de amônio do que quando se empregou sulfato de amônio; segundo o autor, esse fertilizante causou maior acidificação do solo, devido ao efluxo de $\mathrm{H}^{+}$durante a absorção do íon amônio pela planta e a conversão do amônio a nitrato (nitrificação).

Conforme se pôde observar pela revisão da literatura, na maioria dos trabalhos a influência das plantas no $\mathrm{pH}$ dos solos tratados com fertilizantes nitrogenados foi avaliada pela diferença ou pela relação entre o somatório de cátions e o somatório de ânions acumulados na planta. Considerando-se que algumas espécies de planta tendem a acumular mais nitrogênio em seus tecidos do que outras, a diferença entre o somatório de cátions e de ânions deverá refletir melhor a influência dos vegetais na reação do solo se a quantidade daquele elemento na planta for também considerada na avaliação. Nesse sentido, destacamse os trabalhos mais recentes de Pierre e colaboradores, por terem utilizado a relação $\mathrm{EB} / \mathrm{N}$. Porém, nesses estudos, as plantas foram supridas com nitrogênio em sua maior parte na forma nítrica, não havendo informações sobre o efeito que a absorção da forma predominantemente amoniacal teria sobre a relação entre $\mathrm{EB} / \mathrm{N}$ e a alteração no $\mathrm{pH}$. 


\section{MATERIAL E MÉTODOS}

O experimento foi conduzido no período de setembro a dezembro de 1993, em casa de vegetação pertencente ao Departamento de Ciência do Solo da Escola Superior de Agricultura "Luiz de Queiroz"/USP, Campus de Piracicaba, localizado a 22 42 '30" de latitude sul e $47^{\circ} 38^{\prime} 60^{\prime \prime}$ de longitude oeste.

\subsection{Solo Selecionado e Amostragem}

Como substrato foi utilizada amostra do horizonte Ap de um Latossolo Roxo distrófico (LRd), Unidade Barão Geraldo, classificado como Typic Haplorthox ${ }^{9}$, coletada no município de Piracicaba, Estado de São Paulo. A amostra foi seca ao ar, passada em peneira de $2 \mathrm{~mm}$ de abertura e homogeneizada. As principais características físicas e químicas desse solo são apresentadas na Tabela 1 .

- Carta pedológica semi-detalhada do estado de são paulo, quadrícula de Piracicaba SF-23-Y-A-IV, INSTITUTO AGRONÔMICO, 1 a edição, 1989. 


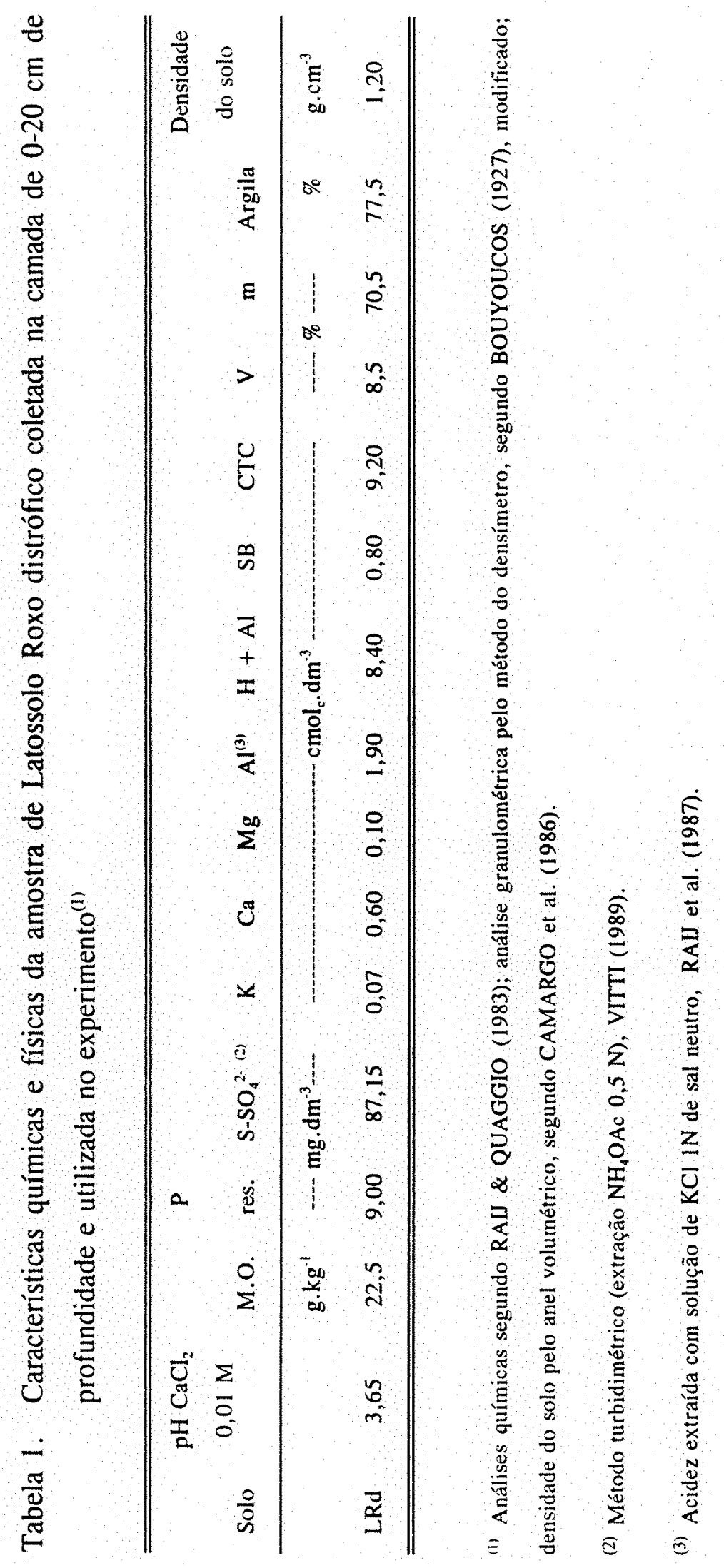




\subsection{Delineamento Experimental}

O delineamento experimental adotado foi inteiramente casualizado, com tratamentos em arranjo fatorial $4 \times 3 \times 3$ com três repetições. O fatorial foi constituído de quatro modos de cultivo (sem cultivo e cultivos com milho, arroz e trigo sarraceno), três fontes de nitrogênio (nitrato de cálcio, NC; nitrato de amônio, NA; e sulfato de amônio, SA) e três doses de nitrogênio $\left(0,200\right.$ e $400 \mathrm{mg} \cdot \mathrm{kg}^{-1}$ de $\left.\mathrm{N}\right)$; embora não contenha nitrogênio, a dose zero foi considerada no fatorial para torná-lo completo, perfazendo 36 tratamentos e 108 parcelas. Foram empregadas sementes de milho (Zea mays L.) hibrido, cv. ICI-8586, com tolerância média à acidez, sementes de arroz (Oryza sativa L.), cv. IAC-165, e sementes de trigo sarraceno (Fagopyrum esculentum Moench); as gramíneas foram fornecidas pelo INSTITUTO AGRONÔMICO DE SÃO PAULO (Campinas), e o trigo sarraceno, pela COOPERATIVA TRITíCOLA MISTA VACARIENSE (RS). As fontes de nitrogênio foram constituídas de reagentes químicos p.a.

\subsection{Instalação e Condução do Experimento}

Antes da sua utilização, a amostra de solo foi tratada com uma mistura de $\mathrm{CaCO}_{3}$ e $\mathrm{MgCO}_{3}$ na proporção de $4: 1$, homogeneizada, umedecida a $60 \%$ da capacidade de retenção de água e incubada em sacos plásticos abertos por 15 dias. A quantidade de corretivo utilizada foi estimada a partir de uma curva de neutralização previamente obtida, e visou elevar o $\mathrm{pH} \mathrm{em} \mathrm{CaCl}_{2}$ do solo a 5,6 , para atingir o equivalente a $76 \%$ da saturação por bases.

Por ocasião do preparo dos vasos, todas as parcelas receberam adição de diversos nutrientes em formas e quantidades especificadas na Tabela 2. O nitrogênio foi aplicado na forma líquida, em formas e quantidades correspondentes a cada tratamento. Após cuidadosa homogeneização, $4 \mathrm{~kg}$ de amostra foram transferidos para vasos de barro internamente tratados com neutrol. Onze sementes de milho, 16 de de arroz e 14 de trigo sarraceno foram plantadas em cada vaso respectivo, às profundidades de $3 \mathrm{~cm}$ para o milho e $1,5 \mathrm{~cm}$ para o arroz e o trigo sarraceno. 
Tabela 2. Adubação básica aplicada às terras utilizadas no experimento

\begin{tabular}{lcccc}
\hline \hline & & & & Dose do \\
Época & Nutriente & Forma & elemento & Estado \\
\hline Preparo & & & $\mathrm{mg} / \mathrm{vaso}$ & \\
dos vasos & $\mathrm{P}$ & $\mathrm{Ca}\left(\mathrm{H}_{2} \mathrm{PO}_{4}\right)_{2} \cdot \mathrm{H}_{2} \mathrm{O}$ & 600 & Sólido \\
& $\mathrm{K}$ & $\mathrm{KCl}$ & 600 & Líquido \\
& $\mathrm{Cu}$ & $\mathrm{CuCl}_{2} \cdot 2 \mathrm{H}_{2} \mathrm{O}$ & 8 & Líquido \\
& $\mathrm{Fe}$ & $\mathrm{Ferro}^{-\mathrm{EDTA}}$ & 40 & Líquido \\
& $\mathrm{Zn}$ & $\mathrm{ZnCl}_{2}$ & 20 & Líquido \\
& $\mathrm{Mn}$ & $\mathrm{MnCl}_{2} \cdot 4 \mathrm{H}_{2} \mathrm{O}$ & 32 & Líquido \\
& $\mathrm{Mo}$ & $\mathrm{Na}_{2} \mathrm{MoO}_{4} \cdot 2 \mathrm{H}_{2} \mathrm{O}$ & 4 & Líquido \\
& $\mathrm{B}$ & $\mathrm{H}_{3} \mathrm{BO}_{3}$ & 4 & Líquido \\
& & & & \\
18 dias após & $\mathrm{Ca}$ & $\left.\mathrm{CH}_{2} \mathrm{PO}_{4}\right)_{2} \cdot \mathrm{H}_{2} \mathrm{O}$ & 200 & Líquido \\
o plantio & $\mathrm{H}$ & $\mathrm{H}_{3} \mathrm{PO}_{3}$ & 4 & Líquido \\
\hline \hline
\end{tabular}

Aos 4 dias após o plantio ocorreu a germinação do milho e do trigo sarraceno, e aos 5 dias, para o arroz. Aos 11 dias foi feito um desbaste, deixando-se 4 plantas de milho, oito de arroz e seis de trigo sarraceno por vaso.

Durante o desenvolvimento das plantas, foram verificados sintomas de deficiência de fósforo, principalmente nas gramíneas, e de boro, na dicotiledônea; para corrigir essas deficiências, esses elementos foram aplicados nas doses, fontes e formas indicadas na Tabela 2.

Aos 24, 32 e 40 dias após o plantio foi efetuada a colheita da parte aérea das plantas de trigo sarraceno, milho e arroz, respectivamente, cortando-se as plantas rente à 
terra. O material verde foi acondicionado em sacos de papel e submetido à secagem em estufa de circulação forçada, com temperatura em torno de $65^{\circ} \mathrm{C}$, até peso constante. Em seguida, foi pesado, passado em moinho tipo Willey e submetido às seguintes determinaçōes:

- Nitrogênio: digestão sulfúrica de $100 \mathrm{mg}$ de material seguida de determinação pelo método semi-micro Kjeldahl (MALAVOLTA et al., 1989).

- Fósforo, cálcio, magnésio, potássio, enxofre e sódio: digestão nitroperclórica de $500 \mathrm{mg}$ de material, seguida de determinação do fósforo pelo método fotocolorimétrico do molibdato-vanadato; do cálcio e magnésio por espectrofotometria de absorção atômica; potássio e sódio por fotometria de chama e do enxofre por turbidimetria do sulfato de bário (MALAVOLTA et al., 1989).

- Cloro: foi utilizado o Método de MOHR, que consta da extração com água seguida de determinação por titulometria do nitrato de prata (MALAVOLTA et al., 1989).

Amostras de terra foram coletadas de cada vaso, secas ao ar, passadas por peneira de $2 \mathrm{~mm}$ de malha, acondicionadas em sacos plásticos e, posteriormente, submetidas às seguintes determinações:

- $\mathrm{pH}$ em $\mathrm{CaCl}_{2}$ : leitura potenciométrica do $\mathrm{pH}$ de suspensão de terra em solução centimolar de $\mathrm{CaCl}_{2}$, na relação $1: 2,5$;

- $\mathrm{pH}$ em água: leitura potenciométrica do pH de suspensão de terra em água na relação $1: 2,5$

- Acidez potencial $(\mathrm{H}+\mathrm{Al})$ : leitura potenciométrica do $\mathrm{pH}$ de suspensão de terra em solução tampão SMP, pH 7,5 (CAMARGO et al., 1986).

- Cálcio, magnésio e potássio trocáveis: extração com solução de acetato de amônio $1 \mathrm{~N}$ ao $\mathrm{pH} 7$ na relação solo: solução de $1: 10$, seguida de leitura em 
espectrofotômetro de absorção atômica, segundo BRICEÑO \& PACHECO (1984).

- Nitrogênio inorgânico: determinado segundo BREMNER (1965); para a extração, $5 \mathrm{~cm}^{3}$ de amostra de solo foram agitados com $50 \mathrm{ml}$ de solução de $\mathrm{KCl} 2 \mathrm{~N}$ por 30 minutos e deixadas em repouso por uma noite. Para a determinação do $\mathrm{N}_{-} \mathrm{NH}_{4}^{+}$, uma alíquota de $10 \mathrm{ml}$ do sobrenadante foi submetida à destilação a vapor na presença de $\mathrm{MgO}$, recolhendo-se $\mathrm{o}$ destilado em solução de $\mathrm{H}_{3} \mathrm{BO}_{3}$ a $2 \%$ contendo mistura de indicadores bromocresol verde e vermelho de metila e titulando-se a amônia com $\mathrm{H}_{2} \mathrm{SO}_{4}$ padronizado. Para a determinação do $\mathrm{N}-\left(\mathrm{NO}_{2}+\mathrm{NO}_{3}\right)$, a destilação foi repetida com a mesma amostra, porém, adicionando-se liga de Devarda para reduzir o $\mathrm{NO}_{2}$ e o $\mathrm{NO}_{3}$ a $\mathrm{NH}_{4}^{+}$. A amônia coletada foi igualmente titulada com $\mathrm{H}_{2} \mathrm{SO}_{4}$ padronizado.

\subsection{Parâmetros Avaliados}

- Valores de $\mathrm{pH}$ em água e $\mathrm{pH}$ em $\mathrm{CaCl}_{2}$ das terras.

- Acidez potencial $(\mathrm{H}+\mathrm{Al})$ das terras.

- Soma de bases (SB), obtida pela soma dos teores de cátions trocáveis Ca, $\mathrm{Mg}$ e $\mathrm{K}$ das amostras de solo, expressos em cmol. $\mathrm{dm}^{-3}$.

- Teor de nitrogênio inorgânico $\left[\mathrm{N}-\mathrm{NH}_{4}\right.$ e $\left.\mathrm{N}-\left(\mathrm{NO}_{2}+\mathrm{NO}_{3}\right)\right]$ nas terras, em $\mathrm{cmol.dm}$.

- Matéria seca da parte aérea das plantas, em g.vaso-1.

- Excesso de bases (EB): soma dos cátions inorgânicos $\mathrm{Ca}^{2+}, \mathrm{Mg}^{2+}, \mathrm{K}^{+} \mathrm{e}$ $\mathrm{Na}^{+}$menos os ânions inorgânicos $\mathrm{H}_{2} \mathrm{PO}_{4}, \mathrm{SO}_{4}{ }^{2} \mathrm{e} \mathrm{Cl}$ em $\mathrm{cmol}_{\mathrm{c}} \cdot \mathrm{kg}^{-1}$ de $\mathrm{MS}$.

- Teor de $\mathrm{N}$ total na parte aérea das plantas em $\mathrm{cmol} . \mathrm{kg}^{-1}$ de $\mathrm{MS}$.

- Relação EB/N total acumulada na parte aérea das plantas. 


\section{RESULTADOS E DISCUSSÃO}

4.1. Influência dos Fertilizantes Nitrogenados e da Cultivação sobre as Propriedades Químicas do Solo

A Tabela 3 revela que todas as variáveis de solo foram influenciadas significativamente pelos três fatores estudados (cultura, fonte de $\mathrm{N}$ e dose de $\mathrm{N}$ ), bem como pelas interações duplas e a tripla.

\subsection{1. $\mathrm{pH}$ em água e pH em $\mathrm{CaCl}_{2}$}

Em quase todas as combinações de doses e culturas, o NC foi o fertilizante que conferiu ao solo os maiores valores de $\mathrm{pH}$ em água, vindo em seguida o $\mathrm{NA} e$, abaixo deste, o SA (Tabela 4). A tendência dos fertilizantes nítricos em elevar o $\mathrm{pH}$ do solo, e a dos amoniacais em baixá-lo, tem sido observada com freqüência (RILEY \& BARBER, 1971; RÖMHELD, 1986; GIJSMAN, 1990b e 1990c). Em solo com pH 6,2, RÖMHELD (1986) encontrou diferenças superiores a três unidades entre o $\mathrm{pH}$ da rizosfera de plantas de trigo tratadas com nitrato de cálcio $(\mathrm{pH} 7,5)$ e o de plantas tratadas com sulfato de amônio (pH 4,5).

Quando os fertilizantes foram aplicados na dose maior no vaso não cultivado, o NA não superou o SA. Essa discrepância provavelmente se deva a diferenças nas taxas de nitrificação.

Os efeitos dos tratamentos sobre os valores de $\mathrm{pH} \mathrm{em} \mathrm{CaCl}_{2}$ (Tabela 5) foram muito semelhantes aos descritos para os índices obtidos em água. A maior diferença entre fontes ocorreu quando se aplicaram $400 \mathrm{mg} \cdot \mathrm{kg}^{-1}$ de $\mathrm{N}$ à terra cultivada com 


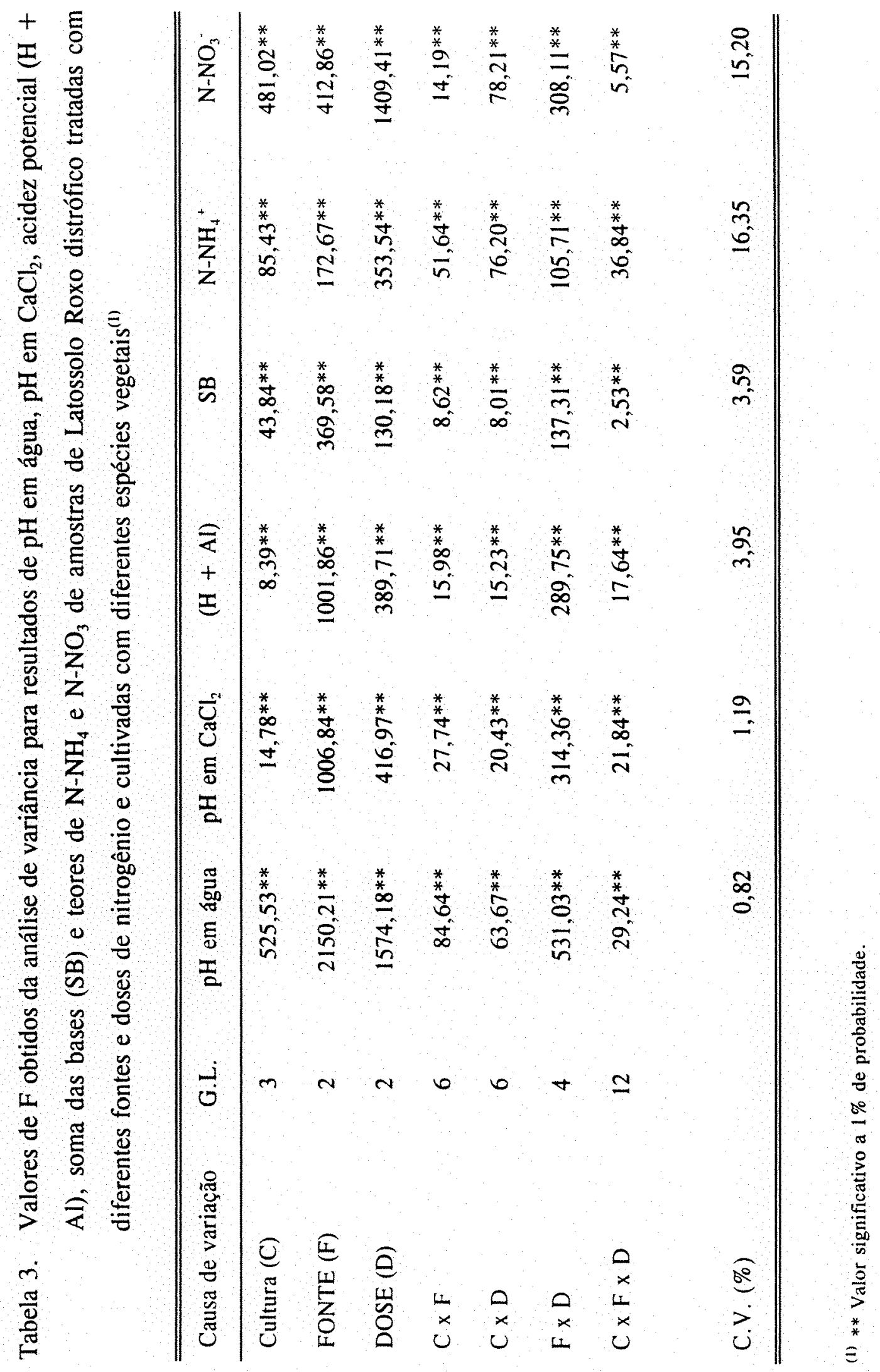


Tabela 4. Valores de pH em água de amostras de Latossolo Roxo distrófico tratadas com diferentes fontes e doses de nitrogênio e cultivadas com diferentes espécies vegetais (médias de três repetições) $)^{(1)}$

\begin{tabular}{|c|c|c|c|c|}
\hline \multirow[b]{2}{*}{ Cultura } & \multirow[b]{2}{*}{ Fonte $^{(2)}$} & \multicolumn{3}{|c|}{ Dose de $\mathrm{N}$ (mg. $\mathrm{kg}^{-1}$ solo) } \\
\hline & & 0 & 200 & 400 \\
\hline \multirow[t]{3}{*}{ Milho } & NC & 5,84 & $6,00 \mathrm{a}$ & $5,95 \mathrm{a}$ \\
\hline & NA & 5,84 & $5,64 \mathrm{~b}$ & $5,34 \mathrm{~b}$ \\
\hline & SA & 5,84 & $5,10 \mathrm{c}$ & $4,72 \mathrm{c}$ \\
\hline \multirow[t]{3}{*}{ Arroz } & NC & 5,86 & $6,20 \mathrm{a}$ & $6,30 a$ \\
\hline & $\mathrm{NA}$ & 5,86 & $5,62 \mathrm{~b}$ & $5,26 \mathrm{~b}$ \\
\hline & SA & 5,86 & $4,95 \mathrm{c}$ & $4,55 \mathrm{c}$ \\
\hline Trigo & $\mathrm{NC}$ & 5,83 & $5,73 \mathrm{a}$ & $5,62 \mathrm{a}$ \\
\hline \multirow[t]{2}{*}{ sarraceno } & $\mathrm{NA}$ & 5,83 & $5,46 \mathrm{~b}$ & $5,10 \mathrm{~b}$ \\
\hline & $\mathrm{SA}$ & 5,83 & $4,98 \mathrm{c}$ & $4,63 \mathrm{c}$ \\
\hline \multirow[t]{3}{*}{ Sem planta } & $\mathrm{NC}$ & 5,61 & $5,42 \mathrm{a}$ & $5,35 \mathrm{a}$ \\
\hline & NA & 5,61 & $4,79 \mathrm{~b}$ & $4,81 \mathrm{~b}$ \\
\hline & SA & 5,61 & $4,51 \mathrm{c}$ & $4,89 \mathrm{~b}$ \\
\hline
\end{tabular}

(1) Dentro de cada cultura e de cada dose, médias acompanhadas da mesma letra não diferem entre si pelo teste de Tukey ao nível de $5 \%$.

${ }^{\text {(2) }} \mathrm{NC}$, nitrato de cálcio; NA, nitrato de amônio; SA, sulfato de amônio. 
Tabela 5. Valores de $\mathrm{pH}$ em $\mathrm{CaCl}_{2}$ de amostras de Latossolo Roxo distrófico tratadas com diferentes fontes e doses de nitrogênio e cultivadas com diferentes espécies vegetais (médias de três repetições) ${ }^{(1)}$

\begin{tabular}{lcccc}
\hline & & \multicolumn{3}{c}{ Dose de N (mg.kg $\left.{ }^{-1}\right)$} \\
\cline { 3 - 5 } Cultura & Fonte $^{(2)}$ & 0 & 200 & 400 \\
\hline Milho & NC & 5,25 & $5,40 \mathrm{a}$ & $5,55 \mathrm{a}$ \\
& NA & 5,25 & $5,10 \mathrm{~b}$ & $4,93 \mathrm{~b}$ \\
& SA & 5,25 & $4,60 \mathrm{c}$ & $4,25 \mathrm{c}$ \\
& & & & \\
Arroz & NC & 5,28 & $5,51 \mathrm{a}$ & $5,96 \mathrm{a}$ \\
& NA & 5,28 & $5,13 \mathrm{~b}$ & $4,85 \mathrm{~b}$ \\
& SA & 5,28 & $4,51 \mathrm{c}$ & $4,27 \mathrm{c}$ \\
Trigo & & & & \\
sarraceno & NC & 5,36 & $5,28 \mathrm{a}$ & $5,43 \mathrm{a}$ \\
& NA & 5,36 & $5,11 \mathrm{~b}$ & $4,83 \mathrm{~b}$ \\
& SA & 5,36 & $4,72 \mathrm{c}$ & $4,45 \mathrm{c}$ \\
& & & & \\
Sem planta & NC & 5,35 & $5,30 \mathrm{a}$ & $5,25 \mathrm{a}$ \\
& NA & 5,35 & $4,70 \mathrm{~b}$ & $4,77 \mathrm{~b}$ \\
& SA & 5,35 & $4,35 \mathrm{c}$ & $4,73 \mathrm{~b}$ \\
\hline \hline
\end{tabular}

(1) Dentro de cada cultura e de cada dose, médias acompanhadas da mesma letra não diferem entre si pelo teste de Tukey ao nível de $5 \%$.

(2) NC, nitrato de cálcio; NA, nitrato de amônio; SA, sulfato de amônio. 
arroz, sendo que foi praticamente a mesma (cerca de 1,7 ) tanto para o $\mathrm{pH}$ em água quanto em $\mathrm{CaCl}_{2}$; o pH em água, por exemplo, foi 6,30 quando se aplicou o $\mathrm{NC}$ e 4,55 quando o SA foi empregado.

As equações polinomiais referentes ao efeito das doses de nitrogênio sobre os valores de $\mathrm{pH}$ mostraram coeficientes de determinação sempre elevados e altamente significativos (Tabela 6) em todas as culturas e fontes de N. Na ausência de plantas, o NC causou pequena redução no pH, provavelmente devido ao seu efeito salino; o NA e o SA, por sua vez, reduziram mais acentuadamente o $\mathrm{pH}$, principalmente o SA. Na presença dos cultivos de milho e arroz, o $\mathrm{NC}$ causou aumentos do $\mathrm{pH}$ em água e em $\mathrm{CaCl}_{2}$ com o aumento da dose (Figuras 1 e 2), fato que certamente se deve à absorção do ânion $\mathrm{NO}_{3}$, acompanhada da eliminação pela raiz de ânions básicos $\left(\mathrm{OH}^{-}\right.$e $\left.\mathrm{HCO}_{3}{ }^{-}\right)$para preservar a eletroneutralidade na planta, conforme também encontraram PIERRE (1928a e 1928b), RÖMHELD (1986), BEKELE et al. (1983) e WALLACE (1994).

Quando se aplicaram as fontes contendo nitrogênio amoniacal (NA e SA), ao contrário, os valores de $\mathrm{pH}$ em água e em $\mathrm{CaCl}_{2}$ decresceram com o aumento da dose de $\mathrm{N}$, revelando ter ocorrido, segundo RAIJ et al. (1988) e ARNOLD \& DIEST (1991), a absorção de um cátion, $\mathrm{o} \mathrm{NH}_{4}{ }^{+}$, acompanhada da extrusão de $\mathrm{H}^{+}$pela raiz para manter $\mathrm{o}$ equilibrio de cargas na planta.

O SA causou maior decréscimo do $\mathrm{pH}$ do que o $\mathrm{NA}$ em todas as amostras, cultivadas ou não; esse efeito, já esperado, concorda com os resultados apresentados por outros autores (WOLCOTT et al., 1965 e STUMPE \& VLEK, 1991). Ao contrário das demais culturas, o trigo sarraceno adubado com $\mathrm{NC}$ resultou em decréscimo significativo dos valores de $\mathrm{pH}$ em água com o aumento da dose de $\mathrm{N}$, provavelmente por se tratar de uma planta dicotiledônea e, portanto, com características de acidificação em geral mais fortes que as monocotiledôneas (RAIJ \& DIEST, 1979). O pH em $\mathrm{CaCl}_{2}$, contudo, diminuiu inicialmente para depois aumentar com a dose maior, provavelmente devido à redução da interferência de sais na leitura do $\mathrm{pH}$ quando se empregam soluções salinas ao 
Tabela 6 - Equações polinomiais estimadas, dos atributos químicos do solo (y) em função das doses de nitrogênio $(x)$, para diferentes fontes de nitrogênio e culturas

\begin{tabular}{|c|c|c|c|c|}
\hline $\begin{array}{l}\text { Atributo } \\
\text { (y) }\end{array}$ & Cultura & Fonte ${ }^{\prime \prime}$ & $\begin{array}{l}\text { Equaçoes } \\
\text { Polinomiais }\end{array}$ & $\begin{array}{l}\text { Coeficiente de } \\
\text { determinação }\left(r^{2}\right)^{2 y}\end{array}$ \\
\hline \multirow[t]{12}{*}{ pH em água } & Milho & NC & $y=5,84+0,0014 x-0,00000275 x^{2}$ & $0,99 * *$ \\
\hline & & NA & $y=5,86-0,0012 x$ & $0,98 * *$ \\
\hline & & SA & $y=5,84-0,0046 x+0,00000458 x^{2}$ & $0,99 * *$ \\
\hline & Arroz & NC & $y=5,86+0,0023 x-0,000003 x^{2}$ & $0,99 * *$ \\
\hline & & NA & $y=5,88-0,0015 x$ & $0,99 * *$ \\
\hline & & SA & $y=5,86-0,0059 x+0,0000065 x^{2}$ & $0,99 * *$ \\
\hline & Trigo & NC & $y=5.83-0.000525 x$ & $0,99 * *$ \\
\hline & sarraceno & NA & $y=5,83-0,00182 x$ & $0,99 * *$ \\
\hline & & SA & $y=5,83-0,0055 x+0,00000638 x^{2}$ & $0,99 * *$ \\
\hline & Sem planta & NC & $y=5,61-0,0013 x+0,00000158 x^{2}$ & $0,99 *$ \\
\hline & & NA & $y=5,61-0,0062 x+0,0000105 x^{2}$ & $0,99 * *$ \\
\hline & & SA & $y=5,61-0,0091 x+0,00001838 x^{2}$ & $0,99 * *$ \\
\hline \multirow[t]{12}{*}{$\mathrm{pH} \mathrm{em} \mathrm{CaCl}_{2}$} & Milho & NC & $y=5,25+0,000742 x$ & $0,99 * *$ \\
\hline & & NA & $y=5.25-0,000808 x$ & $0,99 * *$ \\
\hline & & SA & $y=5,25-0,0040 x+0,00000275 x^{2}$ & $0,99 * *$ \\
\hline & Arroz & NC & $y=5,28+0,00060 x+0,00000375 x^{2}$ & $0,99 * *$ \\
\hline & & NA & $y=5,30-0,0011 x$ & $0,97 * *$ \\
\hline & & SA & $y=5,28-0,0051 x+0,0000065 x^{2}$ & $0,99 * *$ \\
\hline & Trigo & NC & $y=5,36-0,0010 x+0,00000296 x^{2}$ & $0,99 * *$ \\
\hline & sarraceno & NA & $y=5,36-0,0013 x$ & $0,99 * *$ \\
\hline & & $S A$ & $y=5,36-0,00416 x+0,00000471 x^{2}$ & $0,99 * *$ \\
\hline & Sem planta & $\mathrm{NC}$ & $y=5,35-0,00025 x$ & $0,99 *$ \\
\hline & & NA & $y=5,35-0,00502 x+0,00000892 x^{2}$ & $0,99 * *$ \\
\hline & & SA & $y=5,35-0,0084 x+0,00001725 x^{2}$ & $0,99 * *$ \\
\hline
\end{tabular}


- continuação -

\begin{tabular}{|c|c|c|c|c|}
\hline $\begin{array}{l}\text { Atributo } \\
\text { (y) }\end{array}$ & Cultura & Fonte $^{(1)}$ & $\begin{array}{l}\text { Equações } \\
\text { Polinomiais }\end{array}$ & $\begin{array}{c}\text { Coeficiente de } \\
\text { determinação }\left(r^{2}\right)^{(2)}\end{array}$ \\
\hline \multirow[t]{12}{*}{ Acidez potencial } & Milho & NC & $y=3,09-0,0016 x$ & $0,99 * *$ \\
\hline & & NA & $y=3,12+0,0021 x$ & $0,97 * *$ \\
\hline & & $S A$ & $y=3,10+0,0063 x$ & $0,99 * *$ \\
\hline & Arroz & NC & $y=3,12-0,0024 x$ & $0,98 * *$ \\
\hline & & NA & $y=3,09+0,0017 x$ & $0,99 * *$ \\
\hline & & $S A$ & $y=3,14+0,0064 x$ & $0,99 * *$ \\
\hline & Trigo & NC & $y=2,95+0,0017 x-0,00000525 x^{2}$ & $0,99 *$ \\
\hline & sarraceno & NA & $y=2,99+0,0016 x$ & $0,95 * *$ \\
\hline & & SA & $y=3,00+0,0057 x$ & $0,99 * *$ \\
\hline & Sem planta & NC & não significativo & \\
\hline & & NA & $y=2,95+0,0086 x-0,00001417 x^{2}$ & $0,99 * *$ \\
\hline & & $S A$ & $y=2,95+0,0202 x-0,00004083 x^{2}$ & $0,99 * *$ \\
\hline \multirow[t]{12}{*}{ Soma de bases } & Milho & NC & $y=7,39-0,00054 x+0,00001913 x^{2}$ & $0,99 * *$ \\
\hline & & NA & nào significativo & \\
\hline & & $\mathrm{SA}$ & $y=7,39-0,0036 x+0,00001054 x^{2}$ & $0,99 *$ \\
\hline & Arroz & NC & $y=7.68-0.0042 x+0.00003458 x^{2}$ & $0.99 * *$ \\
\hline & & NA & $y=7,68-0,00999 x+0,00002196 x^{2}$ & $0,99 * *$ \\
\hline & & $S A$ & $y=7,68-0,0159 x+0,00003683 x^{2}$ & $0,99 * *$ \\
\hline & Trigo & $\mathrm{NC}$ & $y=7,54-0,0021 x+0,00001988 x^{2}$ & $0,99 * *$ \\
\hline & sarraceno & NA & $y=7,54-0,0052 x+0,00001054 x^{2}$ & $0,99 *$ \\
\hline & & $\mathrm{SA}$ & $y=7,54-0,0056 x+0,00001387 x^{2}$ & $0,99 * *$ \\
\hline & Sem planta & NC & $y=8,11+0.0071 x$ & $0,99 * *$ \\
\hline & & NA & não significativo & \\
\hline & & SA & $y=8,18-0,0057 x+0,00001037 x^{2}$ & $0,99 *$ \\
\hline
\end{tabular}


continuação -

\begin{tabular}{|c|c|c|c|c|}
\hline $\begin{array}{l}\text { Atributo } \\
\text { (y) }\end{array}$ & Cultura & Fonte $^{(1)}$ & $\begin{array}{l}\text { Equações } \\
\text { Polinomiais }\end{array}$ & $\begin{array}{l}\text { Coeficiente de } \\
\text { determinaçáo }\left(r^{2}\right)^{(2)}\end{array}$ \\
\hline \multirow[t]{12}{*}{$\mathrm{NH}_{4}^{+}$} & Milho & NC & nào significativo & \\
\hline & & NA & $y=0.208+0,00044 x$ & $0,90 * *$ \\
\hline & & $S A$ & $y=0,204+0,00066 x$ & $0,92 * *$ \\
\hline & Arroz & $\mathrm{NC}$ & nào significativo & \\
\hline & & NA & $y=0,267+0,000278 x$ & $0,88 *$ \\
\hline & & $\mathrm{SA}$ & $y=0.237+0.00036 x$ & $0.84 * *$ \\
\hline & Trigo & NC & não significativo & \\
\hline & sarraceno & NA & $y=0,251-0,00055 x+0,00000245 x^{2}$ & $0,99 *$ \\
\hline & & $\mathrm{SA}$ & $y=0,251-0,00097 x+0,00000689 x^{2}$ & $0,99 * *$ \\
\hline & Sem planta & NC & não significativo & \\
\hline & & NA & $y=0,226-0,0018 x+0,00000872 x^{2}$ & $0,99 * *$ \\
\hline & & SA & $y=0,226-0,0018 x+0,00001544 x^{2}$ & $0,99 * *$ \\
\hline \multirow[t]{12}{*}{$\mathrm{NO}_{3}$} & Milho & NC & $y=0,059-0,0027 x+0.00001542 x^{2}$ & $0,99 * *$ \\
\hline & & NA & $y=0,059-0,00081 x+0,00000555 x^{2}$ & $0,99 * *$ \\
\hline & & $S A$ & nào significativo & \\
\hline & Arroz & NC & $y=0,066-0,00397 x+0,00001938 x^{2}$ & $0,99 * *$ \\
\hline & & NA & $y=0,066-0,0018 x+0,00000932 x^{2}$ & $0,99 * *$ \\
\hline & & $S A$ & $y=0,066-0,00062 x+0,00000295 x^{2}$ & $0,99 *$ \\
\hline & Trigo & NC & $y=0,069-0,00196 x+0,00001576 x^{2}$ & $0,99 * *$ \\
\hline & sarraceno & $\mathrm{NA}$ & $y=0,069-0,000929 x+0,00000761 x^{2}$ & $0,99 * *$ \\
\hline & & $\mathrm{SA}$ & $y=0.043+0.0010 x$ & $0.95 * *$ \\
\hline & Sem planta & $\mathrm{NC}$ & $y=0,226+0,00599 x$ & $0,99 * *$ \\
\hline & & NA & $y=0,236+0,00593 x-0,00000488 x^{2}$ & $0,99 * *$ \\
\hline & & $S A$ & $y=0,236+0,0062 x-0.00001325 x^{2}$ & $0.99 *$ \\
\hline
\end{tabular}

(1) NC, nitrato de cálcio; NA, nitrato de amônio; SA, sultato de amônio.

(2) * e $* *$, valores significativos a $5 \%$ e $1 \%$ de probabilidade, respectivamente. 
MILHO

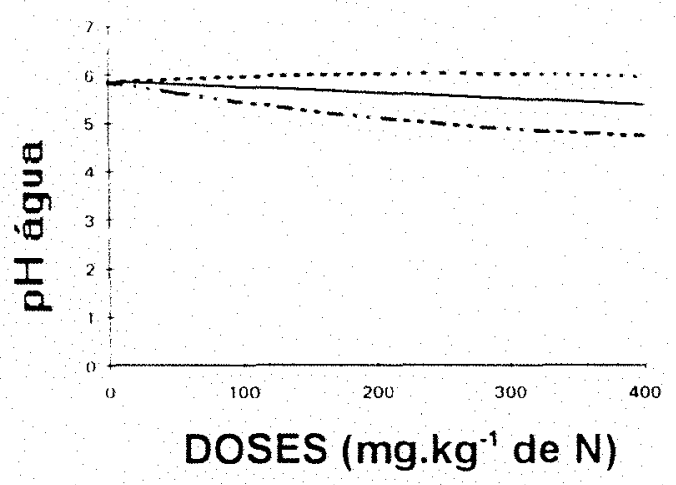

TRIGO SARRACENO

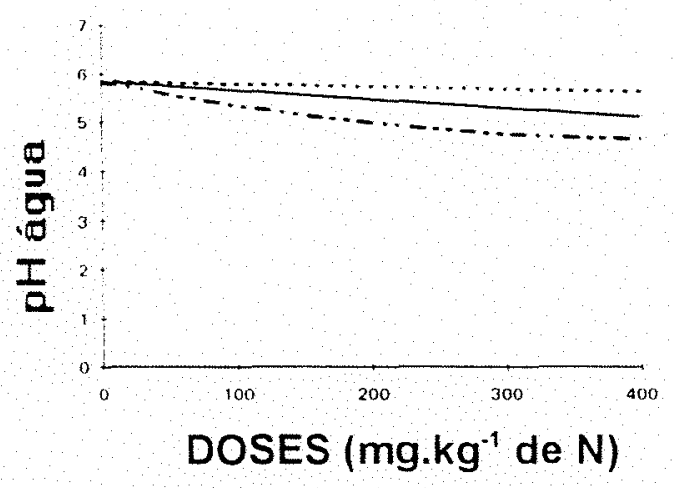

ARROZ

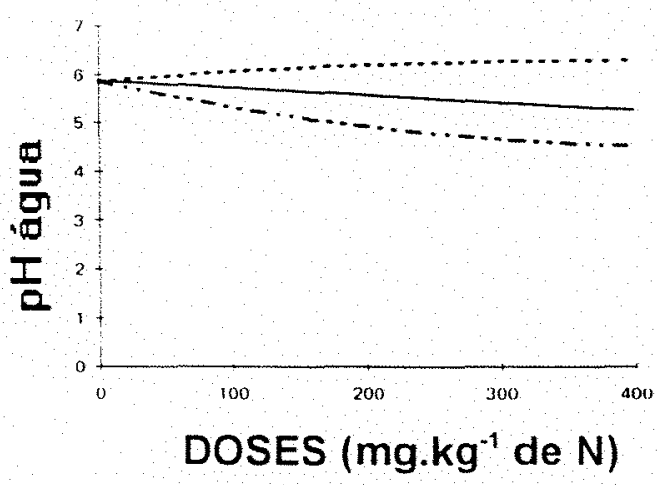

SEM CULTURA

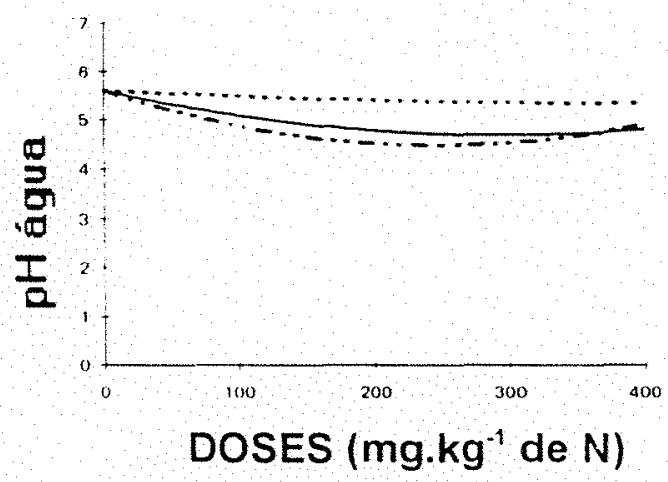

Figura 1. Valores de pH em água de amostras de um Latossolo Roxo distrófico tratadas com diferentes doses de nitrogênio nas formas de nitrato de cálcio (NC), nitrato de amônio (NA) ou sulfato de amônio (SA), e submetidas a diferentes cultivos 
MILHO

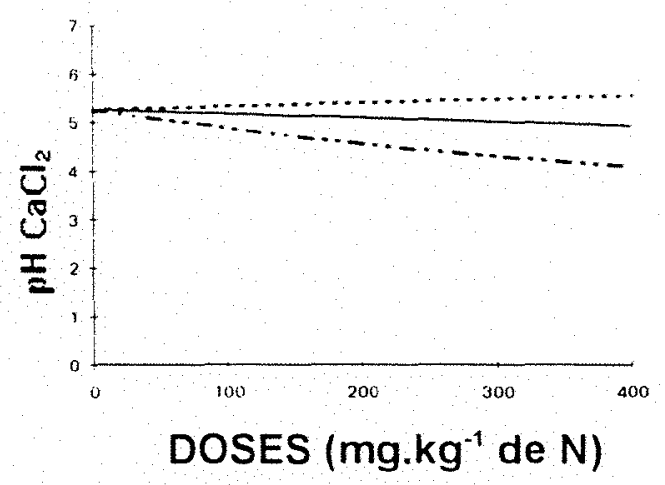

TRIGO SARRACENO

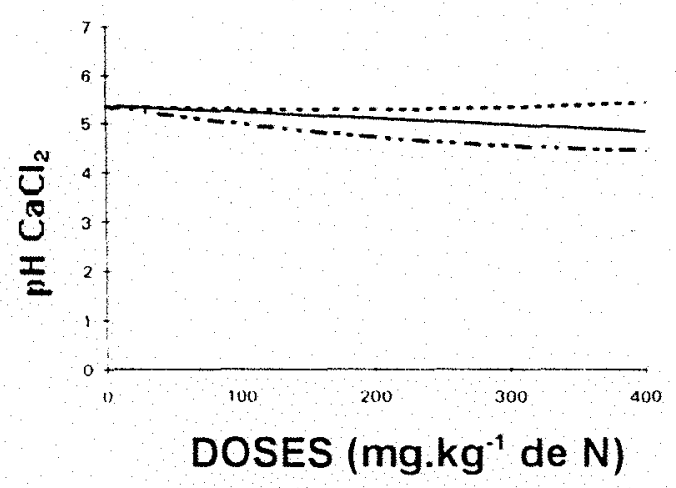

ARROZ

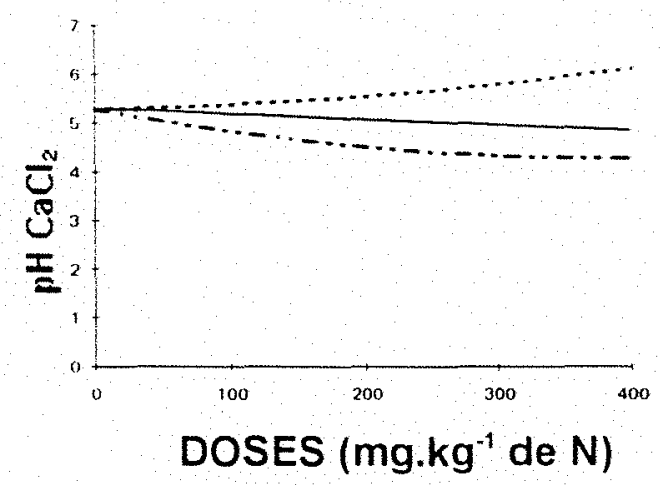

SEM CULTURA

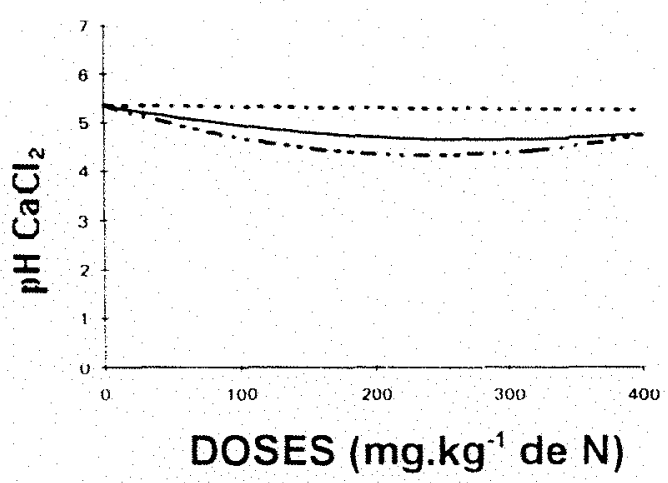

Figura 2. Valores de $\mathrm{pH} \mathrm{em} \mathrm{CaCl}_{2}$ de amostras de um Latossolo Roxo distrófico tratadas com diferentes doses de nitrogênio nas formas de nitrato de cálcio (NC), nitrato de amônio (NA) ou sulfato de amônio (SA), e submetidas a diferentes cultivos 
invés de água (PIERRE et al., 1970 e PETERSEN \& BöTTGER, 1991). Fato similar também ocorreu nas terras não cultivadas, cujos valores de $\mathrm{pH}$ em água e em $\mathrm{CaCl}_{2}$ diminuiram com o aumento da dose de NC.

Quanto ao efeito da cultivação nos valores de $\mathrm{pH}$ em água, verificou-se que sem aplicação de nitrogênio esses índices mostraram-se mais elevados nas terras cultivadas do que nas não cultivadas (Tabela 7). Esse efeito pode ser atribuído ao fato de as plantas absorverem maiores quantidades de ânions do que de cátions, o que leva ao aumento do pH do solo (RILEY \& BARBER, 1969; RAIJ \& DIEST, 1979; NYE, 1981 e BEKELE et al., 1983).

Quando o NC foi aplicado, independentemente da dose, o $\mathrm{pH}$ em água foi mais alto na terra com arroz, decrescendo sucessivamente nas amostras com milho, com trigo sarraceno e sem cultivação. Para a aplicação de NA, também independentemente da dose, os valores mais altos de $\mathrm{pH}$ em água ocorreram nas amostras cultivadas com milho e arroz, decrescendo sucessivamente nas terras com trigo sarraceno e sem plantas. Esses resultados mostram, de fato, que em geral as gramíneas adubadas com nitrato absorvem com maior intensidade os ânions, principalmente nitrato, do que os cátions, o que tende a elevar o pH do solo; por outro lado, as dicotiledôneas atuam de modo inverso (BEKELE et al., 1983). Nas amostras adubadas com SA, os resultados divergiram com a dose empregada: para a aplicação de $200 \mathrm{mg} \cdot \mathrm{kg}^{-1}$ de $\mathrm{N}$, os valores de $\mathrm{pH}$ em água mais elevados ocorreram nas amostras cultivadas, e o mais baixo, na terra não cultivada; quando se aplicou a dose maior de $400 \mathrm{mg} \cdot \mathrm{kg}^{-1}$ de $\mathrm{N}$, ao contrário, o maior índice foi detectado na terra não plantada, e os menores, nas cultivadas.

É possível que essas divergências se devam ao efeito da nitrificação. Conforme será observado no ítem "nitrogênio amoniacal", quando a dose $200 \mathrm{mg} \cdot \mathrm{kg}^{-1}$ de $\mathrm{N}$ foi aplicada na amostra não cultivada, praticamente todo $0 \mathrm{~N}$ foi nitrificado (Tabela 13), gerando forte acidez no meio; a mesma dose em terra cultivada, contudo, teria exercido 
Tabela 7. Efeito da cultivação nos valores de pH em água, de amostras de Latossolo Roxo distrófico tratadas com diferentes fontes e doses de nitrogênic ${ }^{(1)}$

\begin{tabular}{|c|c|c|c|c|}
\hline \multirow[b]{2}{*}{ Dose } & \multicolumn{4}{|c|}{ Culturas } \\
\hline & Milho & Arroz & Trigo sarraceno & Sem planta \\
\hline \multicolumn{5}{|c|}{$\left(\mathrm{mg} \cdot \mathrm{kg}^{-1}\right)$} \\
\hline 0 & $5,84 \mathrm{~A}$ & $5,86 \mathrm{~A}$ & $5,83 \mathrm{~A}$ & $5,61 \mathrm{~B}$ \\
\hline & \multicolumn{4}{|c|}{ Nitrato de cálcio } \\
\hline 200 & $6,00 \mathrm{~B}$ & $6,20 \mathrm{~A}$ & $5,73 \mathrm{C}$ & $5,42 \mathrm{D}$ \\
\hline \multirow[t]{2}{*}{400} & $5,95 \mathrm{~B}$ & $6,30 \mathrm{~A}$ & $5,62 \mathrm{C}$ & $5,35 \mathrm{D}$ \\
\hline & \multicolumn{4}{|c|}{ Nitrato de amônio } \\
\hline 200 & $5,64 \mathrm{~A}$ & $5,62 \mathrm{~A}$ & $5,46 \mathrm{~B}$ & $4,79 \mathrm{C}$ \\
\hline \multirow[t]{2}{*}{400} & $5,34 \mathrm{~A}$ & $5,26 \mathrm{~A}$ & $5,10 \mathrm{~B}$ & $4,81 \mathrm{C}$ \\
\hline & \multicolumn{4}{|c|}{ Sulfato de amônio } \\
\hline 200 & $5,10 \mathrm{~A}$ & $4,95 \mathrm{~B}$ & $4,98 \mathrm{~B}$ & $4,51 \mathrm{C}$ \\
\hline 400 & $4,72 \mathrm{~B}$ & $4,55 \mathrm{C}$ & $4,63 \mathrm{C}$ & $4,89 \mathrm{~A}$ \\
\hline
\end{tabular}

(1) Dentro de cada fonte e de cada dose, médias acompanhadas da mesma letra não diferem entre si pelo teste de Tukey ao nível de $5 \%$ de probabilidade. 
menor efeito acidificante devido à absorção de parte do $\mathrm{NH}_{4}{ }^{+}$pelas plantas. Quando se aplicaram $400 \mathrm{mg} \cdot \mathrm{kg}^{-1}$ de $\mathrm{N}$, contudo, parte significativa do $\mathrm{N}$ amoniacal não foi convertida a nitrato na ausência de plantas, possivelmente devido à inibição das bactérias nitrificadoras pela elevada concentração de $\mathrm{NH}_{4}{ }^{+}$no meio; na presença de plantas, entretanto, a absorção do $\mathrm{NH}_{4}{ }^{+}$teria reduzido a concentração desse íon no meio e facilitado a atuação das bactérias nitrificadoras.

Quanto ao $\mathrm{pH}$ em $\mathrm{CaCl}_{2}$, observou-se que a cultivação exerceu praticamente os mesmos efeitos observados para o pH em água (Tabela 8). Nas terras tratadas com NC e NA os índices tenderam a ser mais altos na presença de plantas do que na ausência destas. Com o emprego do SA na dose $200 \mathrm{mg}^{\mathrm{kg}} \mathrm{kg}^{-1}$ de $\mathrm{N}, \mathrm{o} \mathrm{pH}$ em $\mathrm{CaCl}_{2}$ foi menor na terra não cultivada do que nas amostras cultivadas, o inverso ocorrendo para a aplicação de $400 \mathrm{mg} \cdot \mathrm{kg}^{-1}$ de $\mathrm{N}$; conforme comentado no parágrafo anterior, o motivo desse comportamento pode estar associado a diferenças nas taxas de nitrificação do amônio aplicado em cada dose.

\subsubsection{Acidez Potencial $(\mathbf{H}+\mathbf{A l})$}

Como o $\mathrm{pH}$ e a acidez potencial são características inversamente correlacionadas entre si, as amostras tratadas com NC foram as que apresentaram os menores valores de acidez potencial, enquanto as adubadas com SA mostraram os valores mais altos, independentemente da dose aplicada e da presença ou não de planta (Tabela 9).

Também houve coerência com o pH pelo fato de a maior diferença entre fontes ter ocorrido quando se aplicaram $400 \mathrm{mg} \cdot \mathrm{kg}^{-1}$ de $\mathrm{N}$ à terra cultivada com arroz: o teor de $\mathrm{H}+\mathrm{Al}$ passou dos $2,11 \mathrm{cmol}_{\mathrm{c}} \cdot \mathrm{dm}^{-3}$ encontrados na terra tratada com $\mathrm{NC}$, para os 5,66 $\mathrm{cmol}_{\mathrm{c}} \cdot \mathrm{dm}^{-3}$ na amostra que recebeu SA.

O efeito das doses de $\mathrm{N}$, avaliado através das regressões polinomiais, foi significativo para todas as fontes e culturas exceto para o $\mathrm{NC}$ aplicado em amostra não 
Tabela 8. Efeito da cultivação nos valores de $\mathrm{pH}$ em $\mathrm{CaCl}_{2}$ de amostras de Latossolo Roxo distrófico, tratadas com diferentes fontes e doses de nitrogênio ${ }^{(1)}$

\begin{tabular}{|c|c|c|c|c|}
\hline \multirow[b]{2}{*}{ Dose } & \multicolumn{4}{|c|}{ Culturas } \\
\hline & Milho & Arroz & Trigo sarraceno & Sem planta \\
\hline \multicolumn{5}{|c|}{$\left(\mathrm{mg} \cdot \mathrm{kg}^{-1}\right)$} \\
\hline 0 & $5,25 \mathrm{~A}$ & $5,28 \mathrm{~A}$ & $5,36 \mathrm{~A}$ & $5,35 \mathrm{~A}$ \\
\hline & \multicolumn{4}{|c|}{ Nitrato de cálcio } \\
\hline 200 & $5,40 \mathrm{AB}$ & $5,51 \mathrm{~A}$ & $5,28 \mathrm{~B}$ & $5,30 \mathrm{~B}$ \\
\hline \multirow[t]{2}{*}{400} & $5,55 \mathrm{~B}$ & $5,96 \mathrm{~A}$ & $5,43 \mathrm{~B}$ & $5,25 \mathrm{C}$ \\
\hline & \multicolumn{4}{|c|}{ Nitrato de amônio } \\
\hline 200 & $5,10 \mathrm{~A}$ & $5,13 \mathrm{~A}$ & $5,11 \mathrm{~A}$ & $4,70 \mathrm{~B}$ \\
\hline \multirow[t]{2}{*}{400} & $4,93 \mathrm{~A}$ & $4,85 \mathrm{AB}$ & $4,83 \mathrm{AB}$ & $4,77 \mathrm{~B}$ \\
\hline & \multicolumn{4}{|c|}{ Sulfato de amônio } \\
\hline 200 & $4,60 \mathrm{AB}$ & $4,51 \mathrm{~B}$ & $4,72 \mathrm{~A}$ & $4,35 \mathrm{C}$ \\
\hline 400 & $4,25 \mathrm{C}$ & $4,27 \mathrm{C}$ & $4,45 \mathrm{~B}$ & $4,73 \mathrm{~A}$ \\
\hline
\end{tabular}

(1) Dentro de cada fonte e de cada dose, médias acompanhadas da mesma letra não diferem entre si pelo teste de Tukey ao nível de $5 \%$ de probabilidade. 
Tabela 9. Acidez potencial de amostras de Latossolo Roxo distrófico tratadas com diferentes fontes e doses de nitrogênio e cultivadas com diferentes espécies vegetais (médias de três repetiçōes) $)^{(1)}$

\begin{tabular}{|c|c|c|c|c|}
\hline \multirow[b]{2}{*}{ Cultura } & \multirow[b]{2}{*}{ Fonte $^{(2)}$} & \multicolumn{3}{|c|}{ Dose de $\mathrm{N}\left(\mathrm{mg} \cdot \mathrm{kg}^{-1}\right)$} \\
\hline & & 0 & 200 & 400 \\
\hline & & & $\mathrm{mol}_{\mathrm{c}} \cdot \mathrm{dm}$ & \\
\hline \multirow[t]{3}{*}{ Milho } & NC & 3,08 & $2,80 \mathrm{c}$ & $2,44 \mathrm{c}$ \\
\hline & NA & 3,08 & $3,63 \mathrm{~b}$ & $3,93 \mathrm{~b}$ \\
\hline & SA & 3,08 & $4,39 a$ & $5,60 \mathrm{a}$ \\
\hline \multirow[t]{3}{*}{ Arroz } & $\mathrm{NC}$ & 3,09 & $2,70 \mathrm{c}$ & $2,11 \mathrm{c}$ \\
\hline & NA & 3,09 & $3,43 b$ & $3,77 \mathrm{~b}$ \\
\hline & SA & 3,09 & $4,54 \mathrm{a}$ & $5,66 \mathrm{a}$ \\
\hline Trigo & NC & 2,95 & $3,07 \mathrm{c}$ & $2,78 \mathrm{c}$ \\
\hline \multirow[t]{2}{*}{ sarraceno } & NA & 2,95 & $3,40 \mathrm{~b}$ & $3,60 \mathrm{~b}$ \\
\hline & SA & 2,95 & $4,24 \mathrm{a}$ & $5,23 \mathrm{a}$ \\
\hline \multirow[t]{3}{*}{ Sem planta } & NC & 2,95 & $2,90 \mathrm{c}$ & $2,96 \mathrm{c}$ \\
\hline & NA & 2,95 & $4,10 \mathrm{~b}$ & $4,11 b$ \\
\hline & SA & 2,95 & $5,36 \mathrm{a}$ & $4,50 \mathrm{a}$ \\
\hline
\end{tabular}

(1) Dentro de cada cultura e de cada dose, médias acompanhadas da mesma letra não diferem entre si pelo teste de Tukey ao nível de $5 \%$.

(2) NC, nitrato de cálcio; NA, nitrato de amônio; SA, sulfato de amônio. 
cultivada (Tabela 6). Em todas as terras houve acentuada elevação da acidez potencial com o aumento da dose de SA, e aumentos menos pronunciados quando a fonte foi o NA (Figura 3); o emprego do $\mathrm{NC}$, por outro lado, diminuiu o $\mathrm{H}+\mathrm{Al}$ do solo, o que era esperado devido às propriedades alcalinas desse fertilizante (PIERRE, 1933).

O efeito da cultivação sobre a acidez potencial do solo não foi significativo quando o N não foi aplicado (Tabela 10). Esse resultado é coerente com o que se observou para os valores de $\mathrm{pH}$, os quais foram igualmente pouco afetados pela cultivação na ausência de $\mathrm{N}$ aplicado. Nas terras tratadas com NC, a acidez potencial foi maior na ausência de planta ou quando o trigo sarraceno foi cultivado, decrescendo sucessivamente nas amostras com milho e arroz. Quando o NA foi aplicado, independentemente da dose, a acidez potencial foi menor nas terras cultivadas do que nas não cultivadas, especialmente naquelas plantadas com trigo sarraceno e tratadas com $400 \mathrm{mg} \cdot \mathrm{kg}^{-1}$ de $\mathrm{N}$. Para a aplicação

do SA na dose $200 \mathrm{mg} \cdot \mathrm{kg}^{-1}$ de $\mathrm{N}$, as plantas controlaram a elevação da acidez potencial, mantendo-a cerca de uma unidade abaixo do valor encontrado na amostra não plantada; quando se aplicaram $400 \mathrm{mg} \cdot \mathrm{kg}^{-1}$, contudo, as plantas exerceram efeito inverso, elevando a acidez potencial em até 1,16 unidades. Esse efeito pode ser causado pelo mesmo fenômeno discutido para os valores de $\mathrm{pH}$ : na ausência de planta, a nitrificação do SA foi mais completa (e, portanto, acidificou mais) quando foram aplicados $200 \mathrm{mg} \cdot \mathrm{kg}^{-1} \mathrm{de} \mathrm{N}$ do que quando foram fornecidos $400 \mathrm{mg} \cdot \mathrm{kg}^{-1}$, enquanto na presença de vegetais deu-se o oposto.

\subsubsection{Soma de Bases (SB)}

Os maiores valores de SB ocorreram invariavelmente nas amostras tratadas com NC, o que se explica pela presença do cálcio nesse composto (Tabela 11). Nas amostras adubadas com NA e SA esses índices em geral não diferiram entre si. A maior diferença entre fontes ocorreu novamente na dose maior de $400 \mathrm{mg} \cdot \mathrm{kg}^{-1}$ de $\mathrm{N}$ aplicados no arroz, quando a amostra que recebeu o $\mathrm{NC}$ apresentou uma SB cerca de 4,3 unidades acima das terras tratadas com os demais fertilizantes. 
MILHO

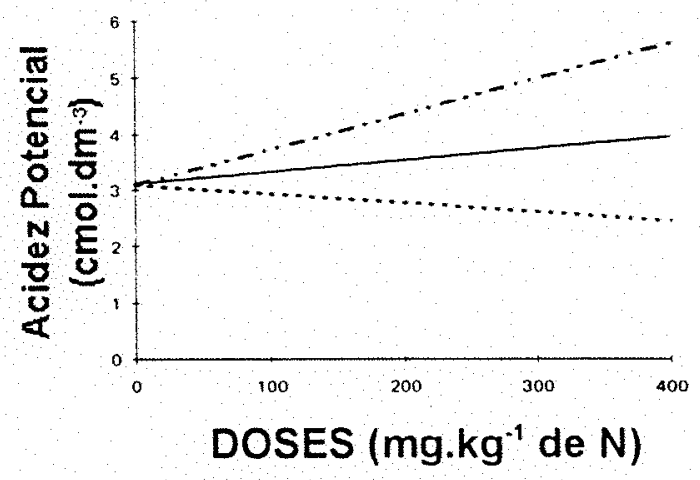

TRIGO SARRACENO

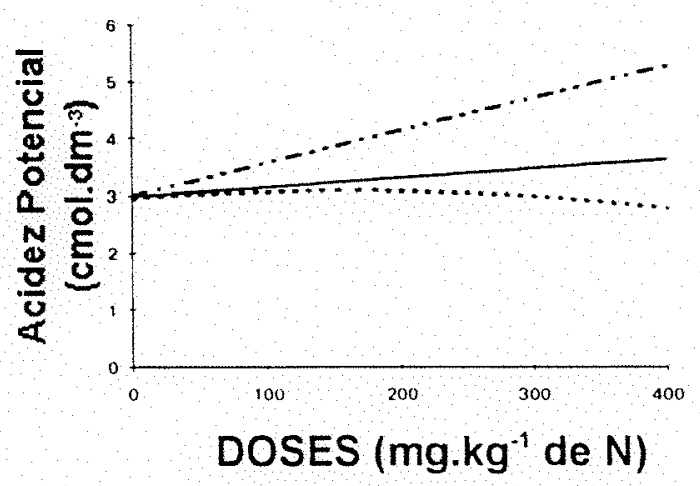

ARROZ

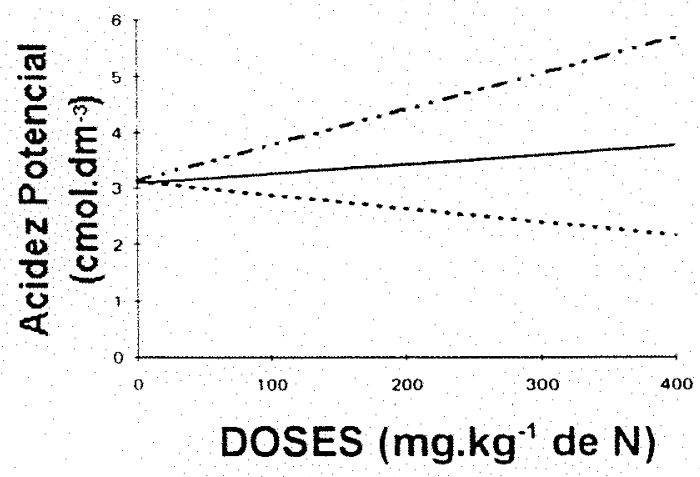

SEM CULTURA

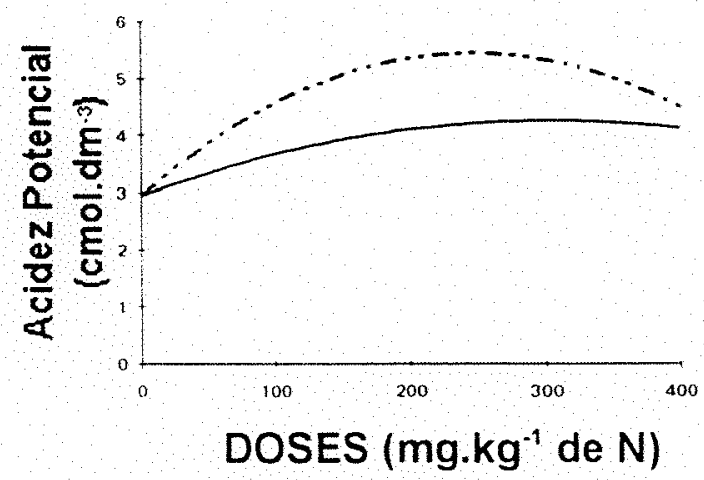

Figura 3. Acidez potencial $(\mathrm{H}+\mathrm{Al})$ de amostras de um Latossolo Roxo distrófico tratadas com diferentes doses de nitrogênio nas formas de nitrato de cálcio (NC), nitrato de amônio (NA) ou sulfato de amônio (SA), e submetidas a diferentes cultivos 
Tabela 10. Efeito da cultivação na acidez potencial $(\mathrm{H}+\mathrm{Al})$ de amostras de Latossolo Roxo distrófico tratadas com diferentes fontes e doses de nitrogennio ${ }^{(1)}$

\begin{tabular}{|c|c|c|c|c|}
\hline \multirow[b]{2}{*}{ Dose } & \multicolumn{4}{|c|}{ Culturas } \\
\hline & Milho & Arroz & Trigo sarraceno & Sem planta \\
\hline$\left(\mathrm{mg} \cdot \mathrm{kg}^{-1}\right)$ & $\ldots \cdots \cdots \cdots$ & $\ldots \ldots \ldots c \mathrm{cn}$ & $\mathrm{dm}^{-3}$ & \\
\hline \multirow[t]{2}{*}{0} & $3,08 \mathrm{~A}$ & $3,09 \mathrm{~A}$ & $2,95 \mathrm{~A}$ & $2,95 \mathrm{~A}$ \\
\hline & \multicolumn{4}{|c|}{ Nitrato de cálcio } \\
\hline 200 & $2,80 \mathrm{AB}$ & $2,70 \mathrm{~B}$ & $3,07 \mathrm{~A}$ & $2,90 \mathrm{AB}$ \\
\hline \multirow[t]{2}{*}{400} & $2,44 \mathrm{~B}$ & $2,11 \mathrm{C}$ & $2,78 \mathrm{~A}$ & $2,96 \mathrm{~A}$ \\
\hline & \multicolumn{4}{|c|}{ Nitrato de amônio } \\
\hline 200 & $3,63 \mathrm{~B}$ & $3,43 \mathrm{~B}$ & $3,40 \mathrm{~B}$ & $4,10 \mathrm{~A}$ \\
\hline \multirow[t]{2}{*}{400} & $3,93 \mathrm{AB}$ & $3,77 \mathrm{BC}$ & $3,60 \mathrm{C}$ & $4,11 \mathrm{~A}$ \\
\hline & \multicolumn{4}{|c|}{ Sulfato de amônio } \\
\hline 200 & $4,39 \mathrm{BC}$ & $4,54 \mathrm{~B}$ & $4,24 \mathrm{C}$ & $5,36 \mathrm{~A}$ \\
\hline 400 & $5,60 \mathrm{~A}$ & $5,66 \mathrm{~A}$ & $5,23 \mathrm{~B}$ & $4,50 \mathrm{C}$ \\
\hline
\end{tabular}

(1) Dentro de cada fonte e de cada dose, médias acompanhadas da mesma letra não diferem entre si pelo teste de Tukey ao nível de $5 \%$ de probabilidade. 
Tabela 11. Soma de bases de amostras de Latossolo Roxo distrófico tratadas com diferentes fontes e doses de nitrogênio e cultivadas com diferentes espécies vegetais (médias de três repetiçōes) ${ }^{(1)}$

\begin{tabular}{|c|c|c|c|c|}
\hline \multirow[b]{2}{*}{ Cultura } & \multirow[b]{2}{*}{ Fonte $^{(2)}$} & \multicolumn{3}{|c|}{ Dose de $\mathrm{N}\left(\mathrm{mg} \cdot \mathrm{kg}^{-1}\right)$} \\
\hline & & 0 & 200 & 400 \\
\hline & & & $\mathrm{mol}_{\mathrm{c}} \cdot \mathrm{dm}$ & \\
\hline \multirow[t]{3}{*}{ Milho } & $\mathrm{NC}$ & 7,39 & $8,05 \mathrm{a}$ & $10,23 \mathrm{a}$ \\
\hline & NA & 7,39 & $6,91 b$ & $7,01 \mathrm{c}$ \\
\hline & SA & 7,39 & $7,10 \mathrm{~b}$ & $7,65 \mathrm{~b}$ \\
\hline \multirow[t]{3}{*}{ Arroz } & $\mathrm{NC}$ & 7,68 & $8,22 \mathrm{a}$ & $11,53 \mathrm{a}$ \\
\hline & NA & 7,68 & $6,56 b$ & $7,20 \mathrm{~b}$ \\
\hline & $\mathrm{SA}$ & 7,68 & $5,97 \mathrm{c}$ & $7,21 \mathrm{~b}$ \\
\hline Trigo & $\mathrm{NC}$ & 7,54 & $7,91 \mathrm{a}$ & $9,88 \mathrm{a}$ \\
\hline \multirow[t]{2}{*}{ sarraceno } & NA & 7,54 & $6,92 b$ & $7,14 \mathrm{~b}$ \\
\hline & $\mathrm{SA}$ & 7,54 & $6,97 \mathrm{~b}$ & $7,51 \mathrm{~b}$ \\
\hline \multirow[t]{3}{*}{ Sem planta } & $\mathrm{NC}$ & 8,18 & $9,39 a$ & $11,01 \mathrm{a}$ \\
\hline & NA & 8,18 & $7,94 \mathrm{~b}$ & $7,80 \mathrm{~b}$ \\
\hline & SA & 8,18 & $7,46 \mathrm{~b}$ & $7,57 \mathrm{~b}$ \\
\hline
\end{tabular}

(1) Dentro de cada cultura e de cada dose, médias acompanhadas da mesma letra não diferem entre si pelo teste de Tukey ao nível de $5 \%$.

(2) NC, nitrato de cálcio; NA, nitrato de amônio; SA, sulfato de amônio. 
$\mathrm{O}$ efeito das doses de $\mathrm{N}$ foi significativo para todas as culturas e fontes de $\mathrm{N}$, exceto NA aplicado nas amostras com milho e naquelas sem plantas (Tabela 6). O aumento da dose de NC causou aumentos nítidos na SB do solo, enquanto as aplicações crescentes de NA e de SA em alguns casos pouco alteraram essa propriedade e, em outros, diminuiram seu valor (Figura 4).

O efeito da cultivação sobre a soma de bases, embora estatisticamente significativo, foi pequeno (Tabela 12). Na ausência de nitrogênio aplicado as amostras cultivadas apresentaram valores similares entre si mas significativamente inferiores ao da terra não cultivada, resultado que está em plena concordância com os relatados por TISDALE et al. (1985) e BOLAN et al. (1991): esses autores verificaram que a remoção de cátions nutrientes pela cultura é um dos fatores que mais contribui para a acidificação do solo. Com o emprego do NC na dose $200 \mathrm{mg} \cdot \mathrm{kg}^{-1}$ de $\mathrm{N}$ também houve diminuição da soma de bases pela presença de plantas, mas na dose maior de $400 \mathrm{mg} \cdot \mathrm{kg}^{-1}$ de $\mathrm{N}$ esse efeito ficou menos nítido. Nas amostras tratadas com NA, independentemente da dose e da espécie vegetal, a SB diminuiu ligeiramente com o cultivo das plantas, enquanto nas parcelas com SA somente as plantas de arroz adubadas com $200 \mathrm{mg} \cdot \mathrm{kg}^{-1}$ de $\mathrm{N}$ alteraram esse parâmetro.

O fato de o SA não provocar diminuições na soma de bases do solo tão evidentes quanto os demais fertilizantes talvez se deva à competição iônica causada pela maior proporção de nitrogênio amoniacal desse adubo: elevadas quantidades do cátion $\mathrm{NH}_{4}^{+}$podem ter inibido a absorção de outros cátions básicos pela planta, notadamente $\mathrm{Ca}^{2+}, \mathrm{Mg}^{2+}$ e $\mathrm{K}^{+}$; esse efeito foi observado anteriormente por HAYNES (1986b). O íon nitrato, ao contrário, estimula a absorção de cátions e inibe a de ânions, talvez, conforme apontam HAYNES \& GOH (1978), devido à competição entre os ânions e o próprio íon nitrato ou entre aqueles e as hidroxilas extrusadas pelas raízes durante a absorção do nitrato. 
MILHO

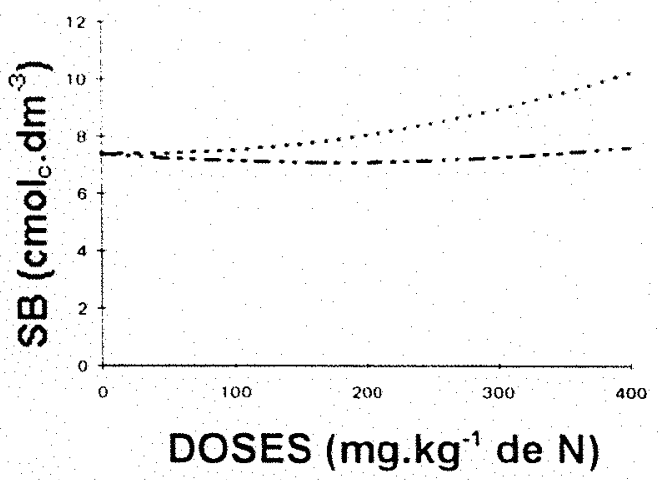

TRIGO SARRACENO

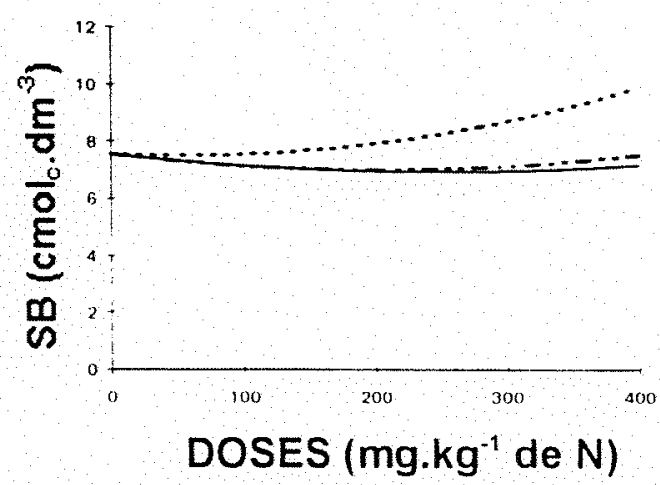

ARROZ

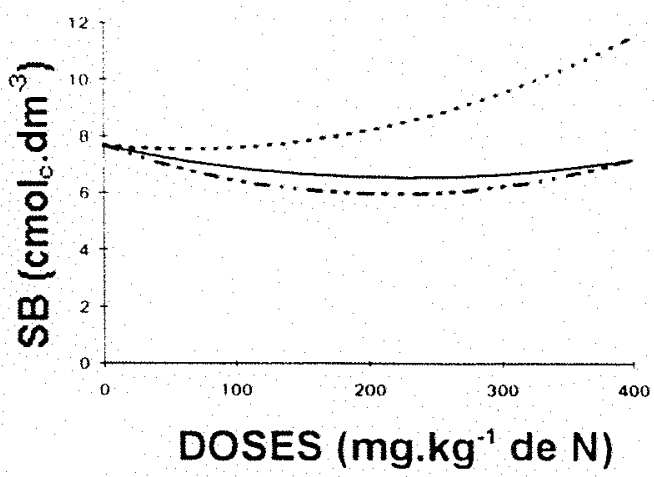

SEM CULTURA

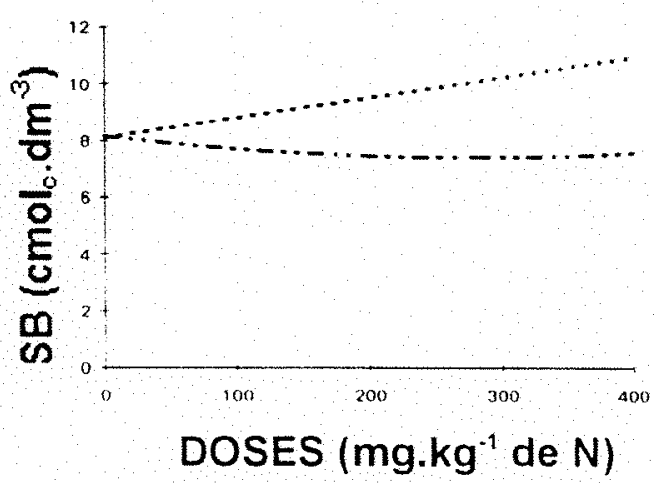

Figura 4. Soma de bases (SB) de amostras de um Latossolo Roxo distrófico tratadas com diferentes doses de nitrogênio nas formas de nitrato de cálcio (NC), nitrato de amônio (NA) ou sulfato de amônio (SA), e submetidas a diferentes cultivos 
Tabela 12. Efeito da cultivação na soma de bases (SB) de amostras de Latossolo Roxo distrófico tratadas com diferentes fontes e doses de nitrogênio ${ }^{(1)}$

\begin{tabular}{|c|c|c|c|c|}
\hline \multirow[b]{2}{*}{ Dose } & \multicolumn{4}{|c|}{ Culturas } \\
\hline & Milho & Arroz & Trigo sarraceno & Sem planta \\
\hline$\left(\mathrm{mg} \cdot \mathrm{kg}^{-1}\right)$ & & $\ldots \mathrm{c}$ & $\mathrm{dm}^{-3}$ & \\
\hline \multirow[t]{2}{*}{0} & $7,39 \mathrm{~B}$ & $7,68 \mathrm{AB}$ & $7,54 \mathrm{~B}$ & $8,18 \mathrm{~A}$ \\
\hline & \multicolumn{4}{|c|}{ Nitrato de cálcio } \\
\hline 200 & $8,05 \mathrm{~B}$ & $8,22 \mathrm{~B}$ & $7,91 \mathrm{~B}$ & $9,39 \mathrm{~A}$ \\
\hline \multirow[t]{2}{*}{400} & $10,23 \mathrm{~B}$ & $11,53 \mathrm{~A}$ & $9,88 \mathrm{~B}$ & $11,01 \mathrm{~A}$ \\
\hline & \multicolumn{4}{|c|}{ Nitrato de amônio } \\
\hline 200 & $6,91 \mathrm{~B}$ & $6,56 \mathrm{~B}$ & $6,92 \mathrm{~B}$ & $7,94 \mathrm{~A}$ \\
\hline \multirow[t]{2}{*}{400} & $7,01 \mathrm{~B}$ & $7,20 \mathrm{~B}$ & $7,14 \mathrm{~B}$ & $7,80 \mathrm{~A}$ \\
\hline & \multicolumn{4}{|c|}{ Sulfato de amônio } \\
\hline 200 & $7,10 \mathrm{~A}$ & $5,97 \mathrm{~B}$ & $6,97 \mathrm{~A}$ & $7,46 \mathrm{~A}$ \\
\hline 400 & $7,65 \mathrm{~A}$ & $7,21 \mathrm{~A}$ & $7,51 \mathrm{~A}$ & $7,57 \mathrm{~A}$ \\
\hline
\end{tabular}

(1) Dentro de cada fonte e de cada dose, inédias acompanhadas da mesma letra não diterem entre si pelo teste de Tukey ao nível de $5 \%$ de probabilidade. 


\subsubsection{Nitrogênio Amoniacal}

Quando o $\mathrm{N}$ foi aplicado na dose $200 \mathrm{mg} \cdot \mathrm{kg}^{-1}$, nas formas de NA ou SA (as fontes que contém a forma amoniacal), e em amostras cultivadas, os teores de nitrogênio amoniacal mostraram-se praticamente iguais em todos os tratamentos, indicando que o $\mathrm{NH}_{4}{ }^{+}$foi quase totalmente nitrificado ou absorvido durante o período de cultivação (Tabela 13); como conseqüência, não houve diferenças significativas entre as fontes. Na ausência de plantas, a nitrificação praticamente consumiu o $\mathrm{NH}_{4}{ }^{+}$aplicado como NA, mas deixou um pequeno resíduo de amônio proveniente do SA.

Quando a dose de $\mathrm{N}$ foi $400 \mathrm{mg} . \mathrm{kg}^{-1}$, a nitrificação e a absorção pelas plantas não chegaram a consumir todo $0 \mathrm{NH}_{4}{ }^{+}$fornecido, de modo que, mesmo nas amostras cultivadas, aquelas tratadas com fontes contendo amônio em geral apresentaram maiores resíduos de $\mathrm{NH}_{4}{ }^{+}$que as adubadas com fertilizante nítrico. Quando não havia plantas, contudo, os resíduos de $\mathrm{NH}_{4}{ }^{+}$foram maiores, principalmente na terra tratada com SA.

Como era de se esperar, o efeito das doses de $\mathrm{N}$ sobre o teor de $\mathrm{N}-\mathrm{NH}_{4}$ do solo foi significativo somente quando uma das fontes contendo amônio foi utilizada (Tabela 6). Por conter maior proporção de nitrogênio na forma amoniacal, o SA causou maiores aumentos no teor de $\mathrm{N}-\mathrm{NH}_{4}$ do solo que o $\mathrm{NA}$, principalmente na amostra não cultivada (Figura 5).

Há que se considerar, ainda, a possibilidade de a taxa de nitrificação ter sido menor quando se aplicou o SA, já que este composto causou baixamentos mais acentuados do $\mathrm{pH}$ (Tabelas 4 e 5); SILVA (1994) observou que a aplicação de SA diminuiu o pH do solo e, conseqüentemente, a velocidade de nitrificação.

Os maiores efeitos da cultivação do solo sobre o seu conteúdo de $\mathrm{NH}_{4}{ }^{+}$ ocorreram quando se aplicaram fontes contendo nitrogênio na forma amoniacal (Tabela 14). Comparando-se com as terras não adubadas, cujos teores de $\mathrm{N}-\mathrm{NH}_{4}$ foram pouco maiores que $0,2 \mathrm{cmol}_{\mathrm{dm}}{ }^{-3}$, verifica-se que mesmo se aplicando $\mathrm{NA}$, a quantidade de amônio 
Tabela 13. Concentração de $\mathrm{N}-\mathrm{NH}_{4}$ em amostras de Latossolo Roxo distrófico tratadas com diferentes fontes e doses de nitrogênio e cultivadas com diferentes espécies vegetais (médias de três repetiçōes) $)^{(1)}$

\begin{tabular}{|c|c|c|c|c|}
\hline \multirow[b]{2}{*}{ Cultura } & \multirow[b]{2}{*}{ Fonte $^{(2)}$} & \multicolumn{3}{|c|}{ Dọse de $\mathrm{N}\left(\mathrm{mg} \cdot \mathrm{kg}^{-1}\right)$} \\
\hline & & 0 & 200 & 400 \\
\hline & & & $\mathrm{cmol}_{\mathrm{c}} \cdot \mathrm{dm}$ & \\
\hline \multirow[t]{3}{*}{ Milho } & NC & 0,225 & $0,213 \mathrm{a}$ & $0,253 \mathrm{~b}$ \\
\hline & $\mathrm{NA}$ & 0,225 & $0,263 \mathrm{a}$ & $0,403 \mathrm{a}$ \\
\hline & SA & 0,225 & $0,293 \mathrm{a}$ & $0,491 \mathrm{a}$ \\
\hline \multirow[t]{3}{*}{ Arroz } & NC & 0,255 & $0,263 \mathrm{a}$ & $0,341 \mathrm{a}$ \\
\hline & NA & 0,255 & $0,346 \mathrm{a}$ & $0,366 \mathrm{a}$ \\
\hline & $\mathrm{SA}$ & 0,255 & $0,273 a$ & $0,400 \mathrm{a}$ \\
\hline Trigo & NC & 0,251 & $0,250 \mathrm{a}$ & $0,330 \mathrm{~b}$ \\
\hline \multirow[t]{2}{*}{ sarraceno } & NA & 0,251 & $0,238 \mathrm{a}$ & $0,421 \mathrm{~b}$ \\
\hline & SA & 0,251 & $0,333 a$ & $0,966 \mathrm{a}$ \\
\hline \multirow[t]{3}{*}{ Sem planta } & $\mathrm{NC}$ & 0,226 & $0,254 \mathrm{~b}$ & $0,230 \mathrm{c}$ \\
\hline & $\mathrm{NA}$ & 0,226 & $0,215 \mathrm{~b}$ & $0,901 \mathrm{~b}$ \\
\hline & $\mathrm{SA}$ & 0,226 & 0,481 a & $1,972 \mathrm{a}$ \\
\hline
\end{tabular}

(1) Dentro de cada cultura e de cada dose, médias acompanhadas da mesma letra nào diferem entre si pelo teste de Tukey ao nível de $5 \%$.

(2) NC, nitrato de cálcio; NA, nitrato de amônio; SA, sulfato de amônio. 
MILHO

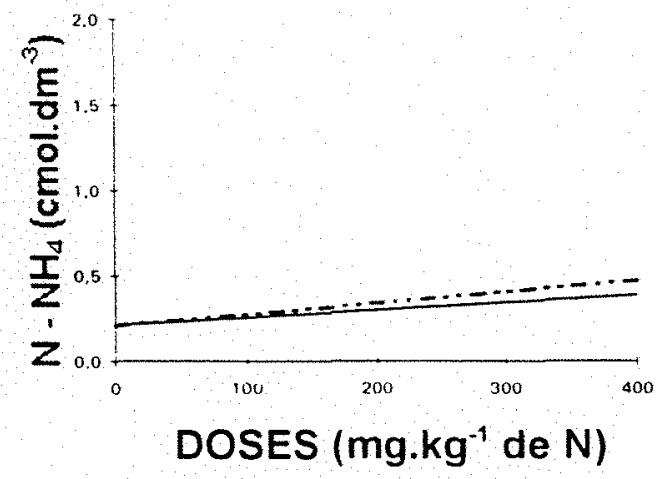

TRIGO SARRACENO

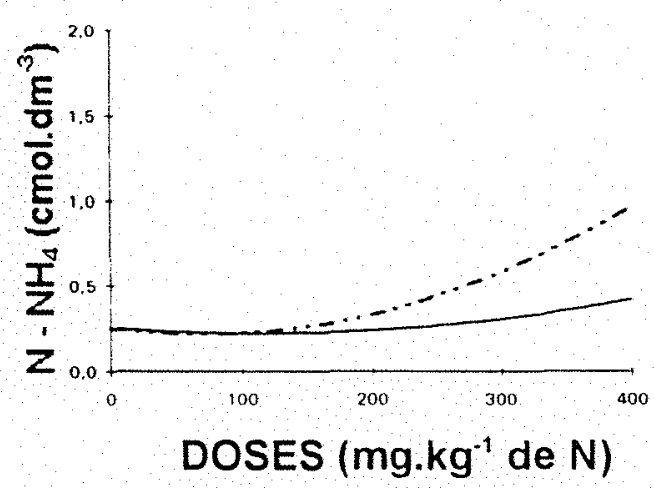

ARROZ

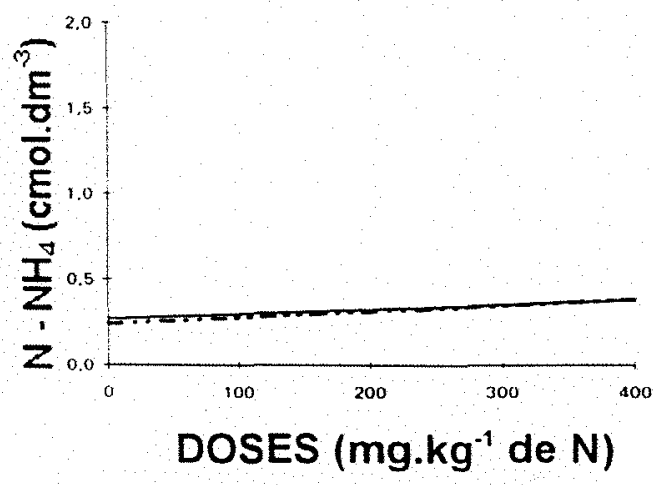

SEM CULTURA

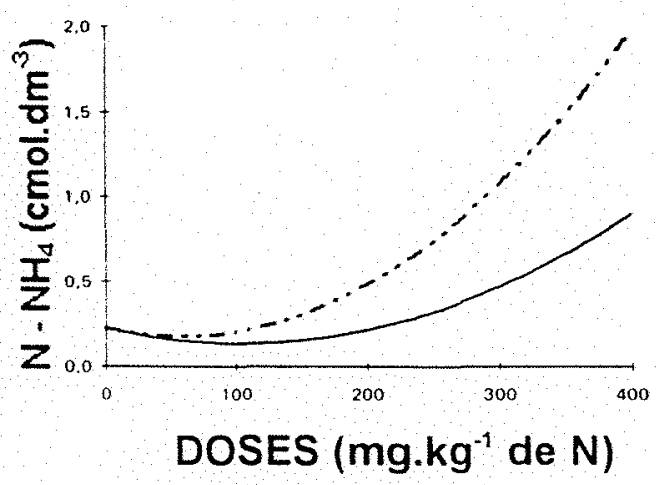

Figura 5. Teores de nitrogênio amoniacal de amostras de um Latossolo Roxo distrófico tratadas com diferentes doses de nitrogênio nas formas de nitrato de cálcio (NC), nitrato de amônio (NA) ou sulfato de amônio (SA), e submetidas a diferentes cultivos 
Tabela 14. Efeito da cultivação na concentração de $\mathrm{N}-\mathrm{NH}_{4}$ de amostras de Latossolo Roxo distrófico tratadas com diferentes fontes e doses de nitrogennio ${ }^{(1)}$

\begin{tabular}{|c|c|c|c|c|}
\hline \multirow[b]{2}{*}{ Dose } & \multicolumn{4}{|c|}{ Culturas } \\
\hline & Milho & Arroz & Trigo sarraceno & sem planta \\
\hline$\left(\mathrm{mg} \cdot \mathrm{kg}^{-1}\right)$ & $\cdots \cdots \cdots \cdots$ & $\ldots \ldots \mathrm{cr}$ & $\mathrm{dm}^{-3}$ & \\
\hline \multirow[t]{2}{*}{0} & $0,225 \mathrm{~A}$ & $0,255 \mathrm{~A}$ & $0,251 \mathrm{~A}$ & $0,226 \mathrm{~A}$ \\
\hline & \multicolumn{4}{|c|}{ Nitrato de cálcio } \\
\hline 200 & $0,213 \mathrm{~A}$ & $0,263 \mathrm{~A}$ & $0,250 \mathrm{~A}$ & $0,254 \mathrm{~A}$ \\
\hline \multirow[t]{2}{*}{400} & $0,253 \mathrm{~A}$ & $0,341 \mathrm{~A}$ & $0,330 \mathrm{~A}$ & $0,230 \mathrm{~A}$ \\
\hline & \multicolumn{4}{|c|}{ Nitrato de amônio } \\
\hline 200 & $0,263 \mathrm{AB}$ & $0,346 \mathrm{~A}$ & $0,238 \mathrm{AB}$ & $0,215 \mathrm{~B}$ \\
\hline \multirow[t]{2}{*}{400} & $0,403 \mathrm{~B}$ & $0,366 \mathrm{~B}$ & $0,421 \mathrm{~B}$ & $0,901 \mathrm{~A}$ \\
\hline & \multicolumn{4}{|c|}{ Sulfato de amônio } \\
\hline 200 & $0,293 \mathrm{~B}$ & $0,273 \mathrm{~B}$ & $0,333 \mathrm{~B}$ & $0,481 \mathrm{~A}$ \\
\hline 400 & $0,491 \mathrm{C}$ & $0,340 \mathrm{C}$ & $0,966 \mathrm{~B}$ & $1,972 \mathrm{~A}$ \\
\hline
\end{tabular}

(1) Dentro de cada fonte e de cada dose, médias acompanhadas da mesma letra não diferem entre si pelo teste de Tukey ao nível de $5 \%$ de probabilidade. 
remanescente no solo foi pequena, tornando-se pouco mais relevante (cerca de $0,7 \mathrm{cmol}$. $\mathrm{dm}^{-3} \mathrm{~N}-\mathrm{NH}_{4}$ ) quando não havia plantas e a dose era $400 \mathrm{mg} \cdot \mathrm{kg}^{-1}$ de $\mathrm{N}$. Nas amostras tratadas com SA na dose menor, os resíduos de $\mathrm{NH}_{4}{ }^{+}$também foram pequenos, principalmente na presença de plantas; para a dose maior, contudo, a quantidade mais elevada de amônio foi encontrada na amostra não cultivada $\left(1,972 \mathrm{cmol} \cdot \mathrm{dm}^{-3} \mathrm{~N}^{-\mathrm{NH}_{4}}\right)$ e na plantada com trigo sarraceno $\left(0,966 \mathrm{cmol} \cdot \mathrm{dm}^{-3} \mathrm{~N}-\mathrm{NH}_{4}\right)$.

\subsubsection{Nitrogênio Nítrico}

Nas terras cultivadas e que receberam $200 \mathrm{mg} \cdot \mathrm{kg}^{-1} \mathrm{de} \mathrm{N}$, não houve variação significativa entre os teores de $\mathrm{N}-\mathrm{NO}_{3}$ quando os diferentes adubos foram aplicados, certamente porque as plantas, através da absorção, mantiveram os níveis de nitrato baixos, independentemente da fonte utilizada (Tabela 15). Na ausência de plantas, contudo, a concentração de $\mathrm{N}_{-} \mathrm{NO}_{3}$ no solo foi maior quando se aplicou a fonte essencialmente nítrica (NC), intermediária quando se empregou um adubo nítrico-amoniacal (NA), e menor quando o fertilizante adicionado foi exclusivamente amoniacal (SA). Quando a dose maior de $400 \mathrm{mg} \cdot \mathrm{kg}^{-1}$ de $\mathrm{N}$ foi empregada, contudo, houve sobras mais significativas de nitrato no solo; como resultado, a citada seqüência NC $>$ NA $>$ SA foi observada em todas as terras, cultivadas ou não.

Com exceção das amostras tratadas com SA e cultivadas com milho, o efeito das doses de $\mathrm{N}$ sobre o teor de nitrato do solo foi significativo para todas as culturas e fontes de $\mathrm{N}$ (Tabela 6). Fica novamente evidenciado, pelas regressões, o efeito destacado do $\mathrm{NC}$ sobre o teor de $\mathrm{N}-\mathrm{NO}_{3}$ do solo em todas as amostras, cultivadas ou não, e os efeitos menores das demais fontes (Figura 6). Nas amostras adubadas com SA e não cultivadas, o teor de nitrato aumentou até a dose $200 \mathrm{mg} \cdot \mathrm{kg}^{-1}$ de $\mathrm{N}$ para, em seguida, diminuir; esse efeito pode ser explicado por uma inibição parcial da nitrificação, causada ou pelo baixamento do $\mathrm{pH}$, ou pela concentração excessivamente elevada de amônio no solo (esta última, decorrente da falta de plantas). CHUNG \& ZASOSKI (1993) e SILVA (1994) verificaram que o baixamento do $\mathrm{pH}$ e a elevação da concentração de amônio exercem efeito negativo sobre a nitrificação. 
Tabela 15. Concentração de $\mathrm{N}-\mathrm{NO}_{3}$ em amostras de Latossolo Roxo distrófico tratadas com diferentes fontes e doses de nitrogênio e cultivadas com diferentes espécies vegetais (médias de três repetiçōes) ${ }^{(1)}$

\begin{tabular}{|c|c|c|c|c|}
\hline \multirow[b]{2}{*}{ Cultura } & \multirow[b]{2}{*}{ Fonte $^{(2)}$} & \multicolumn{3}{|c|}{ Dose de $\mathrm{N} \quad\left(\mathrm{mg} \cdot \mathrm{kg}^{-1}\right)$} \\
\hline & & 0 & 200 & 400 \\
\hline & & $\cdots \cdots$ & $\mathrm{cmol}_{c} \cdot \mathrm{dm}^{-3}$ & \\
\hline \multirow[t]{3}{*}{ Milho } & $\mathrm{NC}$ & 0,059 & $0,135 \mathrm{a}$ & $1,444 \mathrm{a}$ \\
\hline & NA & 0,059 & $0,118 \mathrm{a}$ & $0,621 \mathrm{~b}$ \\
\hline & $\mathrm{SA}$ & 0,059 & $0,072 \mathrm{a}$ & $0,120 \mathrm{c}$ \\
\hline \multirow[t]{3}{*}{ Arroz } & NC & 0,066 & $0,047 \mathrm{a}$ & $1,578 \mathrm{a}$ \\
\hline & NA & 0,066 & $0,085 \mathrm{a}$ & $0,850 \mathrm{~b}$ \\
\hline & $\mathrm{SA}$ & 0,066 & $0,060 \mathrm{a}$ & $0,290 \mathrm{c}$ \\
\hline \multirow{3}{*}{$\begin{array}{l}\text { Trigo } \\
\text { sarraceno }\end{array}$} & $\mathrm{NC}$ & 0,069 & $0,308 \mathrm{a}$ & $1,807 \mathrm{a}$ \\
\hline & NA & 0,069 & $0,188 \mathrm{a}$ & $0,916 b$ \\
\hline & SA & 0,069 & $0,190 \mathrm{a}$ & $0,470 \mathrm{c}$ \\
\hline \multirow[t]{3}{*}{ Sem planta } & $\mathrm{NC}$ & 0,236 & $1,404 \mathrm{a}$ & $2,631 \mathrm{a}$ \\
\hline & NA & 0,236 & $1,230 \mathrm{~b}$ & $1,830 \mathrm{~b}$ \\
\hline & $\mathrm{SA}$ & 0,236 & $0,950 \mathrm{c}$ & $0,603 \mathrm{c}$ \\
\hline
\end{tabular}

(1) Dentro de cada cultura e de cada dose, médias acompanhadas da mesma letra não diferem entre si pelo teste de Tukey ao nível de $5 \%$.

(2) NC, nitrato de cálcio; NA, nitrato de amônio; SA, sulfato de amônio. 
MILHO

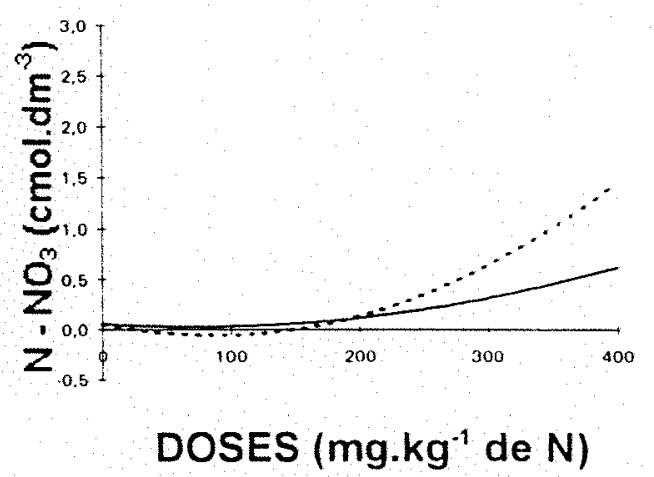

TRIGO SARRACENO

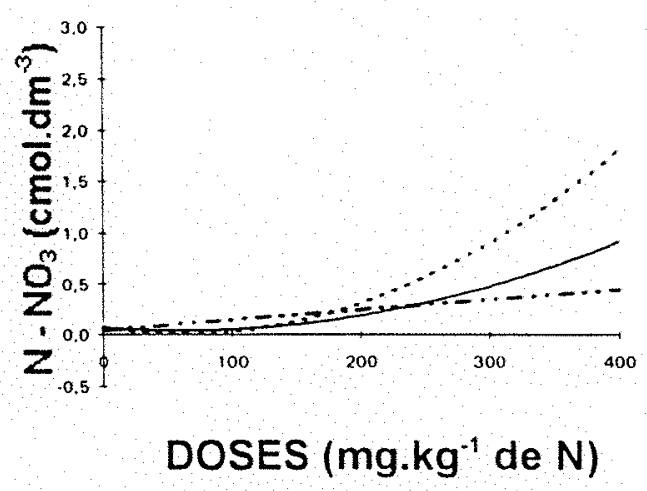

ARROZ

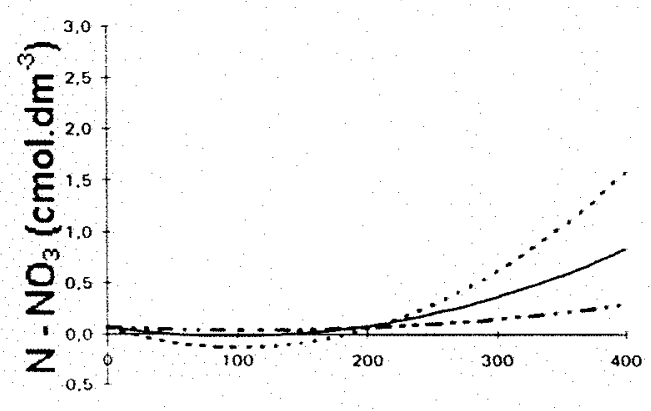

DOSES (mg. $\mathrm{kg}^{-1}$ de N)
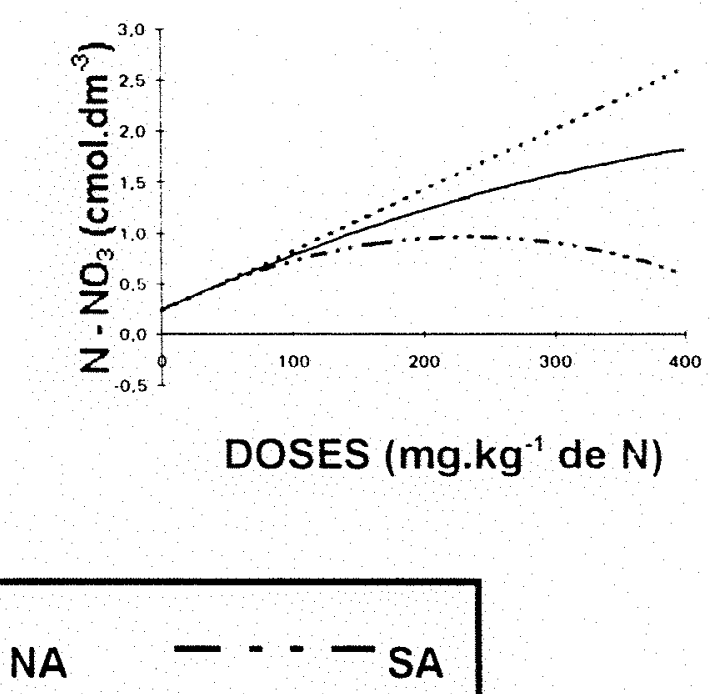

Figura 6. Teores de nitrogênio nítrico de amostras de um Latossolo Roxo distrófico tratadas com diferentes doses de nitrogênio nas formas de nitrato de cálcio (NC), nitrato de amônio (NA) ou sulfato de amônio (SA), e submetidas a diferentes cultivos 
Quanto ao efeito da cultivação nos teores de nitrato no solo, verificou-se que quando o nitrogênio não foi aplicado, a presença de plantas tendeu a baixar o conteúdo de $\mathrm{NO}_{3}{ }_{3}$, o qual chegou a decrescer de 0,236 para até $0,059 \mathrm{cmol} . \mathrm{dm}^{-3} \mathrm{de} \mathrm{N}-\mathrm{NO}_{3}$ (Tabela 16). Nas terras adubadas com NC, NA e SA, esse efeito foi mais nítido, pois em todos os casos menos um, as amostras com plantas mostraram teores de nitrato menores que as não cultivadas. A preferência do trigo sarraceno pelo nitrogênio na forma amoniacal ficou evidente quando essa planta foi adubada somente com a forma nítrica: os resíduos de $\mathrm{NO}_{3}{ }^{\circ}$ nos solos cultivados com a dicotiledônea foram significativamente maiores que os das amostras plantadas com as demais espécies.

\subsection{Influência dos Fertilizantes Nitrogenados sobre os Parâmetros da Planta}

Neste estudo, o fator "cultura" passa a ter apenas três níveis, já que o quarto nível era representado por amostras sem planta. A Tabela 17 mostra que a produção de matéria seca pela parte aérea, o teor de nitrogênio, o somatório de cátions, o somatório de ânions, o excesso de bases e a relação excesso de bases/nitrogênio na parte aérea, foram significativamente influenciados pelos fatores "fonte" e "dose" de nitrogênio, e pela interação tripla.

\subsubsection{Produção de Matéria Seca}

Tanto na dose 200 quanto na dose $400 \mathrm{mg} \cdot \mathrm{kg}^{-1}$ de $\mathrm{N}$, o milho e o arroz apresentaram produções de matéria seca mais elevadas quando o nitrogênio foi fornecido na forma amoniacal do que na nítrica (Tabela 18); o trigo sarraceno, ao contrário, mostrou maiores produçōes quando adubado com a forma nítrica ou a nítrica-amoniacal.

Esses resultados discordam do fato usualmente aceito de que existe uma preferência das monocotiledôneas ao nitrogênio na forma nítrica, e das dicotiledôneas à forma amoniacal (RAIJ \& DIEST, 1979; BEKELE et al., 1983 e WALLACE, 1994). 
Tabela 16. Efeito da cultivação na concentração de $\mathrm{N}-\mathrm{NO}_{3}$ de amostras de Latossolo Roxo distrófico tratadas com diferentes fontes e doses de nitrogênio ${ }^{(1)}$

\begin{tabular}{|c|c|c|c|c|}
\hline \multirow[b]{2}{*}{ Dose } & \multicolumn{4}{|c|}{ Culturas } \\
\hline & Milho & Arroz & Trigo sarraceno & Sem planta \\
\hline$\left(\mathrm{mg} \cdot \mathrm{kg}^{-1}\right)$ & & $\ldots \ldots c$ &. $\mathrm{dm}^{-3}$ & \\
\hline \multirow[t]{2}{*}{0} & $0,059 \mathrm{~B}$ & $0,066 \mathrm{AB}$ & $0,069 \mathrm{AB}$ & $0,236 \mathrm{~A}$ \\
\hline & \multicolumn{4}{|c|}{ Nitrato de cálcio } \\
\hline 200 & $0,135 \mathrm{BC}$ & $0,047 \mathrm{C}$ & $0,308 \mathrm{~B}$ & $1,404 \mathrm{~A}$ \\
\hline \multirow[t]{2}{*}{400} & $1,444 \mathrm{C}$ & $1,578 \mathrm{C}$ & $1,807 \mathrm{~B}$ & $2,631 \mathrm{~A}$ \\
\hline & \multicolumn{4}{|c|}{ Nitrato de amônio } \\
\hline 200 & $0,118 \mathrm{~B}$ & $0,085 \mathrm{~B}$ & $0,188 \mathrm{~B}$ & $1,228 \mathrm{~A}$ \\
\hline \multirow[t]{2}{*}{400} & $0,621 \mathrm{C}$ & $0,849 \mathrm{~B}$ & $0,916 \mathrm{~B}$ & $1,829 \mathrm{~A}$ \\
\hline & \multicolumn{4}{|c|}{ Sulfato de amônio } \\
\hline 200 & $0,072 \mathrm{~B}$ & $0,060 \mathrm{~B}$ & $0,190 \mathrm{~B}$ & $0,949 \mathrm{~A}$ \\
\hline 400 & $0,120 \mathrm{~B}$ & $0,290 \mathrm{~B}$ & $0,470 \mathrm{~A}$ & $0,603 \mathrm{~A}$ \\
\hline
\end{tabular}

(1) Dentro de cada fonte e de cada dose, médias acompanhadas da mesma letra não diferem entre si pelo teste de Tukey ao nível de $5 \%$ de probabilidade. 
Tabela 17. Valores de $F$ obtidos da análise de variância para produção da matéria seca (MS); teor de nitrogênio, somatório de cátions, somatório de ânions, excesso de bases $(\mathrm{EB})^{(1)}$ e relação $\mathrm{EB} / \mathrm{N}$ na parte aérea de plantas de milho, arroz e trigo sarraceno cultivadas em amostras de solo tratadas com diferentes fontes e doses de nitrogênio ${ }^{(2)}$

\begin{tabular}{|c|c|c|c|c|c|c|c|}
\hline $\begin{array}{l}\text { Causa de } \\
\text { variação }\end{array}$ & G.L. & MS & $N$ & $\Sigma$ Cátions & $\Sigma$ Ânions & EB & $\mathrm{EB} / \mathrm{N}$ \\
\hline Cultura (C) & 2 & $492,68^{* *}$ & $229,59^{* *}$ & $2244,87 * *$ & $572,53 * *$ & $1979,20^{* *}$ & $567,99^{* *}$ \\
\hline Fonte (F) & 2 & $30,54^{* *}$ & $12,38^{* *}$ & $209,99 * *$ & $60,86^{* *}$ & $242,05^{* *}$ & $176,32^{* *}$ \\
\hline Dose (D) & 2 & $1921,36^{* *}$ & $339,22 * *$ & $13,32 * *$ & $40,96^{* *}$ & $8,63^{*}$ & $3057,68^{* *}$ \\
\hline $\mathrm{C} \times \mathrm{F}$ & 4 & $31,84^{* *}$ & $5,27 * *$ & $103,77^{* *}$ & $8,49 * *$ & $108.54^{* *}$ & $53,86^{* *}$ \\
\hline$C \times D$ & 4 & $50,75^{* *}$ & $17,52^{* *}$ & $3,81^{* *}$ & $9,86^{* *}$ & $2,79^{*}$ & $91,79 * *$ \\
\hline$F \times D$ & 4 & $8,67 * *$ & $6,35^{* *}$ & $60,20 * *$ & $26,45^{* *}$ & $69,90^{* *}$ & $49,91^{* *}$ \\
\hline$C \times F \times D$ & 8 & $8,94^{* *}$ & $2,41^{*}$ & $28,04 * *$ & $5,24^{* *}$ & $29.57 * *$ & $14.74 * *$ \\
\hline C.V. $(\%)$ & & 6,13 & 14,32 & 5,98 & 3,41 & 8,09 & 6,58 \\
\hline
\end{tabular}

(1) Soma de cátions menos soma de ânions.

(2) * e $\mathrm{e}^{* *}$, valores significativos a $5 \%$ e $1 \%$ de probabilidade. 
Tabela 18. Produção de matéria seca pela parte aérea de plantas cultivadas em amostras de Latossolo Roxo distrófico e tratadas com diferentes fontes e doses de nitrogênio (médias de três repetições) ${ }^{(1)}$

\begin{tabular}{|c|c|c|c|c|}
\hline \multirow[b]{2}{*}{ Cultura } & \multirow[b]{2}{*}{ Fonte $^{(2)}$} & \multicolumn{3}{|c|}{ Dose de $\mathrm{N}\left(\mathrm{mg} \cdot \mathrm{kg}^{-1}\right)$} \\
\hline & & 0 & 200 & 400 \\
\hline & & & g.vaso ${ }^{-1}$ & \\
\hline \multirow[t]{3}{*}{ Milho } & $\mathrm{NC}$ & 6,94 & $18,98 \mathrm{c}$ & $18,59 \mathrm{c}$ \\
\hline & $\mathrm{NA}$ & 6,94 & $24,14 b$ & $22,93 \mathrm{~b}$ \\
\hline & $\mathrm{SA}$ & 6,94 & $27,02 \mathrm{a}$ & $25,61 \mathrm{a}$ \\
\hline \multirow[t]{3}{*}{ Arroz } & $\mathrm{NC}$ & 6,62 & $20,19 b$ & $19,67 b$ \\
\hline & NA & 6,62 & $19,75 \mathrm{~b}$ & $22,06 \mathrm{a}$ \\
\hline & $\mathrm{SA}$ & 6,62 & 23,55 a & $22,79 a$ \\
\hline Trigo & $\mathrm{NC}$ & 4,34 & $14,43 \mathrm{a}$ & $13,71 \mathrm{a}$ \\
\hline \multirow[t]{2}{*}{ sarraceno } & $\mathrm{NA}$ & 4,34 & $14,44 a$ & $14,27 \mathrm{a}$ \\
\hline & $S A$ & 4,34 & $11,96 \mathrm{~b}$ & $11,49 \mathrm{~b}$ \\
\hline
\end{tabular}

(1) Dentro de cada cultura e de cada dose, médias acompanhadas da mesma letra näo diferem entre si pelo teste de Tukey ao nível de $5 \%$.

(2) NC, nitrato de cálcio; NA, nitrato de amónio; SA, sulfato de amônio. 
Porém, em trabalho recente, ANCHENG et al.(1993) observaram que a preferência do arroz à forma amoniacal ou nítrica pode mudar de acordo com o cultivar e a dose de $\mathrm{N}$ : os autores verificaram que o cultivar convencional de arroz (Japonica) absorveu mais amônio do que nitrato, enquanto o arroz híbrido (Indica) utilizou mais intensamente o nitrato do que o amônio em doses altas de nitrogênio. Resultados encontrados por GIGON \& RORISON (1972), mostram que algumas gramíneas apresentam preferência pelo nitrogênio na forma amoniacal.

Poder-se-ia também pensar em um efeito favorável do enxofre contido no SA sobre a produção de matéria seca das gramíneas, porém, essa hipótese não parece provável porque o solo continha teor relativamente elevado $\left(87,15 \mathrm{mg} \cdot \mathrm{dm}^{-3}\right.$ de $\left.\mathrm{S}_{-} \mathrm{SO}_{4}\right)$ desse nutriente, além do que a adição de sulfato deveria beneficiar igualmente o trigo sarraceno.

$\mathrm{O}$ estudo de regressões polinomiais revelou efeito significativo das doses de $\mathrm{N}$ em todas as culturas e para todas as fontes, bem como coeficientes de determinação elevados e altamente significativos (Tabela 19). A Figura 7 mostra que as culturas responderam à adição de nitrogênio de modo razoavelmente uniforme. Independentemente da forma de nitrogênio e da espécie, a produção de matéria seca aumentou até determinada dose, situada entre 250 e $300 \mathrm{mg} \cdot \mathrm{kg}^{-1}$ de $\mathrm{N}$, e decresceu levemente a partir desse ponto.

Esse comportamento mostra que a concentração de nitrogênio na folha ultrapassou a "zona de alimentação de luxo" e o chamado "nível crítico superior", atingindo a "zona de toxidez ou desequilibrio"; segundo MALAVOLTA et al. (1989) nessa zona há um aumento do teor foliar, acompanhado de queda na produção. 
Tabela 19. Equações polinomiais estimadas dos parâmetros vegetais (y) em função das doses de nitrogênio $(x)$, para diferentes fontes de nitrogênio e culturas

\begin{tabular}{|c|c|c|c|c|}
\hline $\begin{array}{l}\text { Parâmetro } \\
\text { (y) }\end{array}$ & Cultura & Fonte $^{(1)}$ & $\begin{array}{l}\text { Equaçōes } \\
\text { Polinomiais }\end{array}$ & $\begin{array}{c}\text { Coeficiente de } \\
\text { determinação }\left(r^{2}\right)^{(2)}\end{array}$ \\
\hline \multirow[t]{9}{*}{ Matéria seca } & Milho & $\mathrm{NC}$ & $y=6,94+0,0913 x-0,00015538 x^{2}$ & $0,99 * *$ \\
\hline & & NA & $y=6,94+0,1320 x-0,00023004 x^{2}$ & $0,99 * *$ \\
\hline & & SA & $y=6,94+0,154 x-0,00026886 x^{2}$ & $0,99 * *$ \\
\hline & Arroz & NC & $y=6,62+0,1031 x-0,0001762 x^{2}$ & $0,99 * *$ \\
\hline & & NA & $y=6,62+0,0927 x-0,00013538 x^{2}$ & $0,99 * *$ \\
\hline & & SA & $y=6,62+0,1289 x-0,00022121 x^{2}$ & $0,99 * *$ \\
\hline & Trigo & NC & $y=4,34+0,0774 x-0,00013504 x^{2}$ & $0,99 * *$ \\
\hline & sarraceno & NA & $y=4,34+0,07618 x-0,00012842 x^{2}$ & $0.99 * *$ \\
\hline & & SA & $y=4,34+0,0583 x-0.00010117 x^{2}$ & $0,99 * *$ \\
\hline \multirow[t]{9}{*}{ Nitrogênio total } & Milho & NC & $y=49,37+0,7092 x-0,00114867 x^{2}$ & $0,99 *$ \\
\hline & & NA & $y=49,58+0,3845 x$ & $0,99 * *$ \\
\hline & & SA & $y=50,94+0,3709 x$ & $0,99 * *$ \\
\hline & Arroz & NC & $y=75,63+0,3340 x$ & $0,97 * *$ \\
\hline & & NA & $y=68,97+0,7708 x-0,00117225 x^{2}$ & $0,99 *$ \\
\hline & & SA & $y=70,69+0,4281 x$ & $0,99 * *$ \\
\hline & Trigo & NC & $y=115,06+0,9419 x-0,00125213 x^{2}$ & $0,99 * *$ \\
\hline & sarraceno & $\mathrm{NA}$ & $y=115,06+1,4884 x-0,00221008 x^{2}$ & $0,99 * *$ \\
\hline & & SA & $y=115,06+1,3610 x-0,00133963 x^{2}$ & $0.99 * *$ \\
\hline
\end{tabular}


- continuação -

\begin{tabular}{|c|c|c|c|c|}
\hline $\begin{array}{l}\text { Parâmetro } \\
\text { (y) }\end{array}$ & Cultura & Fonte & $\begin{array}{l}\text { Equaçōes } \\
\text { Polinomiais }\end{array}$ & $\begin{array}{l}\text { Coeficiente de } \\
\text { determinaçào }\left(r^{2}\right)^{(2)}\end{array}$ \\
\hline \multirow[t]{9}{*}{ I Cátions } & Milho & NC & $y=108,20+0,05337 x$ & $0,87 * *$ \\
\hline & & NA & não significativo & \\
\hline & & SA & $y=110,60-0,179475 x+0,0003494 x^{2}$ & $0,99 *$ \\
\hline & Arroz & NC & nầo significativo & \\
\hline & & NA & não significativo & \\
\hline & & SA & $y=121.06-0.07864 x$ & $0,96 * *$ \\
\hline & Trigo & NC & $y=277,63+0,47374 x-0,00050562 x^{2}$ & $0,99 * *$ \\
\hline & sarraceno & NA & $y=276,11-0,19587 x$ & $0,99 * *$ \\
\hline & & $\mathrm{SA}$ & $y=277.63-0.52994 x+0,00070121 x^{2}$ & $0,99 * *$ \\
\hline \multirow[t]{9}{*}{$\sum$ Ânions } & Milho & NC & $y=35,18-0,051183 x+0,00011025 x^{2}$ & $0,99 * *$ \\
\hline & & NA & não significativo & \\
\hline & & SA & $y=35,18-0,02521 x+0,00011254 x^{2}$ & $0,99 * *$ \\
\hline & Arroz & NC & $y=45,84-0,017392 x$ & $0,94 * *$ \\
\hline & & NA & $y=46,26-0,01221 x$ & $0,99 * *$ \\
\hline & & SA & $y=46,33-0,07225 x+0,00017825 x^{2}$ & $0,99 * *$ \\
\hline & Trigo & $\mathrm{NC}$ & $y=49,12-0,04298 x+0,000055 x^{2}$ & $0,99 *$ \\
\hline & sarraceno & NA & $y=49,12-0,026042 x+0,00006879 x^{2}$ & $0,99 * *$ \\
\hline & & SA & $y=49,00+0,006025 x$ & $0,97 *$ \\
\hline
\end{tabular}


- continuação -

\begin{tabular}{|c|c|c|c|c|}
\hline $\begin{array}{l}\text { Parâmetro } \\
\text { (y) }\end{array}$ & Cultura & Fonte & $\begin{array}{l}\text { Equaçōes } \\
\text { Polinomiais }\end{array}$ & $\begin{array}{l}\text { Coeficiente de } \\
\text { determinação }\left(r^{2}\right)^{(2)}\end{array}$ \\
\hline Excesso de & Milho & NC & $y=74,49+0,0604 x$ & $0,98 * *$ \\
\hline \multirow[t]{8}{*}{ Bases (EB) } & & NA & não significativo & \\
\hline & & $S A$ & $y=72.24-0,05954 x$ & $0,83 * *$ \\
\hline & Arroz & NC & não significativo & \\
\hline & & $\mathrm{NA}$ & não significativo. & \\
\hline & & $\mathrm{SA}$ & $y=77,11-0,0777 x$ & $0,99 * *$ \\
\hline & Trigo & $\mathrm{NC}$ & $y=228,51+0,5167 x-0,00056062 x^{2}$ & $0,99 * *$ \\
\hline & sarraceno & NA & $y=227,90-0,1973 x$ & $0,99 * *$ \\
\hline & & $S A$ & $y=228,51-0,5322 x+0,00069179 x^{2}$ & $0,99 * *$ \\
\hline \multirow[t]{9}{*}{$\mathrm{EB} / \mathrm{N}$} & Milho & $\mathrm{NC}$ & $y=1,54-0,0074 x+0,000013 x^{2}$ & $0,99 * *$ \\
\hline & & NA & $y=1,54-0,0068 x+0,00000963 x^{2}$ & $0,99 * *$ \\
\hline & & SA & $y=1,54-0,00802 x+0,00001208 x^{2}$ & $0,99 * *$ \\
\hline & Arroz & NC & $y=1,11-0.0046 x+0,00000717 x^{2}$ & $0,99 * *$ \\
\hline & & NA & $y=1.11-0,00481 x+0,00000746 x^{2}$ & $0,99 * *$ \\
\hline & & SA & $y=1,11-0,00484 x+0,00000637 x^{2}$ & $0,99 * *$ \\
\hline & Trigo & NC & $y=2,05-0,00614 x+0,00001004 x^{2}$ & $0,99 * *$ \\
\hline & sarraceno & NA & $y=2,05-0,0106 x+0,00001629 x^{2}$ & $0.99 * *$ \\
\hline & & $S A$ & $y=2,05-0,01164 x+0,00001812 x^{2}$ & $0,99 * *$ \\
\hline
\end{tabular}

(1) NC, nitrato de cálcio; NA, nitrato de amônio; SA, sulfato de amônio.

(2) * $e^{* *}$, valores signiticativos a $5 \%$ e $1 \%$ de probabilidade, respectivamente. 

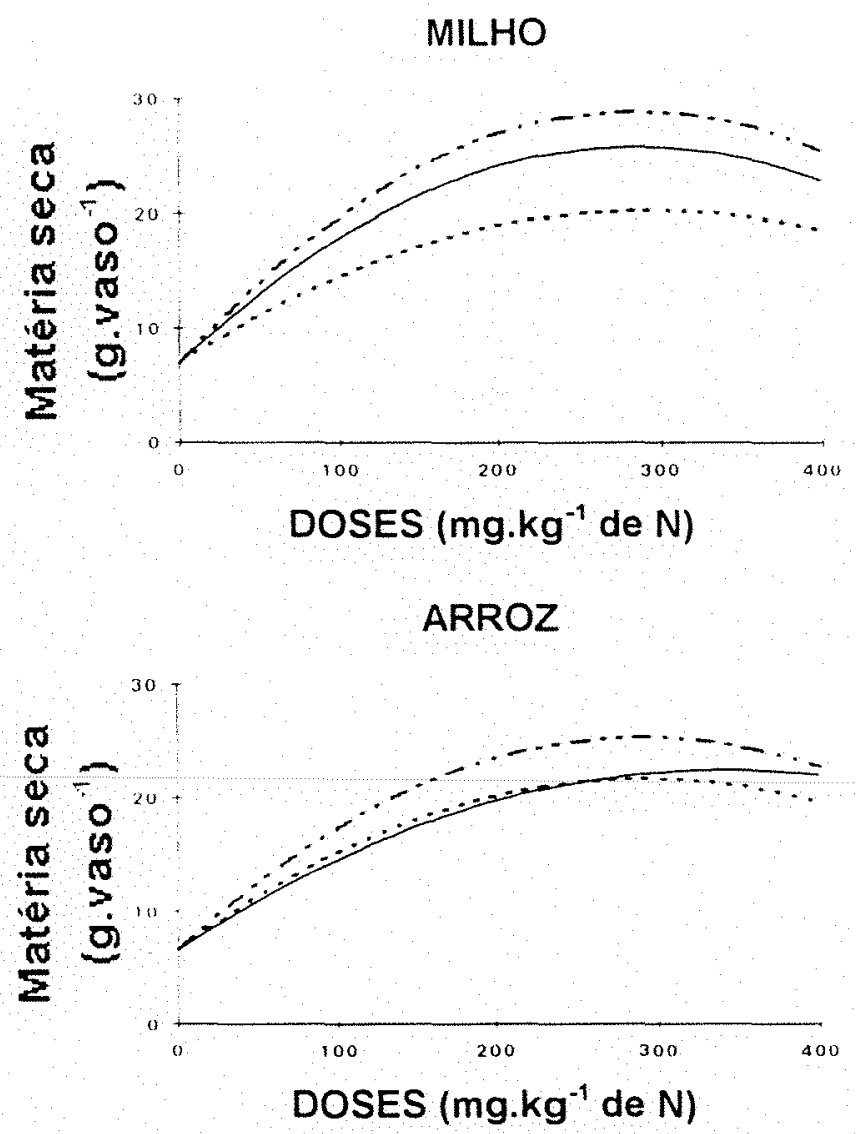

TRIGO SARRACENO

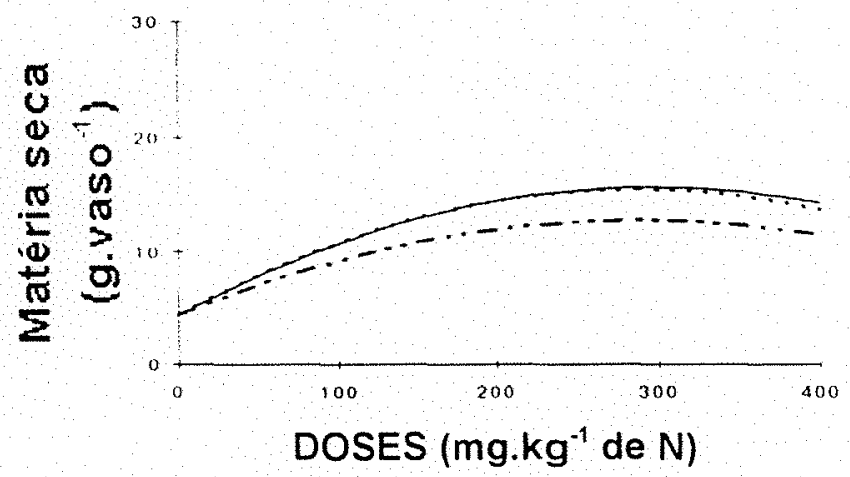

$-\cdots N C \quad-N A \quad--S A$

Figura 7. Produção de matéria seca pela parte aérea de plantas cultivadas em amostras de um Latossolo Roxo distrófico tratadas com diferentes doses de nitrogênio nas formas de nitrato de cálcio (NC), nitrato de amônio (NA) ou sulfato de amônio (SA) 


\subsubsection{Teor de Nitrogênio}

O efeito das fontes nitrogenadas sobre o teor de nitrogênio na parte aérea das plantas foi mal definido nas gramíneas, pois as diferenças entre as fontes exclusivamente nítrica e exclusivamente amoniacal não foram significativas (Tabela 20). Para o trigo sarraceno, contudo, a absorção foi preferencialmente amoniacal; como essa cultura produziu uma quantidade de matéria seca mais elevada quando adubada com o $\mathrm{N}$ na forma nítrica, é possível que o menor acúmulo de nitrogênio nas plantas tratadas com o NC se deva a um efeito de diluição.

As doses de nitrogênio aplicadas, conforme revelou o estudo de regressões, influenciaram significativamente o teor de nitrogênio na parte aérea das três espécies vegetais e para todos os fertilizantes nitrogenados, tendo-se obtido coeficientes de determinação elevados e altamente significativos (Tabela 19). A aplicação de doses crescentes de nitrogênio, como esperado, elevou o teor desse nutriente na planta em até quatro vezes (Figura 8). Nas gramíneas, as respostas obtidas com as diferentes fontes de $\mathrm{N}$ foram similares, mas no trigo sarraceno o SA foi superior ao NA e este, superior ao NC.

Dentre as culturas estudadas, o trigo sarraceno foi a espécie que mostrou os maiores teores de nitrogênio, superando o milho e quase sempre o arroz (Tabela 21); esse comportamento ocorreu independentemente da forma e da dose do nitrogênio aplicado. É possível que o trigo sarraceno possua atributos fisiológicos e bioquímicos que o capacitem a absorver e assimilar o nitrogênio em quantidades maiores que o milho e o arroz; segundo Pate $^{10}$, citado por HAYNES (1986b), plantas herbáceas acumulam consideráveis quantidades de nitrogênio solúvel na forma orgânica nos tecidos verdes.

\subsubsection{Somatório de Cátions}

De modo geral as plantas adubadas com NC tenderam a apresentar maior soma de cátions $\left(\mathrm{Ca}^{2+}+\mathrm{Mg}^{2+}+\mathrm{K}^{+}+\mathrm{Na}^{+}\right)$do que as que receberam NA, e estas, sempre

10 PATE, J.S. Transport and partitioning of nitrogenous solutes. Annu. Rev. Plant Physiol. 31:313-340, 1980. 
Tabela 20. Teor de nitrogênio na parte aérea de plantas cultivadas em amostras de Latossolo Roxo distrófico e tratadas com diferentes fontes e doses de nitrogênio (média de 3 repetições) ${ }^{(1)}$

\begin{tabular}{|c|c|c|c|c|}
\hline \multirow[b]{2}{*}{ Cultura } & \multirow[b]{2}{*}{ Fonte $^{(2)}$} & \multicolumn{3}{|c|}{ Dose de $\mathrm{N}\left(\mathrm{mg} \cdot \mathrm{kg}^{-1}\right)$} \\
\hline & & 0 & 200 & 400 \\
\hline & & $\ldots \cdots \cdots$ & $\mathrm{cmol} \mathrm{kg}^{-1}$ & \\
\hline \multirow[t]{3}{*}{ Milho } & $\mathrm{NC}$ & 49,37 & $145,26 \mathrm{a}$ & $149,26 \mathrm{~b}$ \\
\hline & $\mathrm{NA}$ & 49,37 & $126,94 \mathrm{a}$ & $203,24 \mathrm{a}$ \\
\hline & $S A$ & 49,37 & $128,27 \mathrm{a}$ & $197,74 \mathrm{ab}$ \\
\hline \multirow[t]{3}{*}{ Arroz } & $\mathrm{NC}$ & 68,97 & $155,76 \mathrm{a}$ & $202,57 \mathrm{ab}$ \\
\hline & NA & 68,97 & $176,25 \mathrm{a}$ & $189,74 \mathrm{~b}$ \\
\hline & $\mathrm{SA}$ & 68,97 & $159,76 \mathrm{a}$ & $240,22 \mathrm{a}$ \\
\hline Trigo & $\mathrm{NC}$ & 115,06 & $253,21 \mathrm{~b}$ & $291,20 \mathrm{c}$ \\
\hline \multirow[t]{2}{*}{ sarraceno } & $\mathrm{NA}$ & 115,06 & $324,35 \mathrm{a}$ & $356,83 \mathrm{~b}$ \\
\hline & SA & 115,06 & 333,67 a & $445,12 \mathrm{a}$ \\
\hline
\end{tabular}

(1) Dentro de cada cultura e de cada dose, médias acompanhadas da mesma letra não diferem entre si pelo teste de Tukey ao nível de $5 \%$.

(2) NC, nitrato de cálcio; NA, nitrato de amônio; SA, sulfato de amônio. 
MILHO
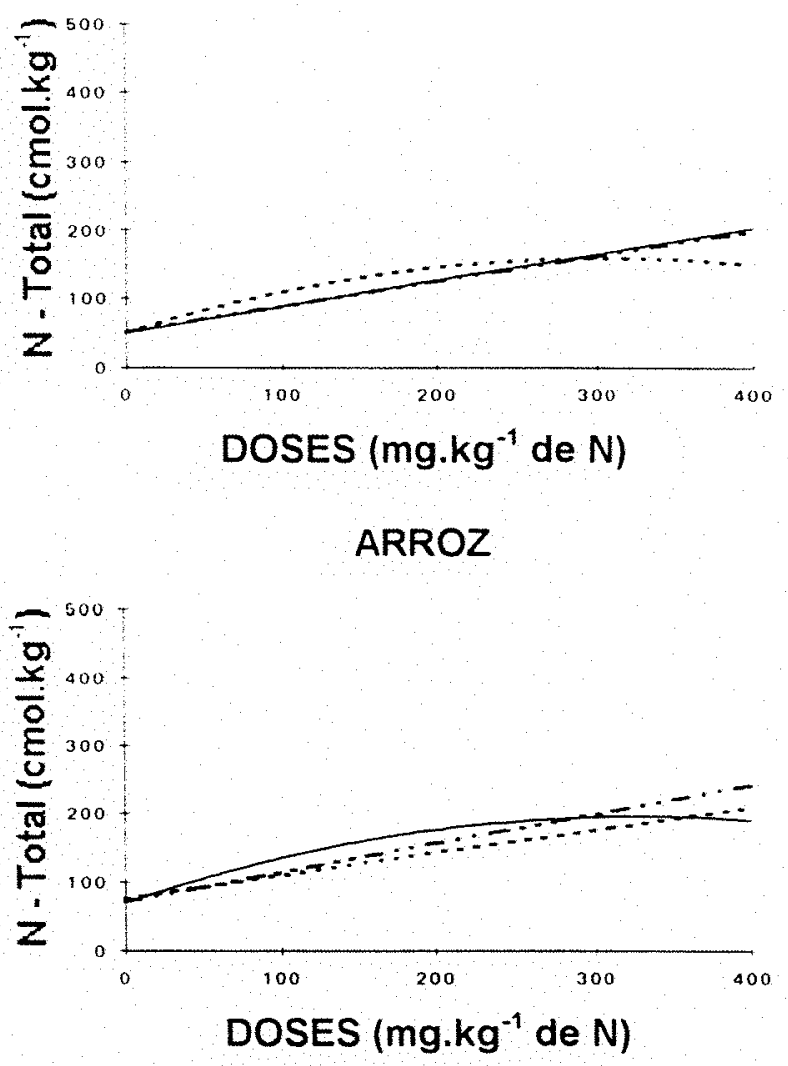

TRIGO SARRACENO

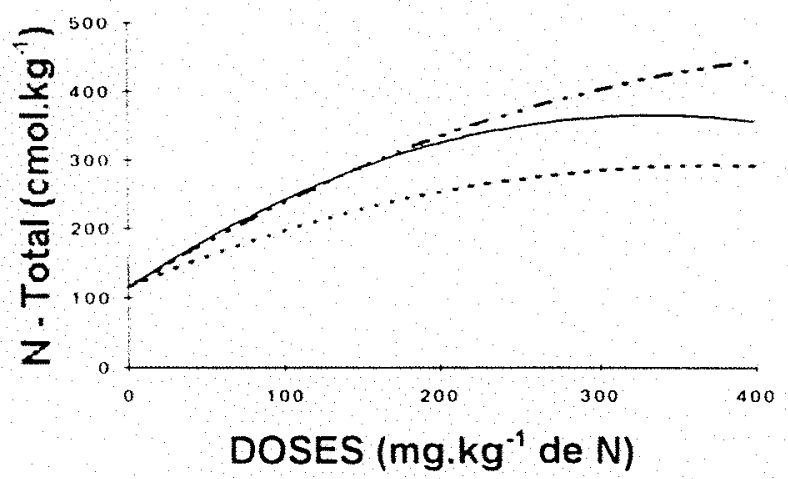

---- NC NA $\quad---S A$

Figura 8. Teores de nitrogênio na parte aérea de plantas cultivadas em amostras de um Latossolo Roxo distrófico tratadas com diferentes doses de nitrogênio nas formas de nitrato de cálcio (NC), nitrato de amônio (NA) ou sulfato de amônio (SA) 
Tabela 21. Efeito da cultivação no teor do nitrogênio total na parte aérea de plantas cultivadas em amostras de Latossolo Roxo distrófico tratadas com diferentes fontes e doses de nitrogênio(i)

\begin{tabular}{|c|c|c|c|}
\hline \multirow[b]{2}{*}{ Dose } & \multicolumn{3}{|c|}{ Culturas } \\
\hline & Milho & Arroz & Trigo sarraceno \\
\hline$\left(\mathrm{mg} \cdot \mathrm{kg}^{-1}\right)$ & & $\mathrm{cmol}_{\mathrm{c}} \cdot \mathrm{kg}^{-1}$ & \\
\hline \multirow[t]{2}{*}{0} & $49,37 \mathrm{~B}$ & $68,97 \mathrm{AB}$ & $115,06 \mathrm{~A}$ \\
\hline & \multicolumn{3}{|c|}{ Nitrato de cálcio } \\
\hline 200 & $145,26 \mathrm{~B}$ & $155,76 \mathrm{~B}$ & $253,21 \mathrm{~A}$ \\
\hline \multirow[t]{2}{*}{400} & $149,26 \mathrm{C}$ & $202,57 \mathrm{~B}$ & $291,20 \mathrm{~A}$ \\
\hline & \multicolumn{3}{|c|}{ Nitrato de amônio } \\
\hline 200 & $126,94 \mathrm{~B}$ & $176,25 \mathrm{~B}$ & $324,35 \mathrm{~A}$ \\
\hline \multirow[t]{2}{*}{400} & $203,24 \mathrm{~B}$ & $189,74 \mathrm{~B}$ & $356,83 \mathrm{~A}$ \\
\hline & \multicolumn{3}{|c|}{ Sulfato de amônio } \\
\hline 200 & $128,27 \mathrm{~B}$ & $159,76 \mathrm{~B}$ & $333,67 \mathrm{~A}$ \\
\hline 400 & $197,74 \mathrm{~B}$ & $240,22 \mathrm{~B}$ & $445,12 \mathrm{~A}$ \\
\hline
\end{tabular}

(1) Dentro de cada fonte e de cada dose, médias acompanhadas da mesma letra náo diferem entre si pelo teste de Tukey ao nivel de $5 \%$ de probabilidade. 
contiveram mais cátions que as tratadas com SA (Tabela 22). Levando-se em conta a necessidade de manutenção da eletroneutralidade na planta, esse efeito provavelmente se deva ao estímulo na absorção de cátions causado pela absorção do ânion nitrato pelas plantas adubadas com o NC, enquanto nas fertilizadas com SA pode ter ocorrido um efeito contrário. TATTINI et al.(1990) e CAO \& TIBBITTS (1993) também verificaram que plantas tratadas com nitrogênio na forma nítrica acumularam maior quantidade de cátions do que de ânions.

A maior diferença entre fontes ocorreu quando estas foram aplicadas na dose maior de $400 \mathrm{mg} \cdot \mathrm{kg}^{-1}$ de $\mathrm{N}$, na cultura do trigo sarraceno: o somatório de cátions passou dos $177,85 \mathrm{cmol}_{c} \cdot \mathrm{kg}^{-1}$ encontrados nas plantas adubadas com SA, para os $386,23 \mathrm{cmol} \cdot \mathrm{kg}^{-1}$ verificados nos vegetais tratados com NC, significando um aumento superior a duas vezes.

As equações polinomiais representando o efeito da dose de $\mathrm{N}$ no somatório de bases da planta foram significativas em todos os casos exceto quando o NA foi aplicado ao milho e o NC e NA foram fornecidos ao arroz (Tabela 19). $\mathrm{O}$ efeito das doses foi o de aumentar a quantidade de cátions quando se aplicou o NC e diminuí-la quando se forneceu o SA (Figura 9); esses efeitos foram mais acentuados no trigo sarraceno que nas gramíneas.

Comparando-se as culturas, verifica-se que os somatórios de cátions mais elevados foram encontrados no trigo sarraceno, em todas as combinações de fontes e doses de nitrogênio (Tabela 23). As quantidades de cátions contidas nas plantas de milho e arroz, por sua vez, não diferiram significativamente entre si exceto para a dose $200 \mathrm{mg} \cdot \mathrm{kg}^{-1} \mathrm{de}$ $\mathrm{N}$ aplicada na forma de NA. Calculando-se médias por cultura, constata-se que a quantidade de cátions acumulada no trigo sarraceno $\left(260,96 \mathrm{cmol}_{\mathrm{c}} \cdot \mathrm{kg}^{-1}\right)$ foi consideravelmente maior que a observada nas gramíneas milho $\left(106,90 \mathrm{cmol}_{\mathrm{c}} \cdot \mathrm{kg}^{-1}\right)$ e arroz $\left(112,86 \mathrm{cmol}_{\mathrm{c}} \cdot \mathrm{kg}^{-1}\right)$.

\subsubsection{Somatório de Ânions}

Houve nítida tendência de as plantas tratadas com SA mostrarem maiores valores de somatório de anions $\left(\mathrm{SO}_{4}^{2-}, \mathrm{H}_{2} \mathrm{PO}_{4}-\mathrm{e} \mathrm{Cl}^{-}\right)$que as plantas adubadas com $\mathrm{NC}$ (Tabela 24). Por ser intermediário aos demais fertilizantes estudados quanto à forma do 
Tabela 22. Somatório de cátions acumulado na parte aérea de plantas cultivadas em amostras de Latossolo Roxo distrófico e tratadas com diferentes fontes e doses de nitrogênio (médias de três repetições) $)^{(1)}$

\begin{tabular}{|c|c|c|c|c|}
\hline \multirow[b]{2}{*}{ Cultura } & \multirow[b]{2}{*}{ Fonte $^{(2)}$} & \multicolumn{3}{|c|}{ Dose de $\mathrm{N}\left(\mathrm{mg} \cdot \mathrm{kg}^{-1}\right)$} \\
\hline & & 0 & 200 & 400 \\
\hline & & & $\mathrm{cmol}_{\mathrm{c}} \cdot \mathrm{kg}^{-1}$ & \\
\hline \multirow[t]{3}{*}{ Milho } & $\mathrm{NC}$ & 110,58 & $114,11 \mathrm{a}$ & $131,93 \mathrm{a}$ \\
\hline & NA & 110,58 & $101,14 \mathrm{ab}$ & $107,19 \mathrm{~b}$ \\
\hline & $\mathrm{SA}$ & 110,58 & $88,66 \mathrm{~b}$ & $94,69 \mathrm{~b}$ \\
\hline \multirow[t]{3}{*}{ Arroz } & $\mathrm{NC}$ & 122,89 & $115,20 \mathrm{ab}$ & $124,22, \mathrm{a}$ \\
\hline & $\mathrm{NA}$ & 122,89 & $121,93 \mathrm{a}$ & $112,70 \mathrm{a}$ \\
\hline & SA & 122,89 & $101,67 \mathrm{~b}$ & $91,43 \mathrm{~b}$ \\
\hline Trigo & $\mathrm{NC}$ & 277,63 & $352,15 \mathrm{a}$ & $386,23 \mathrm{a}$ \\
\hline \multirow[t]{2}{*}{ sarraceno } & NA & 277,63 & $233,89 \mathrm{~b}$ & $199,28 \mathrm{~b}$ \\
\hline & SA & 277,63 & $199,69 c$ & $177,85 \mathrm{c}$ \\
\hline
\end{tabular}

(1) Dentro de cada cultura e de cada dose, médias acompanhadas da mesina letra nāo diferemn entre si pelo teste de Tukey ao nível de $5 \%$.

(2) NC, nitrato de cálcio; NA, nitrato de amônio; SA, sulfato de ainônio. 
MILHO

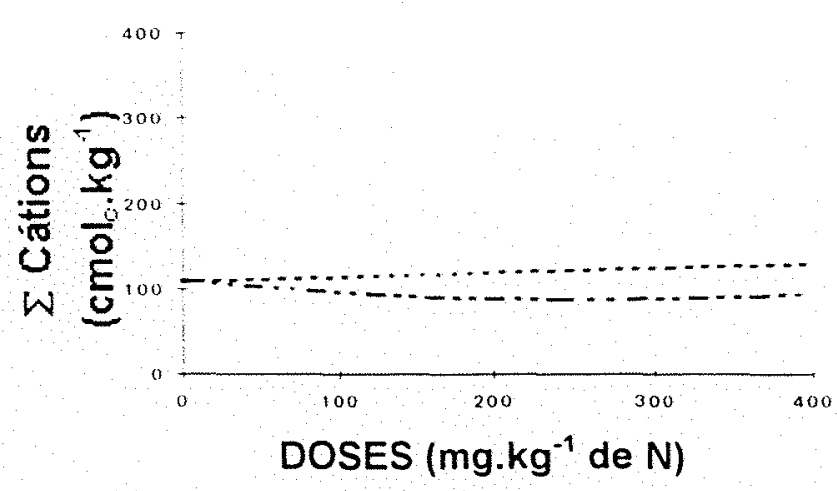

ARROZ
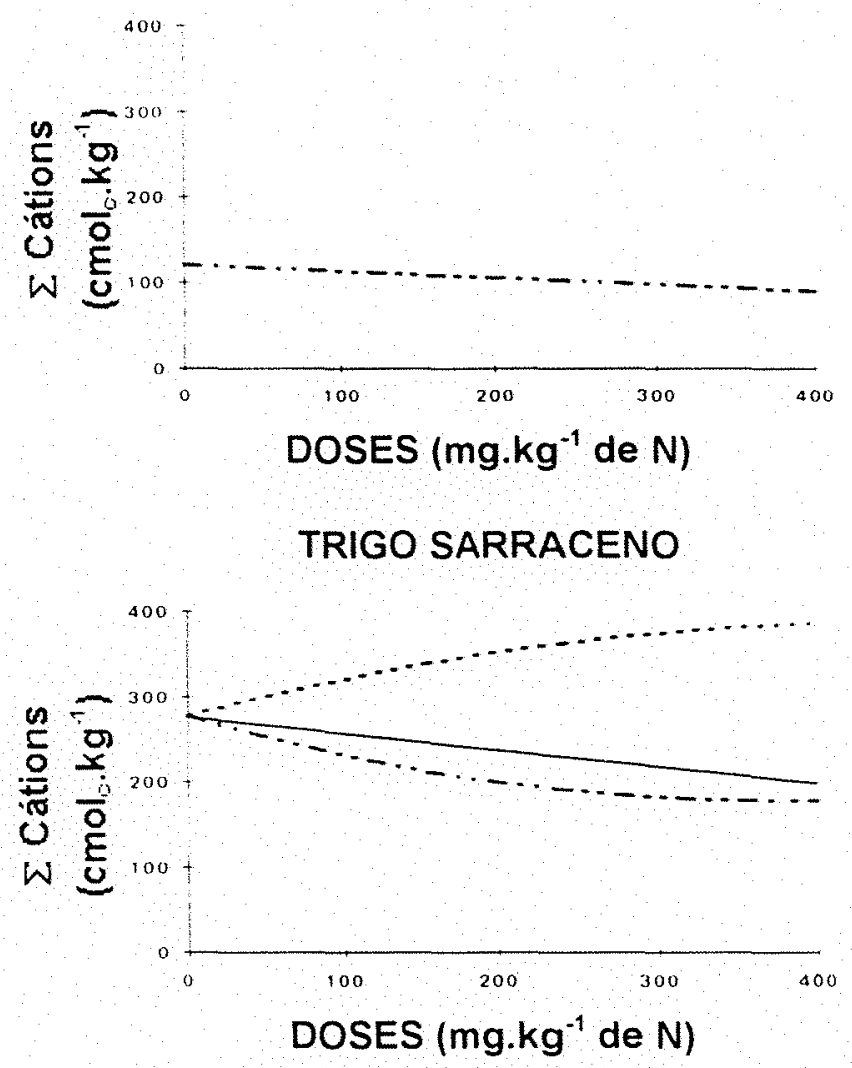

$----N C$

NA

SA

Figura 9. Somatório de cátions na parte aérea de plantas cultivadas em amostras de um Latossolo Roxo distrófico tratadas com diferentes doses de nitrogênio nas formas de nitrato de cálcio (NC), nitrato de amônio (NA) ou sulfato de amônio (SA) 
Tabela 23. Efeito da cultivação no somatório de cátions pela parte aérea de plantas cultivadas em amostras de Latossolo Roxo distrófico e tratadas com diferentes fontes e doses de nitrogenio ${ }^{(1)}$

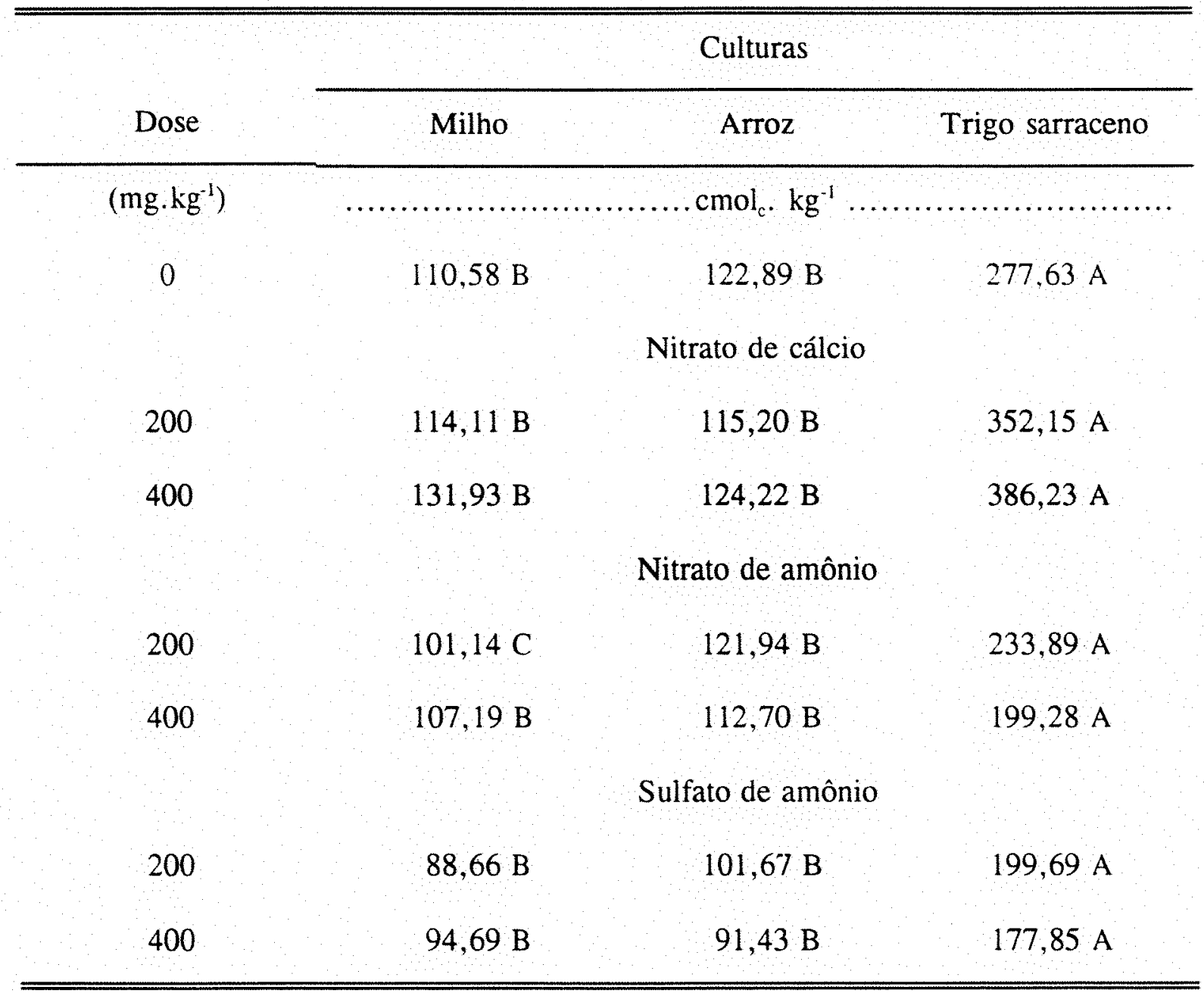

(1) Dentro de cada fonte e de cada dose, inédias acompanhadas da inesma letra não difereın entre si pelo teste de Tukey ao nível de $5 \%$ de probabilidade. 
Tabela 24. Somatório de ânions acumulados na parte aérea das plantas cultivadas em amostras de Latossolo Roxo distrófico e tratadas com diferentes fontes e doses de nitrogênio (médias de três repetiçōes) ${ }^{(1)}$

\begin{tabular}{|c|c|c|c|c|}
\hline \multirow[b]{2}{*}{ Cultura } & \multirow[b]{2}{*}{ Fonte ${ }^{(2)}$} & \multicolumn{3}{|c|}{ Dose de $\mathrm{N}\left(\mathrm{mg} \cdot \mathrm{kg}^{-1}\right)$} \\
\hline & & 0 & 200 & 400 \\
\hline & & & $\mathrm{cmol}_{\mathrm{c}} \cdot \mathrm{kg}^{-1}$ & \\
\hline \multirow[t]{3}{*}{ Milho } & $\mathrm{NC}$ & 35,18 & $29,35 \mathrm{~b}$ & $32,35 \mathrm{~b}$ \\
\hline & NA & 35,18 & $32,99 a$ & $34,53 \mathrm{~b}$ \\
\hline & $\mathrm{SA}$ & 35,18 & $34,64 \mathrm{a}$ & $43,10 a$ \\
\hline \multirow[t]{3}{*}{ Arroz } & NC & 46,33 & $41,38 \mathrm{ab}$ & $39,37 \mathrm{~b}$ \\
\hline & NA & 46,33 & $43,69 \mathrm{a}$ & $41,45 \mathrm{~b}$ \\
\hline & $\mathrm{SA}$ & 46,33 & $39,01 \mathrm{~b}$ & $45,95 \mathrm{a}$ \\
\hline Trigo & $\mathrm{NC}$ & 49,12 & $42,72 \mathrm{c}$ & $40,73 \mathrm{~b}$ \\
\hline \multirow[t]{2}{*}{ sarraceno } & NA & 49,12 & $46,66 \mathrm{~b}$ & $49,71 \mathrm{a}$ \\
\hline & $\mathrm{SA}$ & 49,12 & $49,95 \mathrm{a}$ & $51,53 a$ \\
\hline
\end{tabular}

(1) Dentro de cada cultura e de cada dose, médias acompanhadas da mesma letra não diferem entre si pelo teste de Tukey ao nível de $5 \%$.

(2) NC, nitrato de cálcio; NA, nitrato de amônio; SA, sulfato de amônio. 
nitrogênio, o NA ora assemelhou-se ao NC, ora assemelhou-se ao SA, e ora situou-se entre essas fontes. TATTINI et al.(1990) e CAO \& TIBBITTS (1993) também verificaram que plantas tratadas com nitrogênio na forma amoniacal acumularam maior quantidade de ânions do que de cátions.

Esses resultados mostram que o íon amônio, ao contrário do nitrato, estimula a absorção de ânions pela planta e inibe a assimilação de cátions; segundo HAYNES \& GOH (1978) esse efeito deve-se à competição entre os cátions e o íon amônio ou entre esses e os ions $\mathrm{H}^{+}$excretados pela planta durante a absorção do $\mathrm{NH}_{4}^{+}$. JARVIS \& ROBSON (1983b) verificaram que a concentração total de ânions em plantas de azevém, trevo branco e trevo subterrâneo foi sempre menor quando estas eram adubadas com nitrato do que com amônio, e que disso resultava menor acidez do solo.

As doses de nitrogênio, conforme revelou o estudo de regressōes, influenciaram significativamente o somatório de ânions da planta em todas as fontes e culturas exceto quando o NA foi aplicado nas plantas de milho (Tabela 19). Ao contrário do que ocorreu com o somatório de cátions, o efeito das doses foi o de diminuir o somatório de ânions quando se aplicou o NC e de aumentá-lo quando se forneceu o SA (Figura 10); esses efeitos, que não foram muito pronunciados, são reflexos da necessidade de manutenção da eletroneutralidade da planta quando há absorção desequilibrada de amônio ou nitrato.

Quanto ao efeito da cultivação, os valores de somatório de ânions encontrados no trigo sarraceno foram maiores que os verificados no milho em todas as doses e fontes, e maiores que os observados no arroz em todas as doses mas somente para as fontes NA e SA (Tabela 25).

\subsubsection{Excesso de Bases (EB)}

A fonte nítrica quase sempre resultou valores de EB ( $\Sigma$ cátions - $\Sigma$ ânions) superiores aos observados com a amoniacal (Tabela 26); isso significa que a planta adubada com nitrato absorveu mais intensamente cátions que ânions, fato que, conforme apontam HAYNES \& GOH (1978), BEKELE et al. (1983) e WALLACE (1994), se deve à 
MILHO
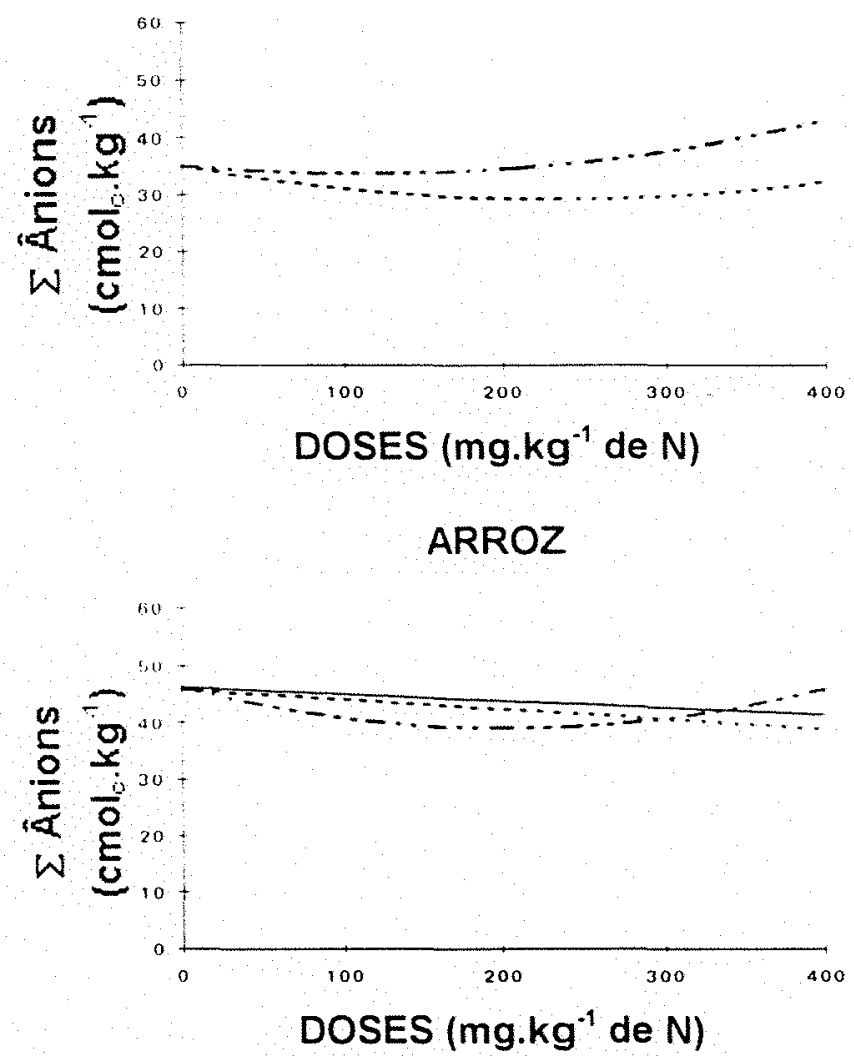

TRIGO SARRACENO

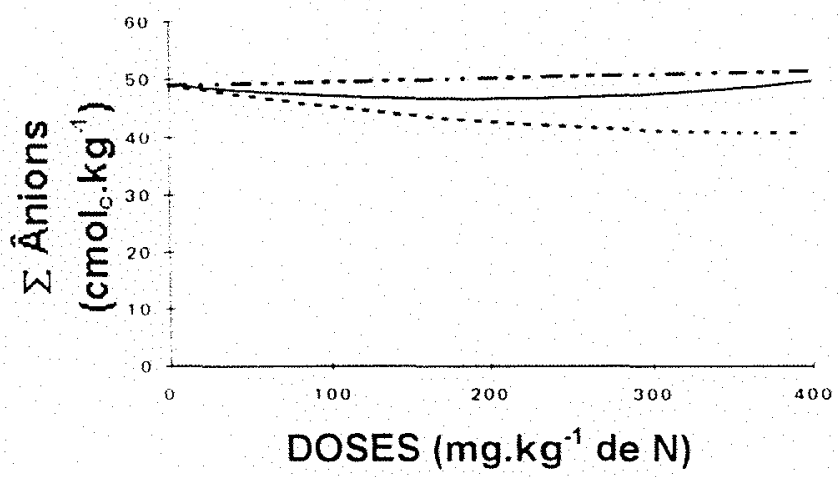

---- NC NA $---S A$

Figura 10. Somatório de ânions na parte aérea de plantas cultivadas em amostras de um Latossolo Roxo distrófico tratadas com diferentes doses de nitrogênio nas formas de nitrato de cálcio (NC), nitrato de amônio (NA) ou sulfato de amônio (SA) 
Tabela 25. Efeito da cultivação no somatório de ânions da parte aérea de plantas cultivadas em amostras de Latossolo Roxo distrófico e tratadas com diferentes fontes e doses de nitrogênio ${ }^{(1)}$

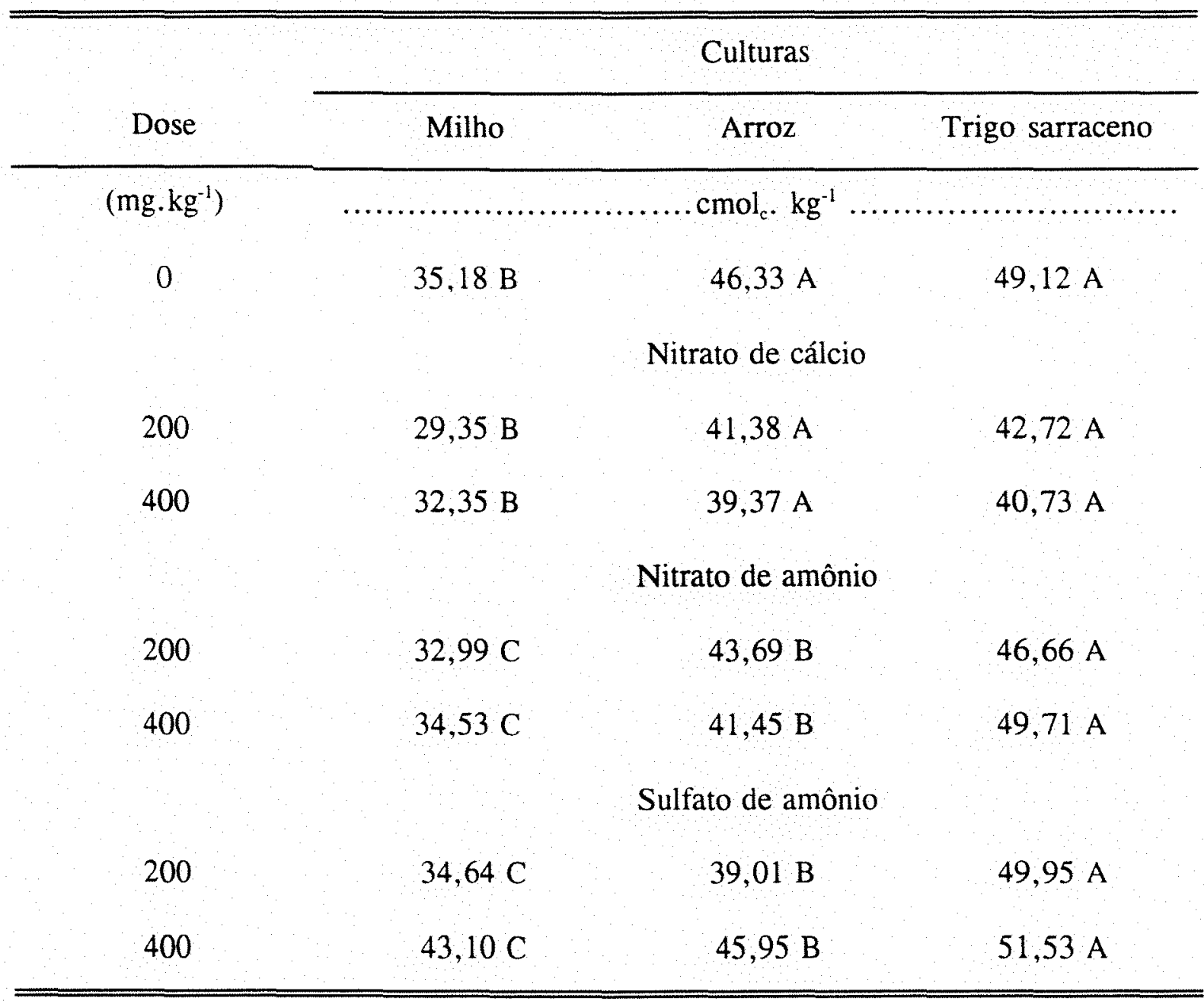

(1) Dentro de cada fonte e de cada dose, médias acompanhadas da mesma letra não diferem entre si pelo teste de Tukey ao nível de $5 \%$ de probabilidade. 
Tabela 26. Excesso de bases na parte aérea de plantas cultivadas em amostras de Latossolo Roxo distrófico e tratadas com diferentes fontes e doses de nitrogênio (média de 3 repetiçōes) ${ }^{(1)}$

\begin{tabular}{|c|c|c|c|c|}
\hline \multirow[b]{2}{*}{ Cultura } & \multirow[b]{2}{*}{ Fonte $^{(2)}$} & \multicolumn{3}{|c|}{ Dose de $\mathrm{N}\left(\mathrm{mg} \cdot \mathrm{kg}^{-1}\right)$} \\
\hline & & 0 & 200 & 400 \\
\hline & & (1) & $\mathrm{cmol} . \mathrm{kg}^{-1}$ & \\
\hline \multirow[t]{3}{*}{ Milho } & $\mathrm{NC}$ & 75,40 & $84,75 \mathrm{a}$ & $99,58 \mathrm{a}$ \\
\hline & $\mathrm{NA}$ & 75,40 & $68,15 \mathrm{ab}$ & $72,66 \mathrm{~b}$ \\
\hline & $\mathrm{SA}$ & 75,40 & $54,02 \mathrm{~b}$ & $51,58 \mathrm{c}$ \\
\hline \multirow[t]{3}{*}{ Arroz } & $\mathrm{NC}$ & 76,56 & $73,83 \mathrm{a}$ & $84,84 a$ \\
\hline & $\mathrm{NA}$ & 76,56 & $78,25 \mathrm{a}$ & $71,26 \mathrm{a}$ \\
\hline & $\mathrm{SA}$ & 76,56 & $62,66 \mathrm{a}$ & $45,48 b$ \\
\hline Trigo & $\mathrm{NC}$ & 228,51 & $309,43 \mathrm{a}$ & $345,50 \mathrm{a}$ \\
\hline \multirow[t]{2}{*}{ sarraceno } & NA & 228,51 & $187,23 b$ & $149,58 b$ \\
\hline & $\mathrm{SA}$ & 228,51 & $149,74 \mathrm{c}$ & $126,31 \mathrm{c}$ \\
\hline
\end{tabular}

(1) Dentro de cada cultura e de cada dose, médias acompanhadas da mesma letra não diferem entre si pelo teste de Tukey ao nível de $5 \%$.

(2) NC, nitrato de cálcio; NA, nitrato de amônio; SA, sulfato de amônio. 
competição entre os ânions e o próprio íon nitrato ou entre aqueles e as hidroxilas extrusadas pelas raízes durante a absorção do nitrato.

O EB das plantas, embora tenha sido menor quando se utilizou a fonte amoniacal, foi sempre positivo, indicando que a quantidade de cátions nutrientes foi maior que a de ânions; de fato, segundo NYE (1981), dentro da planta haverá sempre um excesso de cátions livres sobre os ânions.

Segundo KIRKBY (1968), plantas supridas predominantemente com o íon amônio tem seu crescimento reduzido e apresentam menores teores de $\mathrm{Ca}, \mathrm{Mg}$ e $\mathrm{K}$, embora as concentraçōes de $\mathrm{P} \mathrm{e} \mathrm{Cl}$ sejam maiores que as das plantas cujo nitrogênio foi absorvido na forma de nitrato. Para HAYNES (1986b), a inibição da absorção de cátions, provocada pela nutrição amoniacal, é atribuída à competição iônica durante a absorção de algum cátion por íons $\mathrm{NH}_{4}{ }^{+}$ou pela extrusão de íons $\mathrm{H}^{+}$durante a absorção ativa do amônio.

As regressões polinomiais mostraram que na cultura do milho o efeito das doses de nitrogênio no EB foi significativo somente quando este foi aplicado como NC ou SA (Tabela 19); no arroz, houve efeito de doses somente para o SA, enquanto no trigo sarraceno o efeito ocorreu para todas as fontes nitrogenadas. Nas culturas de milho e trigo sarraceno, observa-se que o aumento da dose de $\mathrm{N}$ na forma de $\mathrm{NC}$ fez elevar o $\mathrm{EB}$, principalmente no trigo sarraceno, enquanto para as demais formas houve redução do EB (Figura 11). Esses resultados confirmam observações de outros autores, de que a aplicação de fertilizantes nítricos tende a elevar o EB da planta, enquanto o fornecimento de adubos amoniacais tende a diminuí-lo (JARVIS \& ROBSON, 1983a e 1983b; e GIJSMAN, 1990b e 1990c).

As comparações entre culturas mostram que o trigo sarraceno apresentou um EB consideravelmente maior que as gramíneas, mesmo quando não foi adubado com nitrogênio (Tabela 27). Como o fornecimento de nitrogênio na forma de nitrato estimula a absorção de bases, as maiores diferenças entre culturas ocorreram quando se aplicou o $\mathrm{NC}$; quando este fertilizante foi aplicado na dose $200 \mathrm{mg} \cdot \mathrm{kg}^{-1}$ de $\mathrm{N}$, o EB aumentou dos 
MILHO

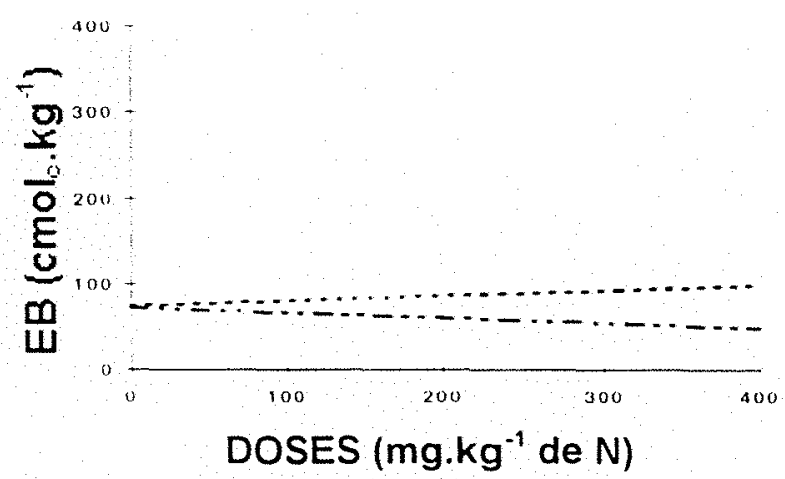

81

ARROZ

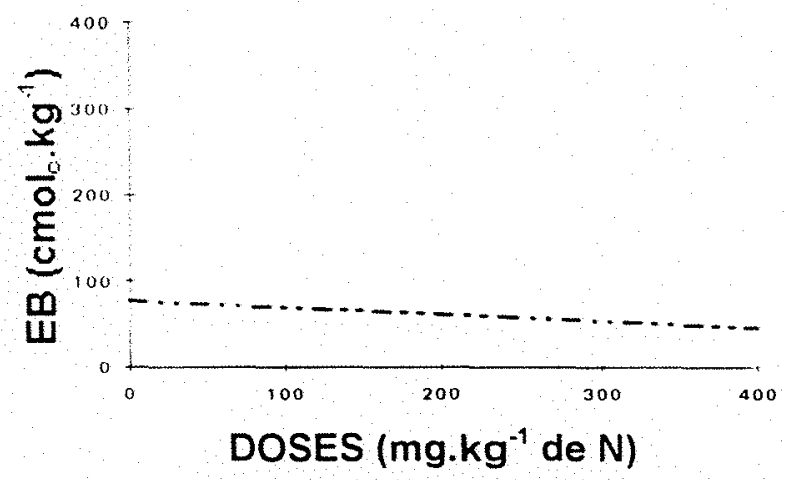

TRIGO SARRACENO

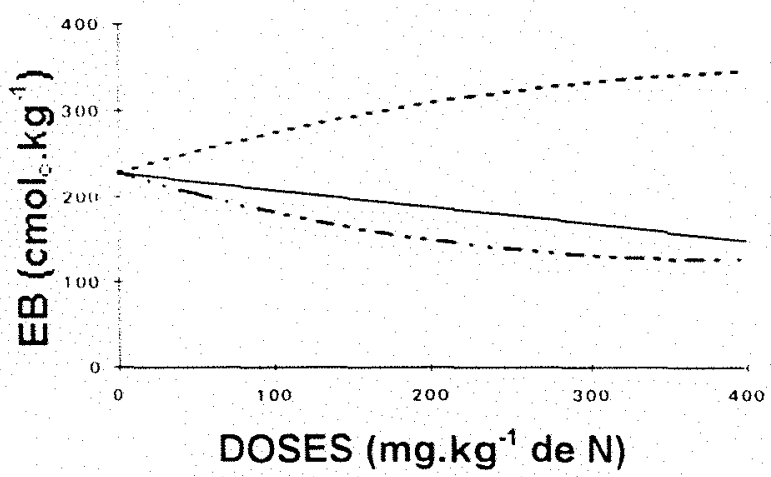

$----N C$

NA

--- SA

Figura 11. Excesso de bases (EB) na parte aérea de plantas cultivadas em amostras de um Latossolo Roxo distrófico tratadas com diferentes doses de nitrogênio nas formas de nitrato de cálcio (NC), nitrato de amônio (NA) ou sulfato de amônio (SA) 
Tabela 27. Efeito da cultivação no excesso de bases na parte aérea de plantas cultivadas em amostras de Latossolo Roxo distrófico e tratadas com diferentes fontes e doses de nitrogênio ${ }^{(1)}$

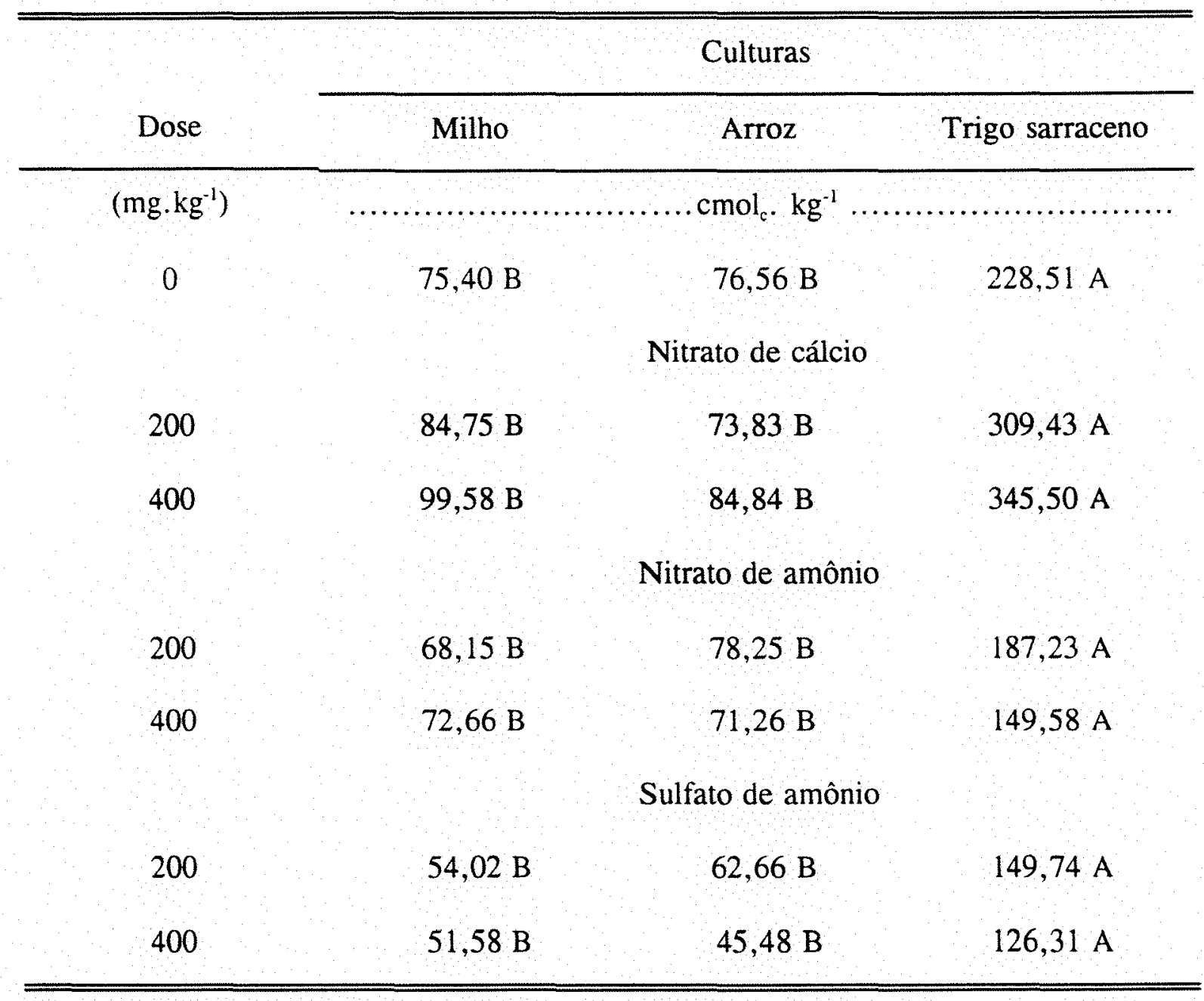

(1) Dentro de cada fonte e de cada dose, médias acompanhadas da mesma letra não diferem entre si pelo teste de Tukey ao nível de $5 \%$ de probabilidade. 
$84,75 \mathrm{cmol}_{\mathrm{c}} \cdot \mathrm{kg}^{-1}$ encontrados nas plantas de milho, ou dos $73,83 \mathrm{cmol}_{\mathrm{c}} \cdot \mathrm{kg}^{-1}$ constatados no arroz, para os $309,43 \mathrm{cmol}_{\mathrm{c}} \cdot \mathrm{kg}^{-1}$ observados no trigo sarraceno, representando aumentos de $265 \%$ e $319 \%$, respectivamente. Na média de todas as fontes e doses, as gramíneas apresentaram valores de EB de 72,31 e $70,41 \mathrm{cmol}_{\mathrm{c}} \cdot \mathrm{kg}^{-1}$, enquanto no trigo sarraceno esse índice foi de $213,76 \mathrm{cmol}_{\mathrm{c}} \cdot \mathrm{kg}^{-1}$. Esses resultados comprovam a elevada tendência de as plantas dicotiledôneas em acumular maior quantidade de cátions que as monocotiledôneas, conforme também observaram PIERRE \& BANWART (1973), RAIJ et al. (1988) e GERENDAS \& SATTELMACHER (1990).

\subsubsection{Relação Excesso de Bases/Nitrogênio (EB/N)}

Em quase todas as combinações de doses e culturas, as plantas adubadas com nitrogènio na forma de nitrato mostraram relações $\mathrm{EB} / \mathrm{N}$ maiores que as tratadas com a forma amoniacal (Tabela 28). Essa diferença ocorreu porque com o emprego da forma nítrica, o EB da parte aérea foi maior do que com a amoniacal (Tabela 26), ao mesmo tempo em que o teor de nitrogênio foi menor (Tabela 20). $O$ efeito foi mais acentuado na dicotiledônea que nas gramíneas, e também mais evidente na dose maior de nitrogênio: quando o trigo sarraceno foi adubado com $400 \mathrm{mg} \cdot \mathrm{kg}^{-1}$ de $\mathrm{N}$, a relação $\mathrm{EB} / \mathrm{N}$ foi 4,1 vezes maior quando se aplicou o $\mathrm{NC}(\mathrm{EB} / \mathrm{N}=1,20)$ do que quando se utilizou o $\mathrm{SA}(\mathrm{EB} / \mathrm{N}=$ $0,29)$. Em outras palavras, esses resultados mostram que a planta acumulou mais cátions por unidade de $\mathrm{N}$ absorvido quando suprida com nitrato do que quando adubada com amônio, principalmente para a dicotiledônea.

$O$ efeito das doses de nitrogênio na relação $\mathrm{EB} / \mathrm{N}$ foi altamente significativo em todas as fontes e culturas (Tabela 19). As maiores relações $\mathrm{EB} / \mathrm{N}$ ocorreram quando não se adicionou nitrogênio (Figura 12), principalmente porque nessas condições o teor desse nutriente no vegetal foi baixo (Tabela 21). Para todas as fontes e culturas, a relação EB/N diminuiu de forma quadrática com o aumento da quantidade aplicada de nitrogênio (Figura 12); isso ocorreu porque os aumentos da quantidade de nitrogênio na planta (Tabela 21), causados pelas aplicações de nitrogênio, não foram acompanhados de iguais aumentos no excesso de bases (Tabela 27). Nas três culturas, quando se aplicou nitrato os decréscimos 
Tabela 28. Relação excesso de bases/N na parte aérea de plantas cultivadas em amostras de Latossolo Roxo distrófico e tratadas com diferentes fontes e doses de nitrogênio (média de 3 repetições) ${ }^{(1)}$

\begin{tabular}{|c|c|c|c|c|}
\hline \multirow[b]{2}{*}{ Cultura } & \multirow[b]{2}{*}{ Fonte $^{(2)}$} & \multicolumn{3}{|c|}{ Dose de $\mathrm{N}\left(\mathrm{mg} \cdot \mathrm{kg}^{-1}\right)$} \\
\hline & & 0 & 200 & 400 \\
\hline \multirow[t]{3}{*}{ Milho } & $\mathrm{NC}$ & 1,54 & 0,58 a & $0,67 \mathrm{a}$ \\
\hline & $\mathrm{NA}$ & 1,54 & $0,56 \mathrm{a}$ & $0,36 \mathrm{~b}$ \\
\hline & $\mathrm{SA}$ & 1,54 & $0,42 \mathrm{~b}$ & $0,27 b$ \\
\hline \multirow[t]{3}{*}{ Arroz } & $\mathrm{NC}$ & 1,11 & $0,48 \mathrm{a}$ & $0,42 \mathrm{a}$ \\
\hline & NA & 1,11 & $0,45 \mathrm{a}$ & $0,38 \mathrm{a}$ \\
\hline & $\mathrm{SA}$ & 1,11 & $0,40 \mathrm{a}$ & $0,19 b$ \\
\hline Trigo & $\mathrm{NC}$ & 2,05 & $1,22 \mathrm{a}$ & $1,20 a$ \\
\hline \multirow[t]{2}{*}{ sarraceno } & NA & 2,05 & $0,58 \mathrm{~b}$ & $0,42 \mathrm{~b}$ \\
\hline & SA & 2,05 & $0,45 \mathrm{c}$ & $0,29 \cdot \mathrm{c}$ \\
\hline
\end{tabular}

(1) Dentro de cada cultura e de cada dose, médias acompanhadas da mesma letra não diferem entre si pelo teste de Tukey ao nível de $5 \%$.

(2) NC, nitrato de cálcio; NA, nitrato de amônio; SA, sulfato de amônio. 
MILHO
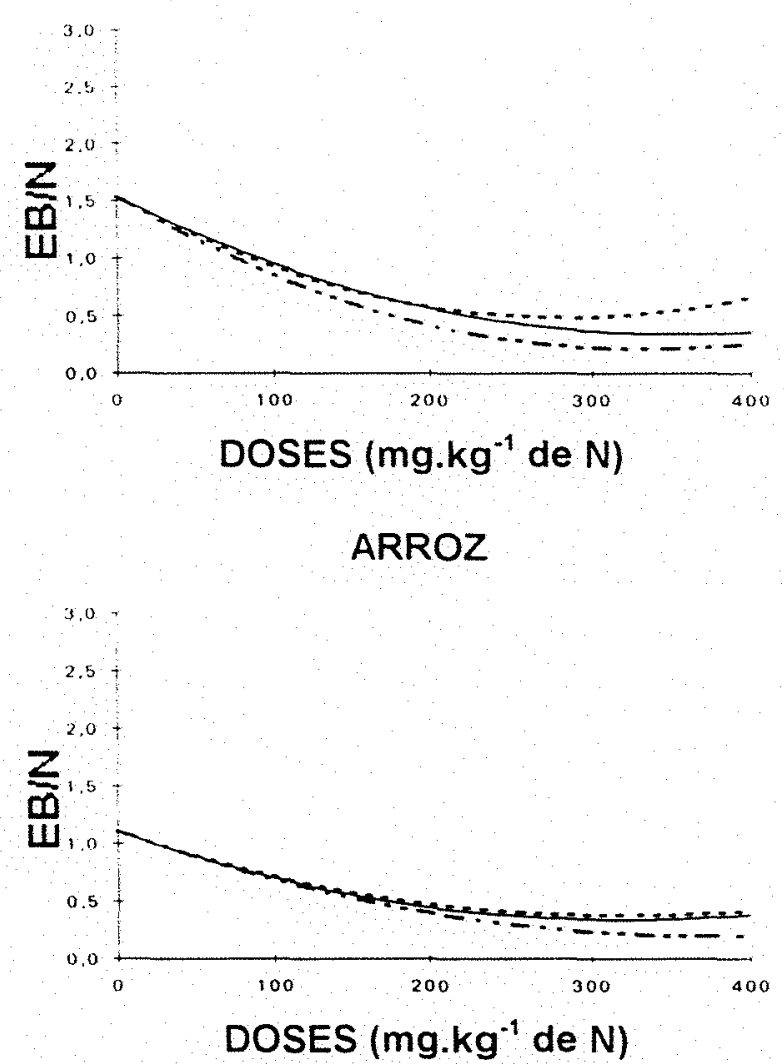

TRIGO SARRACENO

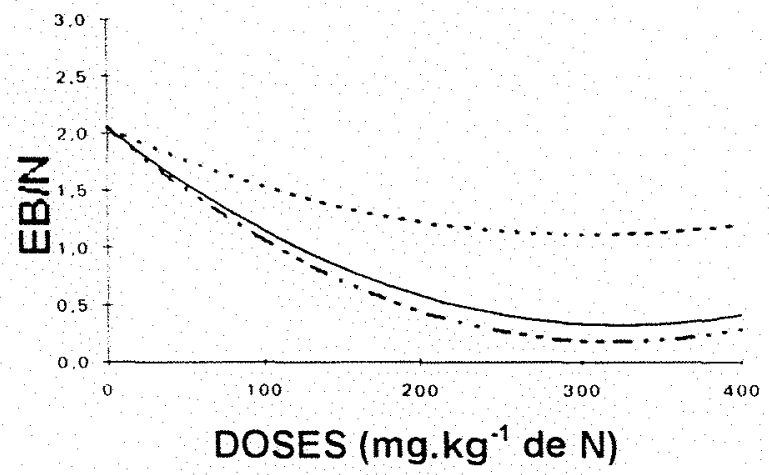

$----N C$

NA

$----S A$

Figura 12. Relação excesso de bases/nitrogênio $(\mathrm{EB} / \mathrm{N})$ na parte aérea de plantas cultivadas em amostras de um Latossolo Roxo distrófico tratadas com diferentes doses de nitrogênio nas formas de nitrato de cálcio (NC), nitrato de amônio (NA) ou sulfato de amônio (SA) 
da relação $\mathrm{EB} / \mathrm{N}$ com o aumento da dose de $\mathrm{N}$ foram menores do que quando se forneceu o amônio, tendo essa diferença sido mais acentuada para a dicotiledônea do que para as monocotiledôneas.

Comparando-se as culturas, verifica-se que na ausência de nitrogênio aplicado, assim como na presença de $\mathrm{NC}$, o trigo sarraceno mostrou relações $\mathrm{EB} / \mathrm{N}$ superiores às das gramíneas em até 2,9 vezes, mas quando a forma amoniacal foi aplicada, a relação no trigo sarraceno caiu apreciavelmente ao nível das gramíneas (Tabela 29). Essa queda foi causada tanto pela diminuição do excesso de bases (Tabela 27), uma vez que o amônio estimula a absorção de ânions e reprime a de cátions, quanto pelo aumento do teor de nitrogênio na planta (Tabela 21).

Quando o nitrogênio foi fornecido na forma nítrica, as plantas de milho e arroz apresentaram relações $\mathrm{EB} / \mathrm{N}$ menores que 1 e um efeito alcalinizante sobre o solo, enquanto as de trigo sarraceno mostraram relações maiores que 1 e um efeito acidificante; esses resultados concordam com os de PIERRE et al. (1970) e de PIERRE \& BANWART (1973); contudo, quando o $\mathrm{N}$ foi aplicado na forma nítrica-amoniacal ou amoniacal, as relações $\mathrm{EB} / \mathrm{N}$ foram sempre menores que 1 , independentemente do padrāo de absorção de cada espécie, e o efeito das plantas foi sempre acidificante.

\subsection{Correlações entre o pH do Solo e os Parâmetros de Planta}

Dentre as correlações mais importantes estão aquelas envolvendo o pH em $\mathrm{CaCl}_{2}$ e em $\mathrm{H}_{2} \mathrm{O}$ do solo e os seguintes parâmetros de planta: somatório de cátions, somatório de ânions, EB e relação EB/N. A Tabela 30 apresenta os coeficientes de correlação linear encontrados para essas correlações.

A discussão a seguir dará ênfase às culturas de milho e trigo sarraceno e aos fertilizantes NC e SA, por terem apresentado comportamentos mais contrastantes; a cultura do arroz, provavelmente pelo fato de ser uma gramínea, apresentou correlações semelhantes às do milho. De maneira geral, as correlações obtidas com o pH em água foram mais significativas que as verificadas com o $\mathrm{pH}$ em $\mathrm{CaCl}_{2}$. 
Tabela 29. Efeito da cultivação na relação excesso de bases/ $\mathrm{N}$ da parte aérea de plantas cultivadas em amostras de Latossolo Roxo distrófico e tratadas com diferentes fontes e doses de nitrogênio ${ }^{(1)}$

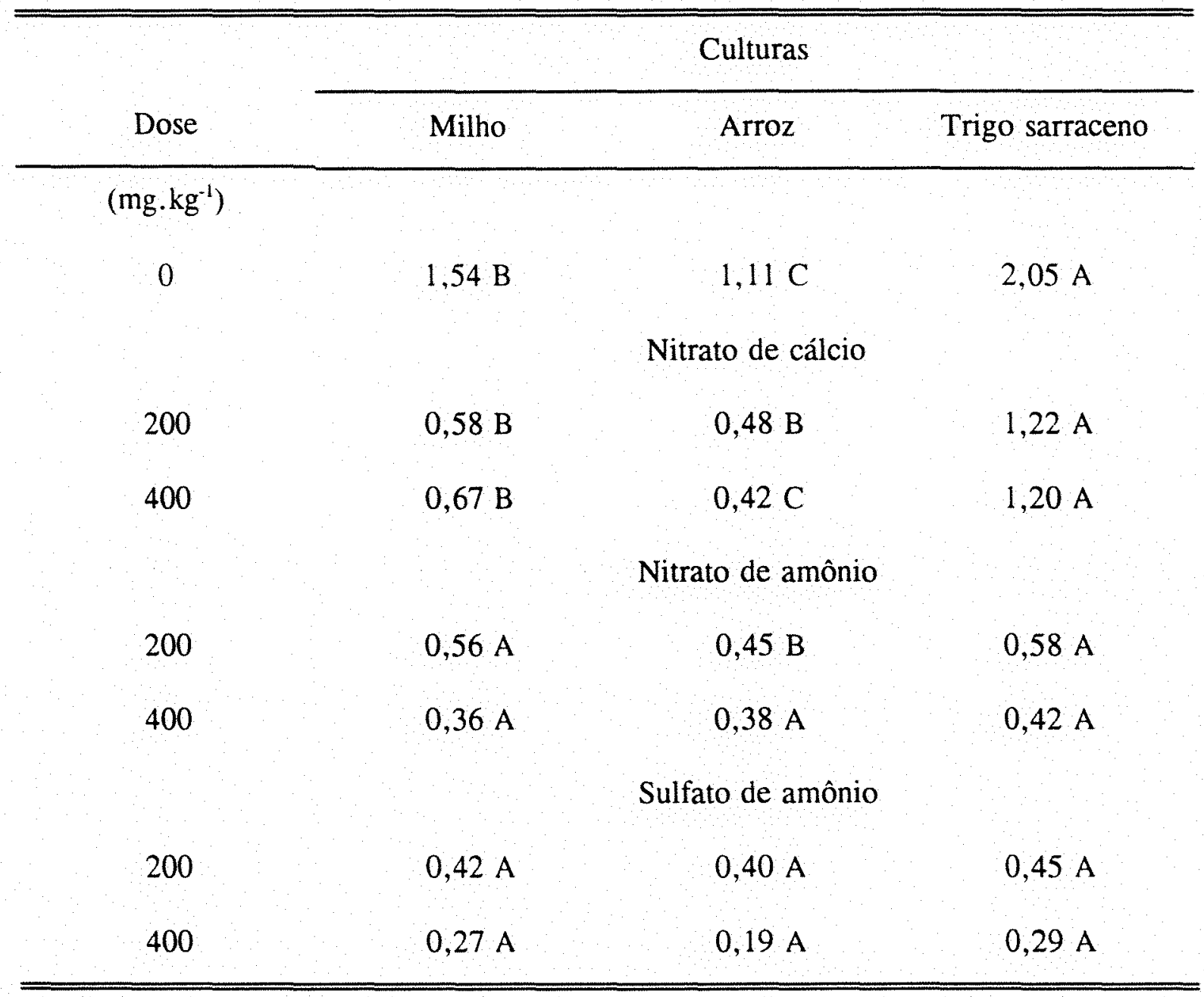

(1) Dentro de cada fonte e de cada dose, médias acompanhadas da mesma letra não diferem entre si pelo teste de Tukey ao nível de $5 \%$ de probabilidade. 


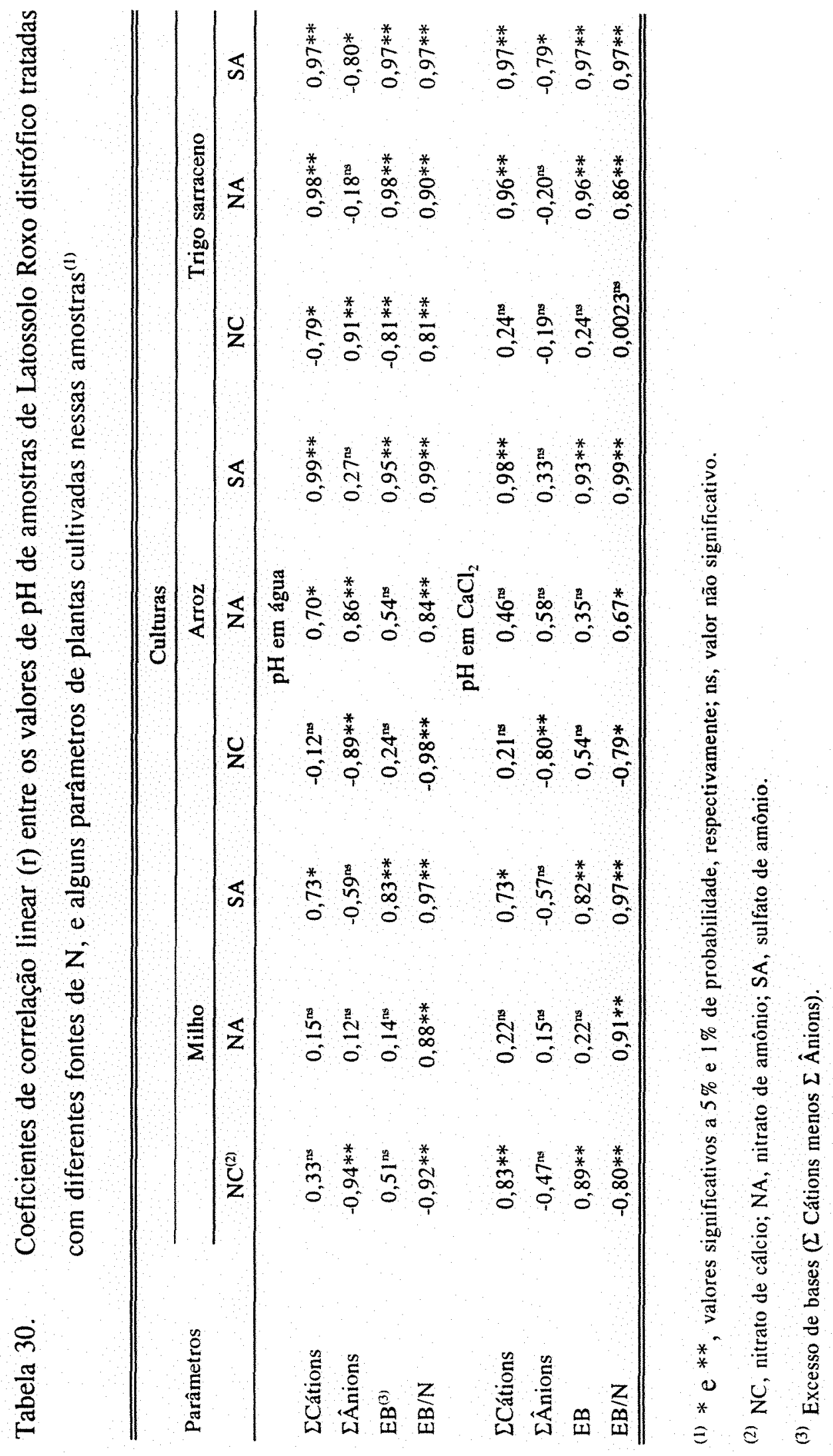




\section{a) Somatório de Cátions}

Na cultura de milho adubada com NC, o somatório de cátions correlacionou-se positivamente com o $\mathrm{pH} \mathrm{em} \mathrm{CaCl}\left(\mathrm{r}=0,83^{* *}\right)$; esse resultado ocorreu porque as gramíneas, quando adubadas com nitrato, causam elevação do $\mathrm{pH}$ do solo e, ao mesmo tempo, acumulam maior quantidade de cátions nutrientes para manter o equilíbrio iônico interno. Na cultura do trigo sarraceno, ao contrário, o somatório de cátions correlacionou-se negativamente com o pH em água $\left(r=-0,79^{*}\right)$, visto que o trigo sarraceno, independentemente da forma de $\mathrm{N}$ fornecida, absorve maior proporção de cátions do que de ânions; como consequência, o pH do solo diminuiu e o somatório de cátions aumentou.

Para as plantas de milho tratadas com SA, o somatório de cátions correlacionouse positivamente com ambos os valores de $\mathrm{pH}$ em água e em $\mathrm{CaCl}_{2}\left(\mathrm{r}=0,73^{\circ}\right)$; esse resultado deve-se ao fato de a forma amoniacal ter baixado o $\mathrm{pH}$ do solo (provavelmente em sua maior parte devido à nitrificação, e em menor parte devido à absorção do $\mathrm{NH}_{4}{ }^{+}$ pela planta, acompanhada de extrusão de íons $\mathrm{H}^{+}$) e ao mesmo tempo ter diminuido o somatório de cátions pelo efeito de competição entre estes e os íons $\mathrm{NH}_{4}{ }^{+}$ou íons $\mathrm{H}^{+}$ liberados pela raiz. Nas plantas de trigo sarraceno, os coeficientes de correlação com os valores de $\mathrm{pH}$ foram maiores $\left(\mathrm{r}=0,97^{\circ}\right)$, provavelmente porque essa espécie tem maior preferência pela forma amoniacal; como descrito para o milho, a forma amoniacal baixou o pH do solo e, concomitantemente, diminuiu o somatório de cátions.

\section{b) Somatório de Ânions}

Na cultura do milho adubado com NC o somatório de ânions correlacionou-se negativamente com o pH em $\mathrm{CaCl}_{2}\left(r=-0,94^{* *}\right)$; esses resultados ocorreram porque as gramíneas, na presença de nitrato, elevam o pH do solo, ao mesmo tempo em que acumulam menor quantidade de ânions em seus tecidos devido à competição entre estes e o próprio íon nitrato proveniente do fertilizante, ou entre aqueles e as hidroxilas extrusadas pelas raízes durante a absorção do nitrato. No caso do trigo sarraceno, a correlação com o $\mathrm{pH}$ em água foi positiva $\left(r=0,91^{*}\right)$ porque as dicotiledôneas, independentemente da 
forma de nitrogênio fornecida, absorvem maior proporção de cátions que de ânions, o que faz baixar o pH; ao mesmo tempo, o nitrato fornecido, por competição aniônica, reduz o acúmulo de ânions na planta.

Quanto ao SA aplicado ao milho, as correlações com os valores de $\mathrm{pH}$ em água e em $\mathrm{CaCl}_{2}$ não foram significativas. Quando aplicado ao trigo sarraceno, contudo, a correlação com os valores de $\mathrm{pH}$ em água e em $\mathrm{CaCl}_{2}$ foi negativa e significativa $\left(\mathrm{r}=-0,80^{*}\right.$ e $-0,79^{*}$, respectivamente); isso ocorreu porque o $\mathrm{pH}$ do solo diminuiu, provavelmente em parte devido à maior absorção de amônio que nitrato, e em parte pelo efeito da nitrificação, enquanto o somatório de ânions aumentou, já que o amônio estimula a absorção desses íons.

\section{c) Excesso de Bases (EB)}

Para a aplicação de NC na cultura do milho, a correlação entre o EB e o pH em $\mathrm{CaCl}_{2}$ foi positiva e altamente significativa $\left(r=0,89^{* *}\right)$; os resultados mostram, de fato, que a gramínea, por ter preferência à forma nítrica, elevou o $\mathrm{pH}$ do solo; ao mesmo tempo, o EB aumentou porque o nitrato estimula a absorção de cátions nutrientes na planta e reduz a de ânions. Na cultura do trigo sarraceno houve correlação negativa e altamente significativa para os valores de $\mathrm{pH}$ em água $\left(\mathrm{r}=-0,81^{\circ}\right)$; é que o trigo, absorvendo mais cátions que ânions, ao mesmo tempo baixou o $\mathrm{pH}$ do solo e aumentou a diferença entre cátions e ânions acumulados.

Os coeficientes de correlação obtidos quando as plantas de milho foram adubadas com SA mostraram valores positivos e altamente significativos para $\mathrm{pH}$ em água e em $\mathrm{CaCl}_{2}\left(\mathrm{r}=0,83^{* *}\right.$ e $0,82^{* *}$, respectivamente); aqui, o SA baixou o $\mathrm{pH}$ do solo devido à nitrificação, principalmente, ao mesmo tempo em que a diferença entre cátions e ânions acumulados na planta diminuiu devido à competição iônica citada anteriormente. Para o trigo sarraceno os coeficientes de correlação também foram positivos e altamente significativos para os valores de $\mathrm{pH}$ em água e em $\mathrm{CaCl}_{2}\left(\mathrm{r}=0,97^{* *}\right)$; o mesmo comentário feito para milho adubado com SA é válido para explicar este caso, com a diferença que os 
coeficientes de correlação foram mais elevados e significativos para ambas as leituras de $\mathrm{pH}$.

\section{d) Relação Excesso de Bases/Nitrogênio (EB/N)}

As correlaçōes entre a relação $\mathrm{EB} / \mathrm{N}$ e os valores de $\mathrm{pH}$ em água e em $\mathrm{CaCl}_{2}$ forneceram coeficientes negativos e altamente significativos $\left(r=-0,92^{* *}\right.$ e $\left.-0,80^{* *}\right)$ quando as plantas de milho foram adubadas com NC; nessa condição, à medida que a gramínea aumentou o $\mathrm{pH}$ do solo pela extrusão de íons $\mathrm{OH}$, o exceso de bases acumuladas na planta aumentou 1,3 vezes devido ao fornecimento do $\mathrm{N}$ na forma nítrica; contudo, o teor de nitrogênio na planta aumentou em maior proporção ( 3 vezes), causando o decréscimo da relação $\mathrm{EB} / \mathrm{N}$; como conseqüência, os coeficientes de correlação para $\mathrm{EB} / \mathrm{N}$ e para $\mathrm{EB}$ apresentaram sinais opostos. Ao contrário do milho, no trigo sarraceno a relação EB/N correlacionou-se positivamente com o $\mathrm{pH}$ em água $\left(\mathrm{r}=0,81^{\circ}\right)$; aqui, a relação $\mathrm{EB} / \mathrm{N}$ também decresceu com a aplicação do $\mathrm{NC}$, pois o conteúdo de nitrogênio na planta aumentou mais que o excesso de bases; contudo, a dicotiledônea, devido ao seu padrão de absorção, baixou o $\mathrm{pH}$ do solo pela liberação de íons $\mathrm{H}^{+}$pelas raízes.

Para as culturas do milho e do trigo sarraceno fertilizadas com o SA, os coeficientes de correlação foram iguais, positivos e altamente significativos para ambas as determinaçōes de $\mathrm{pH}$ do solo $\left(\mathrm{r}=0,97^{\circ}\right)$, em todos esses casos houve redução do $\mathrm{pH}$ do solo, seja devida à extrusão de prótons pelas raízes, seja pela nitrificação do amônio; simultaneamente, a relação EB/N também diminuiu como resultado do aumento dos teores de nitrogênio e da redução do excesso de bases das plantas.

Com base nos resultados da Tabela 28 , verifica-se que as observações de Pierre e colaboradores, de que plantas com relações EB/N menores que um apresentam efeito alcalinizante sobre o solo, enquanto as que possuem relaçōes maiores que um mostram efeito acidificante, foram válidas somente quando adubadas com o $\mathrm{N}$ na forma nítrica; porém, quando se correlacionou a relação $\mathrm{EB} / \mathrm{N}$ do trigo sarraceno com o $\mathrm{pH}$ em água do solo, obteve-se um coeficiente positivo, igual a $0,81^{* *}$ (Tabela 30 ); esse resultado 
aparentemente paradoxal é explicado pelo fato de essa cultura ter acidificado o meio quando adubada com nitrato, ao mesmo tempo em que a relação EB/N diminuiu.

As observações feitas por aqueles autores não foram válidas quando o $\mathrm{N}$ foi aplicado nas formas nitrica-amoniacal ou amoniacal porque nesses casos: (a) não houve alcalinização do solo cultivado com as gramíneas, embora a relação EB/N tenha sido baixa; e (b) houve efeito acidificante do solo cultivado com o trigo sarraceno, embora as relações $\mathrm{EB} / \mathrm{N}$ da planta tenham sido baixas. Apesar dessas discordâncias, as correlações positivas obtidas entre $\mathrm{EB} / \mathrm{N}$ e o $\mathrm{pH}$ foram coerentes: conforme explicado anteriormente, as fontes amoniacais baixaram o $\mathrm{pH}$ do solo ao mesmo tempo em que a relação $E B / N$ diminuiu. 


\section{CONCLUSÕES}

a) Na ausência de plantas, o efeito acidificante dos adubos sobre o solo foi maior para o $\mathrm{SA}$ do que para o NA, mostrando-se pequeno para NC;

b) $\mathrm{O} N \mathrm{NC}$, associado a plantas de milho e arroz, causou elevação do $\mathrm{pH}$, mas na presença do trigo sarraceno exerceu pouca influência na reação do solo; o NA e o SA mostraram-se sempre acidificantes;

c) As plantas tratadas com NC apresentaram maiores valores de EB que as adubadas com NA e SA, sugerindo que o nitrato estimulou a absorção de cátions e reduziu a de ânions;

d) Independentemente da fonte nitrogenada, o trigo sarraceno apresentou maiores valores de EB do que o milho e o arroz, indicando que a aquela dicotiledônea acumulou maior quantidade de cátions que as monocotiledôneas;

e) As plantas adubadas com o nitrogênio na forma de nitrato mostraram relaçōes $\mathrm{EB} / \mathrm{N}$ maiores que as tratadas com a forma amoniacal;

f) Os aumentos do teor de nitrogênio nas plantas, causados pelas aplicações dos fertilizantes, não foram acompanhados de iguais aumentos no excesso de bases, resultando em diminuição da relação $\mathrm{EB} / \mathrm{N}$;

g) Na ausência de nitrogênio aplicado, assim como na presença de NC, o trigo sarraceno mostrou relações $\mathrm{EB} / \mathrm{N}$ superiores às das gramíneas, mas quando a forma amoniacal foi aplicada, a relação no trigo sarraceno caiu ao nível das gramíneas;

h) $\mathrm{O}$ nitrogênio na forma nítrica conferiu relações $\mathrm{EB} / \mathrm{N}$ menores que 1 nas plantas de milho e arroz, e efeito alcalinizante no solo; por outro lado, resultou relações maiores que 
um nas plantas de trigo sarraceno e efeito acidificante no solo. $O$ nitrogênio nas formas nítrica-amoniacal e amoniacal propiciou relaçōes $\mathrm{EB} / \mathrm{N}$ menores que um independentemente da espécie cultivada, e um efeito acidificante no solo;

i) As observações de Pierre e colaboradores, de que plantas com relaçōes EB/N menores que um, apresentam efeito alcalinizante sobre o solo, enquanto as que possuem relaçōes maiores que um, mostram efeito acidificante, foram válidas somente quando adubadas com o $\mathrm{N}$ na forma nítrica, não se verificando quando se empregaram as formas nítricaamoniacal e amoniacal. 


\section{REFERÊNCIAS BIBLIOGRÁFICAS}

AKTAS, M. \& EGMOND, F. van. Effect of nitrate nutrition on iron utilization by an Feefficient and an Fe-inefficient soybean cultivar. Plant and Soil, The Hague, 51:257-74, 1979.

ALEXANDER, M. Nitrification. In: BARTHOLOMEW, W.V. \& CLARK, F.E., ed. Soil nitrogen. Madison, American Society of Agronomy, 1965. p.309-46.

ANCHENG, L.; JIANMING, X.; XIAOE, Y. Effect of nitrogen $\left(\mathrm{NH}_{4} \mathrm{NO}_{3}\right)$ supply on absorption of ammonium and nitrate by conventional and hybrid rice during reproductive growth. Plant and Soil, The Hague, 155/156:395-8, 1993.

ARNOLD, G. \& DIEST, A. van. Nitrogen supply, tree growth and soil acidification. Fertilizer Research, Dordrecht, 27:29-38, 1991.

BARBER, K.L. \& PIERZYNSKI, G.M. Ammonium and nitrate source effects on field crops. Journal of Fertilizer Issues, St. Louis, 8(3): 57-62, 1991.

BEKELE, T.; CINO, B.J.; EHLERT, P.A.I.; DER MAAS, A.A. van.; DIEST, A. van. An evaluation of plant-borne factors promoting the solubilization of alkaline rock phosphates. Plant and Soil, The Hague, 75:361-8, 1983.

BHELLA, H.S. \& WILCOX, G.E. Lime and nitrogen influence soil acidity, nutritional status, vegetative growth, and yield of muskmelon. Journal of the American Society for Horticultural Science, Alexandria, 114(4): 606-10, 1989.

BOLAN, N.S.; HEDLEY, M.J.; WHITE, R.E. Processes of soil acidification during nitrogen cycling with emphasis on legume based pastures. Plant and Soil, The Hague, 134:53-63, 1991. 
BREMNER, J.M. Inorganic forms of nitrogen. In: BLACK, C.A., ed. Methods of soil analysis. Madison, American Society of Agronomy, 1965a. pt. 2: Chemical and microbiological properties, p.1179-237.

BREMNER, J.M. Organic nitrogen in soils. In: BARTHOLOMEW, M.W. \& CLARCK, F.E., ed. Soil nitrogen. Madison, American Society of Agronomy, 1965b. p.93-149.

BREMNER, J.M.; KEENEY, D.R. Determination and isotope-ratio analysis of different forms of nitrogens in soils: 3 . Exchangeable ammonium, nitrate and nitrite by extraction-distillation methods. Soil Science Society of American Proceedings, Madison, 30: 577-83, 1966.

BRICEÑO, J.A.; PACHECO, R. Métodos analíticos para el estudio de suelos y plantas. San José, Editorial de la Universidad de Costa Rica, 1984. 137p.

BROADBENT, F.E.; TYLER, K.B.; HILL, G.N. Nitrification of ammoniacal fertilizers in some California soils. Hilgardia, Berkeley, 27: 247-69, 1957.

CAMARGO, O.A.; MONIZ, A.C.; JORGE, J.A.; VALADARES, J.M.A.S. Métodos de análise química, mineralógica e física de solos do Instituto Agronômico. Campinas, Instituto Agronômico, 1986. 94p. (IAC. Boletim Técnico, 106).

CAMBRAIA, J.; CHANDÍAS, J.A.T.; ESTEVĀO, M.M.; SANT'ANNA, R. Efeito do alumínio sobre o balanço iônico e sobre a capacidade das plantas de sorgo para modificar o pH das soluçōes nutritivas. Revista Ceres, Viçosa, 34(193):284-92, 1987.

CAO, W. \& TIBBITTS, T.W. Study of various $\mathrm{NH}_{4}{ }^{+} / \mathrm{NO}_{3}^{-}$mixtures for enhancing growth of potatoes. Journal of Plant Nutrition, New York, 16(9):1691-704, 1993.

CHUNG, J.B. \& ZASOSKI, R.J. Effect of high ammonium levels on nitrification, soil acidification, and exchangeable cation dynamics. Communications in Soil Science and Plant Analysis, New York, 24(17/18):2123-35, 1993. 
CROWTER, E.M. IV. The soil reaction of continuously manured plots at Rothansted and Woburn. Journal of Agricultural Science, Cambridge, 15:222-31, 1925.

CUNNINGHAM, R.K. Cation-anion relationships in crop nutrition. I. Factors affecting cations in Italian rye-grass. Journal of Agricultural Science, Cambridge, 63:97-101, 1964a.

CUNNINGHAM, R.K. Cation-anion relationships in crop nutrition. II. Factors affecting the ratios of sum of the cations: sum of the anions in Italian rye-grass. Journal of Agricultural Science, Cambridge, 63:103-8, $1964 \mathrm{~b}$.

CUNNINGHAM, R.K. Cation-anion relationships in crop nutrition. III. Relationships between the ratios of sum of the cations: sum of the anions and nitrogen concentrations in several plant species. Journal of Agricultural Science, Cambridge, 63:109-11, 1964c.

DANCER, W.S.; PETERSON, L.A.; CHESTERS, G. Ammonification and nitrification of $\mathrm{N}$ as influenced by soil $\mathrm{pH}$ and previous $\mathrm{N}$ treatments. Soil Science Society of American Proceedings, Madison, 37:67-9, 1973.

DONALD, L.; STANGEL, H.J., PESEK Jr, J.T. Advances in knowledge of nitrogen fertilization in the U.S.A. since 1950. In: MCVICKAR, M.H.; BRIDGER, G.L.; NELSON, L.B., ed. Fertilizers technology and usage. Madison, Soil Science Society of America, 1963. p. 75-129.

EPSTEIN, E. Metabolismo mineral. In: - Nutrição mineral das plantas; princípios e perspectivas. Rio de Janeiro, Livros Técnicos e Científicos, 1975. p. $235-66$.

FASSBENDER, H.W. \& BORNEMISZA, E. Química de suelos con énfasis en suelos de América Latina. 2.ed. San José, IICA, 1987. 420p. 
GERENDÁS, J. \& SATTELMACHER, B. Influence of nitrogen form and concentration on growth and ionic balance of tomato (Lycopersicum esculentum) and potato (Solanum tuberosum). In: INTERNATIONAL PLANT NUTRITION COLLOQUIUM, 11., Wageningen, 1989. Plant nutrition - physiology and applications; proceedings. Dordrecht, Kluwer Academic Publ., 1990 p. 33-7. (Developments in Plant and Soil Sciences, 41).

GIGON, A. \& RORISON, J.H. The response of some ecologically distinct plant species to nitrate and ammonium-nitrogen. Journal of Ecology, London, 60: 93-102, 1972.

GIJSMAN, A.J. Rhizosphere pH along different root zones of Douglas-fir (Pseudotsuga menziesii) as effected by source of nitrogen. In: INTERNATIONAL PLANT NUTRITION COLLOQUIUM, 11., Wageningen, 1989. Plant nutrition - physiology and applications; proceedings. Dordrecht, Kluwer Academic Publ., 1990a. p.45-51. (Developments in Plant and Soil Sciences, 41).

GIJSMAN, A.J. Nitrogen nutrition of Douglas-fir (Pseudotsuga menziesii) on strongly acid sandy soil. I. Growth, nutrient uptake and ionic balance. Plant and Soil, The Hague, 126:53-61, $1990 \mathrm{~b}$.

GIJSMAN, A.J. Nitrogen nutrition of Douglas-fir (Pseudotsuga menziesii) on strongly acid sandy soil. II. Proton excretion and rhizosphere $\mathrm{pH}$. Plant and Soil, The Hague, 126:63-70, $1990 \mathrm{c}$.

HANWAY, J.J.; HERRICK, J.B.; WILLRICH, T.L.; BENNETT, P.C.; MCCALL, J.T. The nitrate problem. Ames, Iowa Cooperative Extension Service in Agriculture and Home Economics, 1963. (Special Reports, 34).

HARTWELL, B.I. \& DAMON, S.C. Relative lime needs of sulphate of ammonia and nitrate of soda and of different crops. Journal of the American Society of Agronomy, Madison, 19:843-9, 1927. 
HAVILL, D.C.; LEE, J.A.; STEWART, G.R. Nitrate utilization by species from acid and calcareos soil. The New Phytologist, Oxford, 73:1221-31, 1974.

HÄUSSLING, M.; LEISEN, E.; MARSCHNER, H.; RÖMHELD, V. An improved method for non-destrutive measurements of the $\mathrm{pH}$ at the root-soil interface (rhizosphere). Journal of Plant Physiology, Stuttgart, 117:371-5, 1985.

HAYNES, R.J. Uptake and assimilation of mineral nitrogen by plants. In: $\therefore$ ed. Mineral nitrogen in the plant-soil system. Madison, Academic Press, $1986 \mathrm{~b}$. p. $303-78$.

HAYNES, R.J. Nitrification. In: , ed. Mineral nitrogen in the plant-soil system. Madison, Academic Press. 1986a. p.127-65.

HAYNES, R.J. Active ion uptake and maintenance of cation-anion balance: A critical examination of their role in regulating rhizosphere $\mathrm{pH}$. Plant and Soil, The Hague, 126:247-64, 1990.

HAYNES, R.J. \& GOH, K.M. Ammonium and nitrate nutrition of plants. Biological Reviews, Cambridge, 53:465-510, 1978.

HELYAR, K.R. Nitrogen cycling and soil acidification. Journal of the Australian Institute of Agricultural Science, Sydney, 42:217-21, 1976.

HIROCE, R.; BATAGLIA, O.C., BAUMGARTNER, J.G.; FURLANI, A.M.C.; MORAES, F.R.P. de. Efeitos de quatro fontes de adubo nitrogenado nas características químicas do solo e na composição foliar de cafeeiro. Ciência e Cultura, São Paulo, 29(1): 67-71, 1977.

JARVIS, S.C. \& ROBSON, A.D. The effects of nitrogen nutrition of plants on the development of acidity in western Australian soils. I. Effects with subterraneam clover grown under leaching conditions. Australian Journal of Agricultural Research, East Melbourne, 34: 341-53, 1983a. 
JARVIS, S.C. \& ROBSON, A.D. The effects of nitrogen nutrition of plants on the development of acidity in western Australian soils. II. Effects of differences in cation/anion balance between plant species grown under non-leaching conditions. Australian Journal of Agricultural Research, East Melbourne, 34:355-65, 1983b.

JARVIS, S.C. \& ROBSON, A.D. A comparison of the cation/anion balance of ten cultivars of Trifolium subterraneum L., and their effects on soil acidity. Plant and Soil, The Hague, 75:235-43, 1983c.

KIEHL, J.C.; MELLO, F.A.F.; ARZOLLA, S. Efeito acidificante de alguns adubos nitrogenados em solos de diferentes texturas. O Solo, São Paulo, 63: 19-24, 1981.

KIRKBY, E.A. Influence of ammonium and nitrate nutrition on the cation-anion balance and nitrogen and carbohydrate metabolism of white mustard plants grown in dilute nutrient solution. Soil Science, Baltimore, 105:133-41, 1968.

KIRKBY, E.A. \& MENGEL, K. Ionic balance in different tissues of tomato plant in relation to nitrate, urea or ammonium nutrition. Plant Physiology, Rockville, 42:614, 1967.

KRAJINA, V.J.; MADOC-JONES, S.; MELLOR, G. Ammonium and nitrate in the nitrogen economy of some conifers growing in Douglas-fir communities of the Pacific northwest of America. Soil Biology and Biochemistry, Oxford, 5: 143-7, 1973.

LEE, J.A. \& STEWART, G.R. Ecological aspects of nitrogen assimilation. Advances in Botanical Research, New York, 6:1-43, 1978.

LIU, L. \& SHELP, B.J. Nitrogen partitioning in greenhouse-grown broccoli in response to varying $\mathrm{NH}_{4}^{+}: \mathrm{NO}_{3}^{-}$ratios. Communications in Soil Science and Plant Analysis, New York, 24(1/2):45-60, 1993. 
LOCATELLI, M. Efeito de formas, fontes e doses de nitrogênio sobre o crescimento e composição mineral de mudas de Eucalyptus grandis W. Hill (ex Maiden). Viçosa, 1974. 64p. (Mestrado - Universidade Federal de Viçosa).

MAHLER, R.L.; HALVORSON, A.R.; KOEHLER, F.E. Long-term acidification of farmland in northern Idaho and eastern Washington. Communications in Soil Science and Plant Analysis, New York, 16(1): 83-95, 1985.

MALAVOLTA, E.; VITTI, G.C.; OLIVEIRA, S.A. Avaliação do estado nutricional das plantas: principios e aplicaçōes. Piracicaba, Potafos, 1989. 201p.

MALHI, S.S.; NYBORG, M.; CALDWELL, C.D.; HOYT, P.B.; LEITCH, R.H. Effect of ammonium and nitrate on growth and yield of barley on acid soils. Communications in Soil Science and Plant Analysis, New York, 19(7/12):1049-63, 1988.

MCCRACKEN, D.V.; CORAK, S.J.; SMITH, M.S.; FRYE, W.W., BLEVINS, R.L. Residual effects of nitrogen fertilization and winter cover cropping on nitrogen availability. Soil Science Society of America Journal, Madison, 53: 1459-64, 1989.

MELLO, F.A.F. Uréia fertilizante. Campinas, Fundação Cargill, 1987. 192 p.

MELLO, F.A.F. \& ANDRADE, R.G. A influência de alguns adubos nitrogenados sobre o $\mathrm{pH}$ do solo. Revista de Agricultura, Piracicaba, 48:68-78, 1973.

MELLO, F.A.F. \& ARZOLLA, S. Acidificação do solo por adubo nitrogenado. Efeitos residuais após a primeira e segunda colheita. Revista de Agricultura, Piracicaba, 58: $17-24,1983$.

MELLO, F.A.F.; POSSIDIO, E.L.; PEREIRA, J.R.; ARAÚJO, J.P.; ABRAMOF, L.; COSTA, O.A. Efeito acidificante da uréia e do sulfato de amônio em um Latossolo Vermelho Escuro. Revista de Agricultura, Piracicaba, 41:291-6, 1986. 
MORAES, F.R.P. de. Efeito de alguns fertilizantes nitrogenados sobre o pH do solo e a concentração de alumínio e manganês nas folhas de cafeeiros. In: CONGRESSO BRASILEIRO SOBRE PESQUISAS CAFEEIRAS, 2., Poços de Caldas, 1974. Resumos... Brasília, EMBRAPA, 1974. p.279-80.

MORAES, F.R.P.; LAZZARINI, W.; TOLEDO, S.V.; CERVELLINI, G.S.; FUJIWARA, M. Fontes e doses de nitrogênio na adubação do cafeeiro. I. Latossolo roxo transição para Latossolo Vermelho-escuro, orto. Bragantia, Campinas, 35:63$77,1976$.

NELSON, L.E. \& SELBY, R. The effect of nitrogen sources and iron levels on the growth and composition of sitka spruce, and scots pine. Plant and Soil, The Hague, 41: $573-88,1974$.

NEVES, O.S.; VIEGAS, G.P.; FREIRE, E.S. Efeito do uso contínuo de certos adubos azotados sobre o pH do solo. Bragantia, Campinas, 19:125-32, 1960.

NYATSANGA, T. \& PIERRE, W.H. Effects of nitrogen fixation by legumes on soil acidity. Agronomy Journal, Madison, 65: 936-40, 1973.

NYBORG, M. \& HOYT, P.B. Effects of soil acidity and liming on mineralization of soil nitrogen. Canadian Journal of Soil Science, Ottawa, 58:331-8, 1978.

NYE, P.H. Changes of $\mathrm{pH}$ across the rhizosphere induced by roots. Plant and Soil, The Hague 61:7-26, 1981.

OBI, A.O. Long-term effects of the continuous cultivation of a tropical ultisol in southwestern Nigeria. Experimental Agriculture, Cambridge, 25:207-15, 1989.

OSMOLOVSKAYA, N.G. \& IVANOVA, I.L. Regulation of ionic balance in bean and beet leaves during ammonium and nitrate nutrition. Soviet Plant Physiology, New York, 36(5):831-7, 1990. 
PATTEN, K.D.; HABY, V.A.; LEONARD, A.T.; NEUENDORFF, E.W ; DAVIS, J.V. Nitrogen source effects on rabbiteye bluberry plant-soil interactions. Communication in Soil Science and Plant Analysis, New York, 19(7/12):1065-74, 1988.

PEET, M.M. Tomato responses to ammonium and nitrate nutrition under controlled rootzone pH. Journal of Plant Nutrition, New York, 8(9):787-98, 1985.

PETERSEN, W. \& BÖTTGER, M. Contribution of organic acids to the acidification of the rhizosphere of maize seedlings. Plant and Soil, The Hague, 132:159-63, 1991.

PEUKE, A.D. \& TISCHNER, R. Effects of variation in nitrogen nutrition on growth of poplar (Populus trichocarpa) clones. In: INTERNATIONAL PLANT NUTRITION COLLOQUIUM, 11., Wageningen, 1989. Plant nutrition - physiology and applications; proceedings. Dordrecht, Kluwer Academic Publ,, 1990. p.53-9. (Developments in Plant and Soil Sciences, 41).

PIERRE, W.H. Nitrogenous fertilizers and soil acidity: I: Effect of various nitrogenous fertilizers on soil reaction. Journal of the American Society of Agronomy, Madison, 20. $254-69,1928$ a.

PIERRE, W.H. Nitrogenous fertilizers and soil acidity: II: The use of fertilizers combinations, lime, and basic slag in correcting the acidity formed by various nitrogenous fertilizers. Journal of the Americam Society of Agronomy, Madison, 20: $270-9,1928 b$.

PIERRE, W.H. Determination of equivalent acidity and basicity of fertilizers. Industrial and Engineering Chemistry, Washington, 5(4): 229-34, July 1933.

PIERRE, W.H. \& BANWART, W.L. Excess-base and excess-base/nitrogen ratio of various crop species and parts of plants. Agronomy Journal, Madison, 61: 91-6, 1973. 
PIERRE, W.H.; MEISINGER, J.; BIRCHETT, J.R. Cation-anion balance in crops as a facts in determining the effect of nitrogen fertilizers on soil acidity. Agronomy Journal, Madison, 62: 106-12, 1970.

PIERRE, W.H.; WEBB, J.R.; SHRADER, W.D. Quantitative effects of nitrogen fertilizers on the development and downward movement of soil acidity in relation to level of fertilization and crop removal in a continuous corn cropping system. Agronomy Journal, Madison, 63: 291-7, 1971.

RAIJ, B. van \& DIEST, A.van. Utilization of phosphate from different sources by six plant species. Plant and Soil, The Hague, 51:577-89, 1979.

RAIJ, B. van; CANTARELlA, H.; FURLANI, P.R. Efeito na reação do solo da absorção de amônio e nitrato pelo sorgo, na presença e na ausência de gesso. Revista Brasileira de Ciência do Solo, Campinas, 12: 131-6, 1988.

RASMUSSEN, P.E. \& ROHDE, C.R. Soil adification from ammonium-nitrogen fertilization in moldbourd plow and stubble- mulch wheat-fallow tillage. Soil Science Society of America Journal, Madison, 53: 119-22, 1989.

RILEY, D. \& BARBER, S.A. Bicarbonate accumulation and pH changes at the soybean (Glycine max L. Merr.) root-soil interface. Soil Science Society of American Proceedings, Madison, 33:905-8, 1969.

RILEY, D. \& BARBER, S.A. Effect of ammonium and nitrate fertilization on phosphorus uptake as related to root-induced $\mathrm{pH}$ changes at the root-soil interface. Soil Science Society of American Proceedings, Madison, 35:301-6, 1971.

RÖMHELD, V. pH changes in the rhizosphere of various crop plants, in relation to the supply of plant nutrients. Potash Review Subj, 6, 1986. 55th s. 
RÖMHELD, V. \& MARSCHNER, H. Plant induced pH changes in the rhizosphere of 'Fe-efficient' and 'Fe-inefficient' soybean and corn cultivars. Journal of Plant Nutrition, New York, 7:623-30, 1984.

SAITO, S.M.T. Efeito da matéria orgânica e de um inibidor de nitrificação na absorção de ${ }^{15} \mathrm{NH}_{4}$ e ${ }^{15} \mathrm{NO}_{3}$ pelo milho. Piracicaba, 1974. 75p. (Mestrado - Escola Superior de Agricultura "Luiz de Queiroz"/USP).

SCHJORRING, J.K. Nitrate and ammonium absorption by plants growing at a sufficient or insufficient level of phosphorus in nutrient solutions. Plant and Soil, The Hague, 91:313-8, 1986.

SILVA, C.A. Efeito da correção da acidez e de fontes de nitrogênio na nitrificação do solo e no crescimento do feijoeiro (Phaseolus vulgaris L.). Lavras, 1994. 104p. (Mestrado - Escola Superior de Agricultura de Lavras).

STEVENSON, F.J. Origen and distribution of nitrogen in soil. In: STEVENSON, F.J., ed. Nitrogen in agricultural soils. Madison, Soil Science Society American, 1982. p. $1-42$.

STUMPE, J.M. \& VLEK, P.L.G. Acidification induced by different nitrogen sources in columns of selected tropical soils. Soil Science Society of America Journal, Madison, 55:145-51, 1991.

TATTINI, M.; CIMATO, A.; BERTONI, P.; LOMBARDO, M. Nitrogen nutrition of self-rooted olive in sand culture. Effect of $\mathrm{NH}_{4}-\mathrm{N} / \mathrm{NO}_{3}-\mathrm{N}$ on growth and nutritional status. Acta Horticulturae, Wageningen, 286:311-3, 1990.

THERIOS, I.N. \& SAKELLARIADIS, S.D. Effects of nitrogen form on growth and mineral composition of olive plants (Olea europaea L.). Scientia Horticulturae, Amsterdam, 35:167-77, 1988. 
TISDALE, S.L.; NELSON, W.L.; BEATON, J.D. Soil fertility and fertilizers. 4.ed. New York, McMillan, 1985. 754p.

TROELSTRA, S.R. \& BLACQUIÈRE, T. Growth, ionic balance, proton excretion, and nitrate reductase activity in Alnus and Hippophaë supplied with different sources of nitrogen. Plant and Soil, The Hague, 91:381-4, 1986.

VOLK, N.J. \& TIDMORE, J.W. The effect of different sources of nitrogen on soil reaction, exchangeable ions and yield of crops. Soil Science, Baltimore, 61: 477-82, 1946.

WALLACE, A. Soil acidification, from use of too much fertilizer. Communications in Soil Science and Plant Analysis, New York, 25(1/2):87-92, 1994.

WHEELER, H.J. Ammonium salts and calcium cyanamid. In: ., Manures and fertilizers. New York, Macmillan, 1918. cap. 14, p.147-64.

WOLCOTT, A.R.; FOTH, H.D.; DAVIS, J.F.; SHICKLUNA, J.C. Nitrogen carriers: I. Soil effects. Soil Science Society Americam Proceedings, Madison, 29: 405-10, 1965. 